
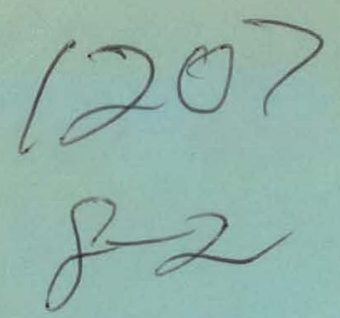

\title{
MASTER
}

$5 A N-1207-2$

Report No. 101-IR

\section{A BIPHASE TURBINE BOTTOMING CYCLE \\ FOR A DIESEL ENGINE}

LANCE HAYS

Prepared for the U.S. Energy Research and

Development Administration under Contract No. F (04-3)-12.07

July 31,1976

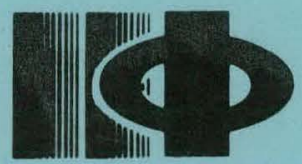

\section{Biphase Engines, Inc.}

SANTA MONICA, CALIFORNIA 90406

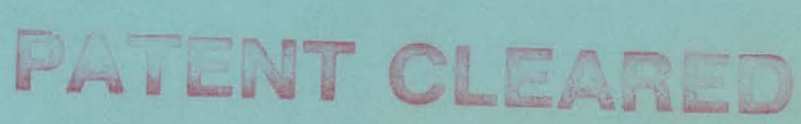

JUN 121979

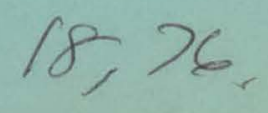




\section{DISCLAIMER}

This report was prepared as an account of work sponsored by an agency of the United States Government. Neither the United States Government nor any agency Thereof, nor any of their employees, makes any warranty, express or implied, or assumes any legal liability or responsibility for the accuracy, completeness, or usefulness of any information, apparatus, product, or process disclosed, or represents that its use would not infringe privately owned rights. Reference herein to any specific commercial product, process, or service by trade name, trademark, manufacturer, or otherwise does not necessarily constitute or imply its endorsement, recommendation, or favoring by the United States Government or any agency thereof. The views and opinions of authors expressed herein do not necessarily state or reflect those of the United States Government or any agency thereof. 


\section{DISCLAIMER}

Portions of this document may be illegible in electronic image products. Images are produced from the best available original document. 
Report No. 101-1R

\section{A BIPHASE TURBINE BOTTOMING CYCLE FOR A DIESEL ENGINE}

Prepared for the U.S. Energy Research and Development Administration under Contract No. E(04-3)-1207

$$
\text { July } 31,1976
$$

Prepared and Approved by

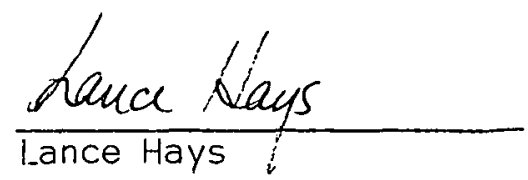




\section{ACKNOWLEDGEMENT}

Technical direction for this program is provided by John Cuttica of the Conservation Division of ERDA headquarters.

The assistance of Robert Spies and Paul Thys in the turbine design is gratefully acknowledged.

Special thanks are also given to Ying Mei Chen for her calculations and careful preparation of the text and figures. 
Application of a two-phase turbine system to waste heat recovery was examined. Bottoming cycle efficiencies ranging from 15-30\% were calculated for a $720^{\circ} \mathrm{F}$ diesel exhaust temperature. A single stage demonstration unit, designed for non-toxic fluids (water and Dow-Therm A) and for atmospheric seals and bearings, had a cycle efficiency of $23 \%$. The net output power was $276 \mathrm{HP}$ at $8,100 \mathrm{rpm}$, increasing the total shaft power from 1,800 HP for the diesel alone, to 2,076 HP for the combined system. A four stage organic turbine, for the same application, had a rotational speed of $14,700 \mathrm{rpm}$ while a four stage steam turbine had 26,000 rpm. Fabrication drawings were prepared for the turbine and nozzle. The major improvement leading to higher cycle efficiency and lower turbine rpm was found to be the use of a liquid component with lower sensible heat. A possible reduction in capital cost was found to be the use of a contact heat exchanger instead of tube-fin construction. A program resulting in the demonstration of a two-phase bottoming system was planned and the required cost estimated. The program would result in a feasibility test of the nozzle and turbine at the end of the first year, a laboratory performance test of the bottoming system by the end of the second year and a field demonstration test and laboratory endurance test of the bottoming system during the third year. 


\title{
TABLE OF CONTENTS
}

\author{
Text Page
}

\section{Abstract}

I. Introduction

11. Two-Phase Cycles

111. Cycle Performance 27

IV. Reference Cycle 46

V. Turbine Design 55

Vi. System Specifications 60

VII. Program Plan 66

VIII. Conclusions 77

References

Appendices

A. Expander Relations

B. Analysis of Two-Phase Cycles

C. Summary of Turbine Design

D. Steam Turbine Analysis and Design 


\section{INTRODUCTION}

Effective utilization of waste heat is an energy conservation measure which can have a very large impact on fuel consumption in this country. Conversion of the waste heat into a useful form of energy (such as electricity or mechanical shaft power) has an added advantage in that the basic tooling and plant designs can be preserved. Furthermore, reduction of both air and thermal pollution is a direct consequence of increasing the useful power output for a given amount of fuel.

Many processes and devices have hot exhaust gases that would be suitable for the heat source for energy conversion systems. A particularly attractive class of devices are internal combustion engines, both diesel and spark ignition. These engines account for nearly one third of the country's energy consumption. 'Moreover, the available energy in the exhaust gases is equal in magnitude to the useful power output for the engine. Existing estimates of bottoming cycle performance have indicated improvements of $15-20 \%$ (1) in the fuel economy resulting in a large potential savings if all engines were so equipped. Figure 1 (after Ref. 2) shows an energy diagram for a typical diesel engine with latent heat cooling. The exhaust gas energy is $33 \%$ of the heat input compared to 39\% of the heat input which appears as useful work output. This diagram also shows a potential recovery of about $20 \%$ as the heat value of steam raised by the exhaust gases. For typical steam systems this heat can be converted to shaft power to raise the total engine shaft output by about $5-7 \frac{1}{2} \%^{(2)}$.

The subject of this study, and the simplest application of this type, is ufilicaliun of the waste heat trom a large, stationary diesel engine. Stationary engines don't have the same space and weight limitations, or control and transient operation requirements as vehicular power plants. Therefore, the steady state performance and reliability aspects of bottoming systems can be demonstrated without the complications necessitated by mobile applications. 


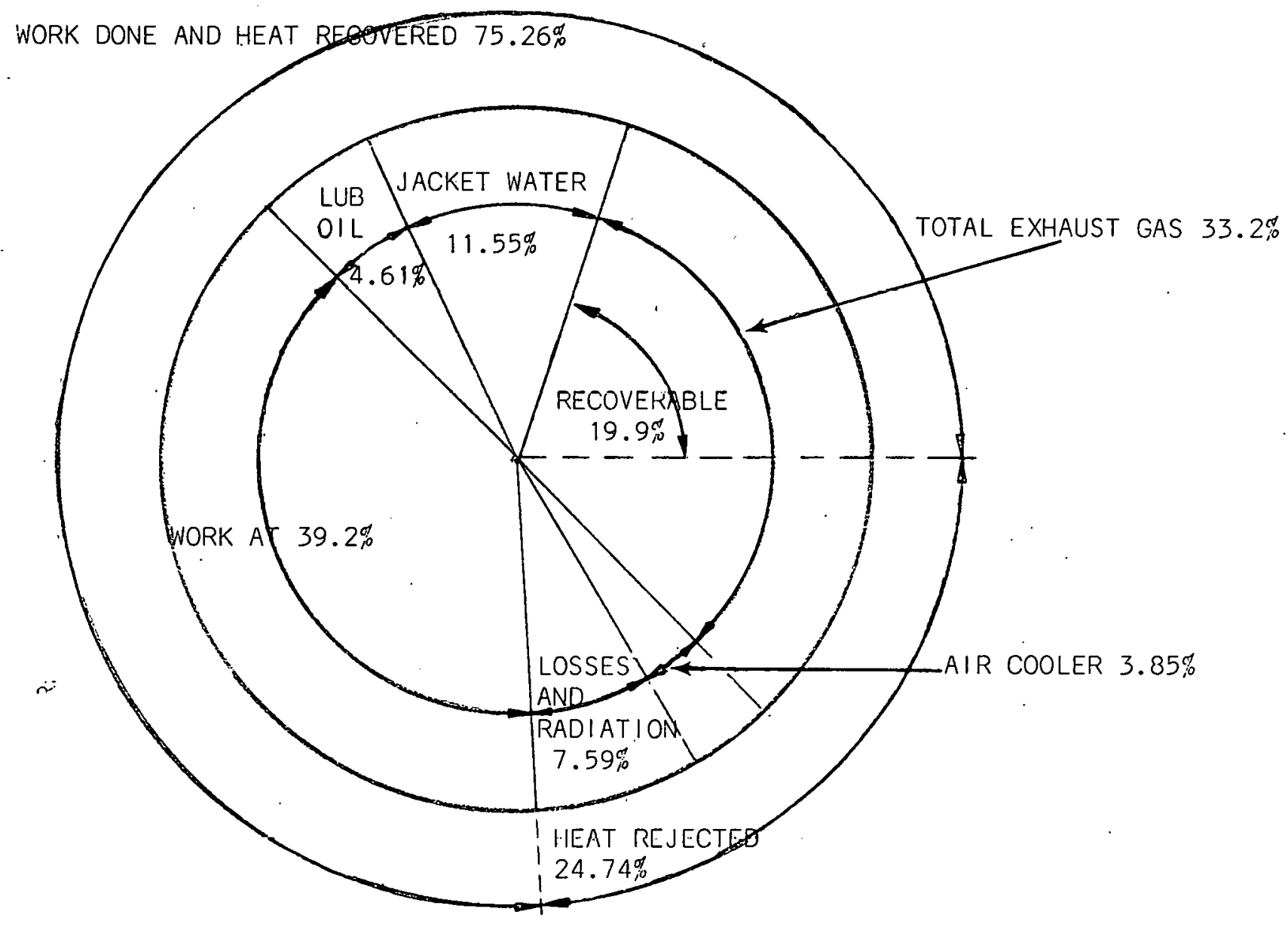

Fig. 1 - Diagrammatic Representation of Heat Balance with Latent lleat Cooling for Diesel [ngine 
Current approaches for waste heat conversion inciude both closed cycle and open cycle heat engines. Only the closed cycle variations will be considered here. The steam Rankine cycle has been used commercially as a bottoming system for gas turbines $(3,4)$. Systems of this type have reduced the heat rate form $13,500 \mathrm{~B} / \mathrm{kWh}$ with a gas turbine alone to $9,600 \mathrm{~B} / \mathrm{kWh}$ for the combined cycle. Thus, a fuel savings of $30 \%$ results from the addition of this bottoming system. Commercial systems have also been placed in operation using steam bottoming cycles to recover waste heat from diesel engines. Figure 2 is a schematic of a typical system described in Ref. 2. As discussed previously, this type of system with $240 / 280$ psig, $600 / 650^{\circ} \mathrm{F}$ steam increases the shaft power output by $5 \frac{1}{2}$ to $7 \%$.

Another approach to waste heat conversion is the use of a Rankine cycle with an organic working fluid. Ref. 5 discusses the use of an organic vapor turbine system to bottom a diesel engine. A "bread board" system tested resulted in a $12 \%$ increase in power without an increase in fuel consumption. An organic vapor expander was also used by Chapman ${ }^{(6)}$ to bottom a spark ignition engine. In this case, an orbital vane expander was used as the power conversion component. Advantages resulting from the use of an organic vapor instead of steam include a greater thermodynamic efficiency and a somewhat lower turbine or expander rpm. Disadvantages include expensive fluid and seal requirements, non-availability of commercial components and the high capital cost of the system cumponents, and the use of trxir. working fluids (e.g. toluene and 'FS-85).

The subject of this design study is the use of a two-phase power system to convert the waste heat from a diesel engine to useful power. The two-phase power. system while similar, has several potential advantages relative to a Rankine cycle bottoming system.

1. The turbine has a lower rpm than a vapor-alone turbine, simplifying transmission problems. For example, the single stage turbine of this design study has a shaft speed of 8,100 r.pm compared to 14,700 for a four stage organic vapor turbine for. the same application (7). A steam turbine with the same number of stages would have a rotation 


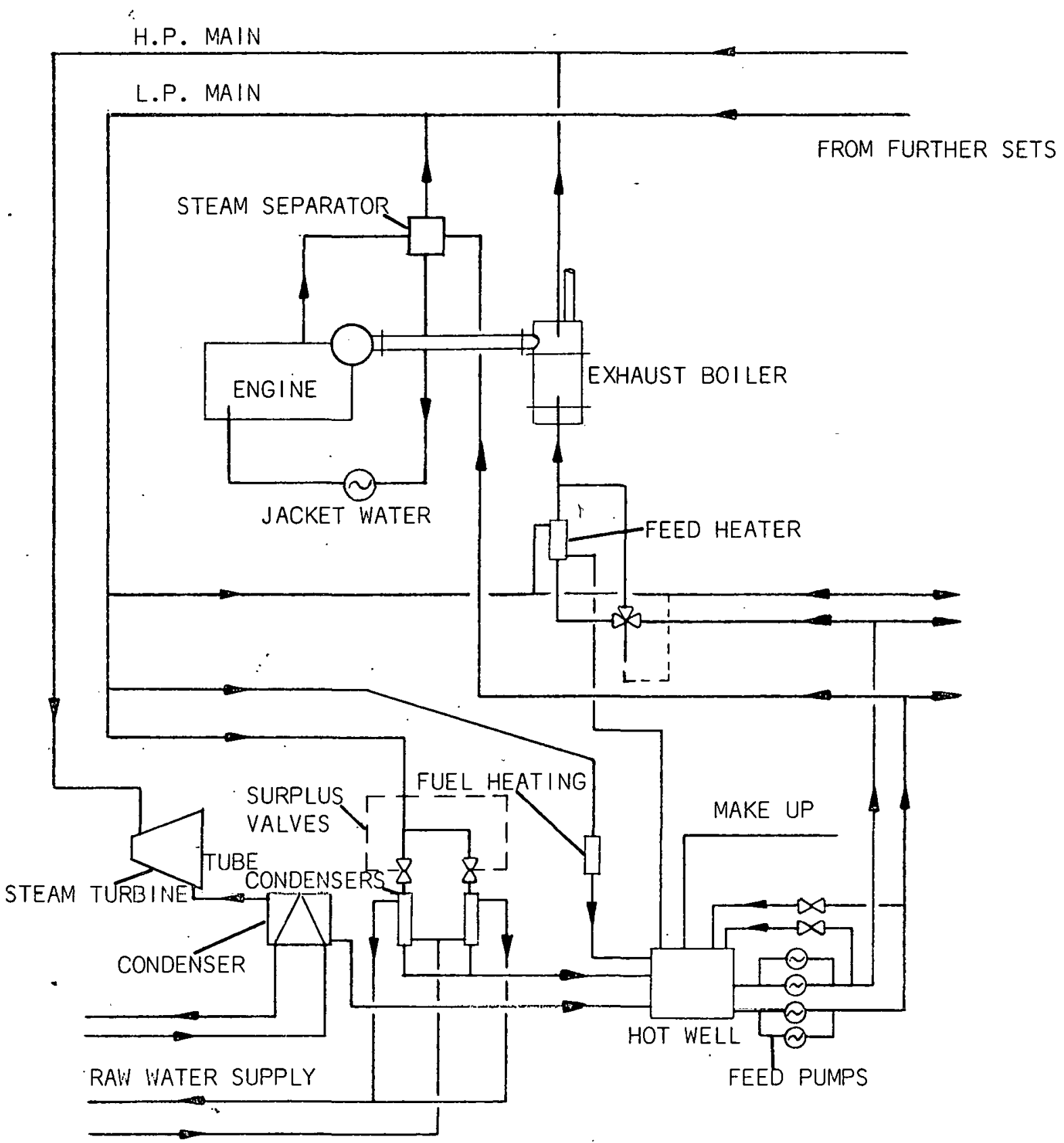

Fig. \% - Layout of Complete Engine Heat-Recovery Syslem 
speed of about 26,000 rpm. As discussed later the twophase turbine rpm can be reduced further by increasing the mass ratio of liquid to vapor, but at the expense of pumping losses.

2. The two-phase cycle has a gas to liquid heat exchanger instead of a boiler and maximizes the exhaust gas energy available for conversion. The available energy to the system can be maximized because heat transfer is to the liquid phase. Figure 3 illustrates temperature profiles for typical steam and organic vapor. boilers compared to the liquid heat exchanger of the two-phase turbine engine. Since the loss of available energy is proportional to the temperature difference it can be seen that a higher thermodynamic efficiency is possible with the two-phase cycle compared to the vapor cycle.

3. The turbine, seals, bearings and other items associated with the rotating unit are simple, low cost components. This is a consequence of the low rpm and the transformation of the energy from the gas to the high density liquid phase.

4. Variations of the two-phase power cycle exist which may allow the use of a contact heat exchanger for the exhaust gas, reducing the capital cosf relative to a tube-fin heat exchanger.

Other possible advantageous features include higher ultimate efficiency, simplified control requirements, and good part load efficiency.

In order to determine the performance and design of a two-phase turbine, cycle calculations were conducted for several two-phase systems. A reference cycle was selected which represented a compromise between efficiency, rpm, and simplicity of construction. The two-phase nozzle and. 


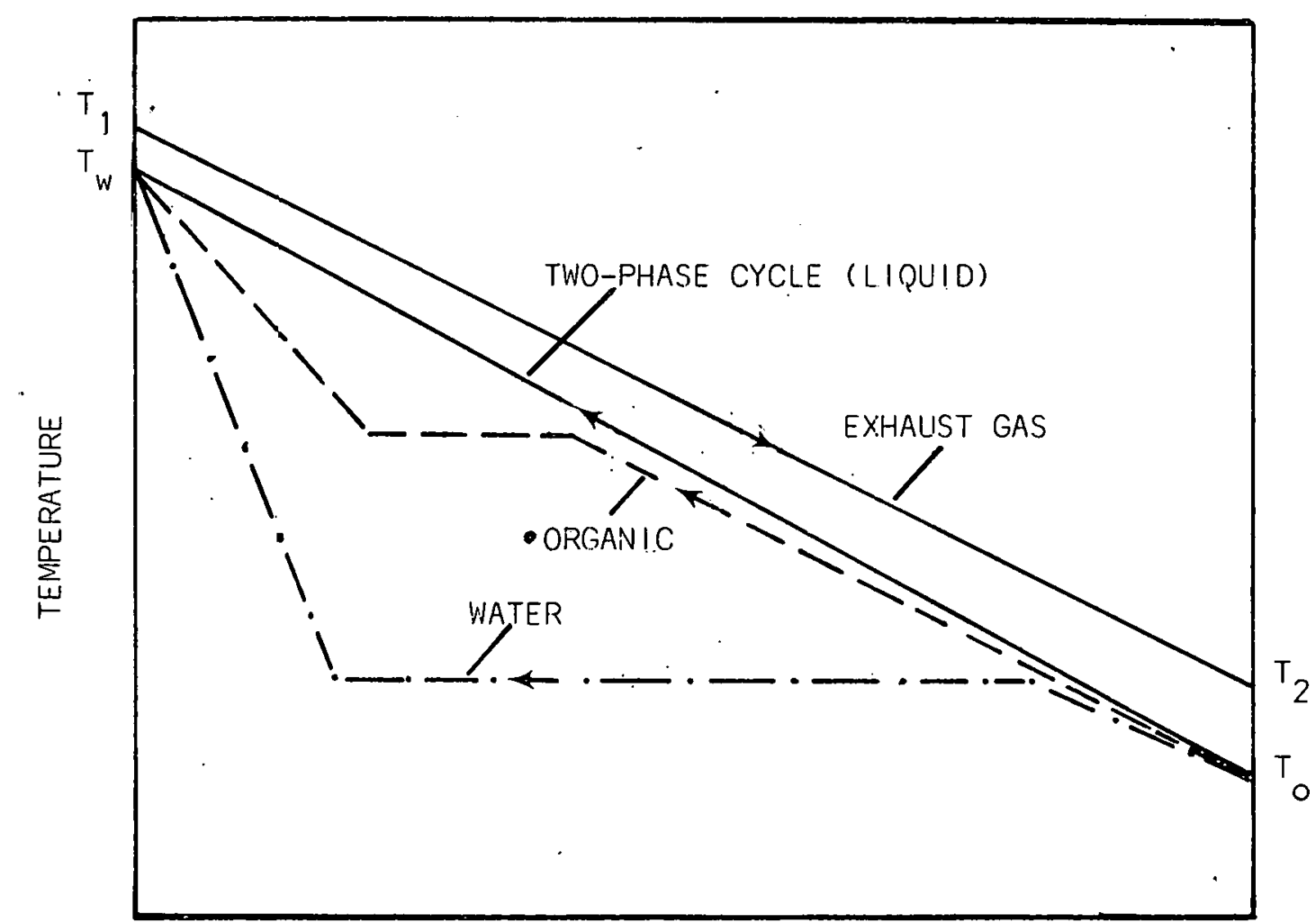

PERCENT OF TOTAL HEAT TRANSFERRED

Fig. 3 - Comparison of Temperature Profiles of Two-Phase Cycle Heat Exchanger and Organic Steam Vapor Generators 
turbine were designed for the conditions of the reference cycle and fabrication drawings were prepared. Functional requirements of the major system components were specified and'a program resulting in the demonstration of a two-phase bottoming cycle was formulated. 


\section{TWO-PHASE CYCLES}

Several different two-phase bottoming cycles were considered for the design study. In each variation, the common feature is that heat transfer occurs from the exhaust gas to the liquid phase. However, the working fluid may consist of one or more chemical species, staging can be used, and a contact heat exchanger can be used in place of a conventional tube- $f$ in heat exchanger.

In this section, the basic principles of two-phase nozzles and turbines are discussed, followed by a brief description of each cycle.

\section{TWO-PHASE NOZZLES AND TURBINES}

The two elements which are responsible for the unique characteristics of the two-phase turbine engine are the two-phase nozzle and the turbine wheel. The nozzle produces efficient conversion of liquid enthalpy to vapor enthalpy to vapor and liquid kinetic energy. This is achieved by mixing a finely dispersed hot liquid of low vapor pressure (such as oil) with a liquid possessing higher vapor pressure (such as water or Freon). The water vaporizes to steam at high pressure. The steam is subsequently expanded to low pressure and high velocity, dragging the oil droplets to a high velocity also. The presence of large amounts of finely dispersed liquid has a similar effect on the nozzle exit velocity as a large increase in molecular weight of the vapor would, i.e. a high mass flow rate and low spouting velocity are obtained. Figure 4 shows the nozzle exit velocity as a function of the ratio of 1 iquid to gas. Starting at a value of about 4,000 $\mathrm{ft} / \mathrm{s}$ for all gas, the exit velocity is reduced to less than 1,000 $\mathrm{ft} / \mathrm{s}$ for a mass ratio of 30 . Thus, a much lower turbine wheel speed can be 
Fig. 4 - Exit Velocity of Two-Phase Nozzles

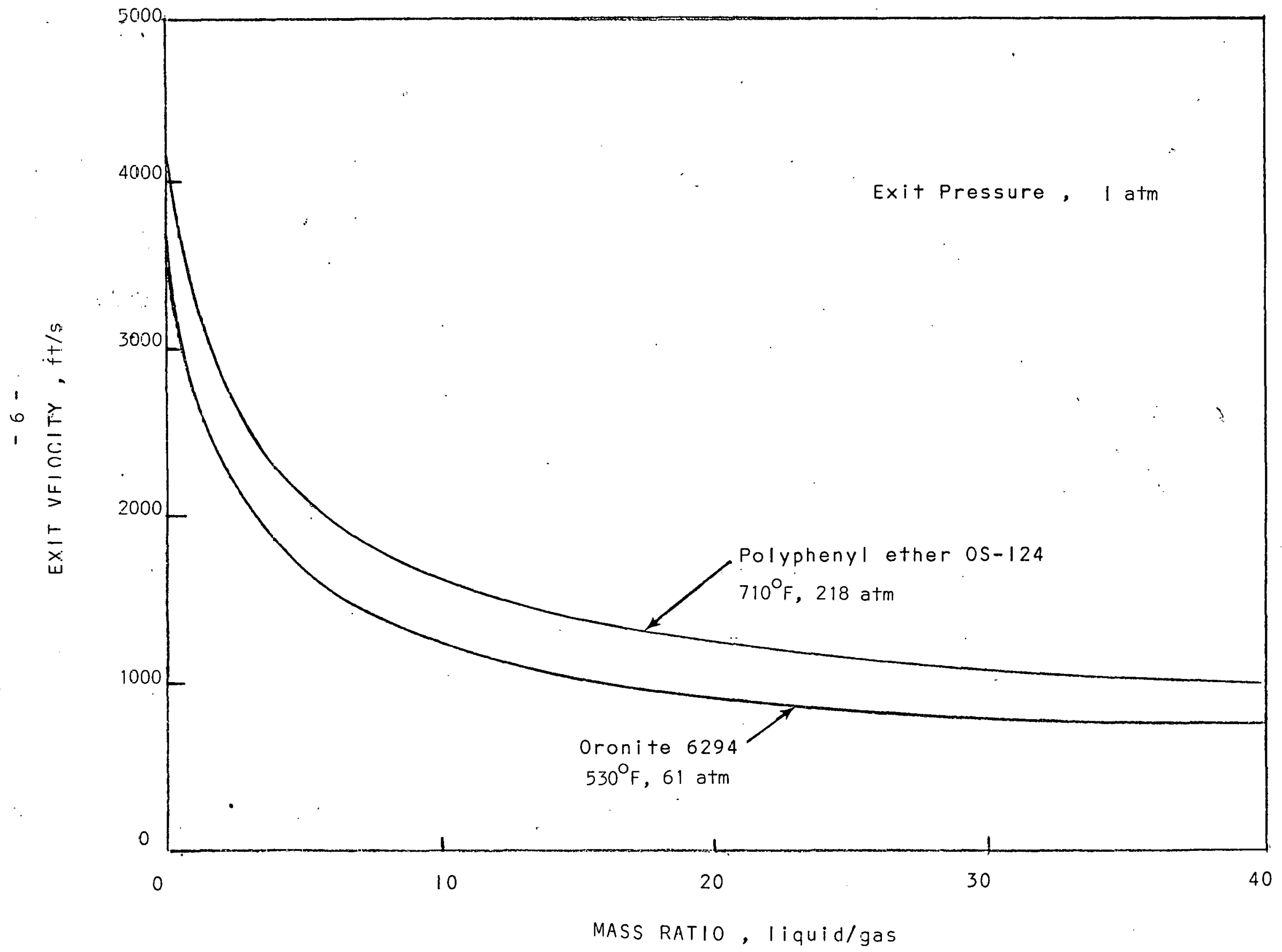


used for maximum efficiency than for the vapor alone.

The relation of the nozzle and turbine wheel for a single stage, impulse circumferential configuration is shown in Figures 5 and 6 . The geometry can be very similar to a simple Pelton wheel. The only difference is that the initial impingement zone is inclined at a more gradual angle than the Pelton wheel, to avoid two-phase impact losses; and the surface area can be made less than that of a Pelton wheel because of the concentration of the liquid phase after impingement. Another geometry which can be used is very similar to a conventional axial flow impulse turbine.

A variation of the above turbine which offers elimination of the primary. oil. pump and may have a higher efficiency for some applications, is a rotary separator turbine. Here the two-phase mixture is impinged on a rotating separator surface which results in a high velocity liquid annulus. The liquid flows into a radial inflow turbine, which in its simplest case is a rotating pitot tube and diffuser. The liquid is discharged through the base and enough pressure is retained to enable circulation through the heat exchanger to the nozzle. Another version is the use of a simple "U-tube" to recover the liquid energy.

Figures 7 and 8 illustrate this turbine design, consisting of nozzle(s), rotating separator, and liquid turbine. The liquid and gas mixture comprising the working fluid is supplied at high pressure to the nozzle inlets. The mixture expands to low pressure at the nozzle exits, and the rosulting high-velocity two-phase jets impinge on the inner surface of the rim of the rotating separator. The liquid becomes concentrated in a layer on the. immer surface due to the inertia of the liquid and centrifugal force while the gas flows radially inward through passages and enters the gas discharge pipe through ports in the stationary housing. The rotating separator is supported by bearings mounted in the housing. 


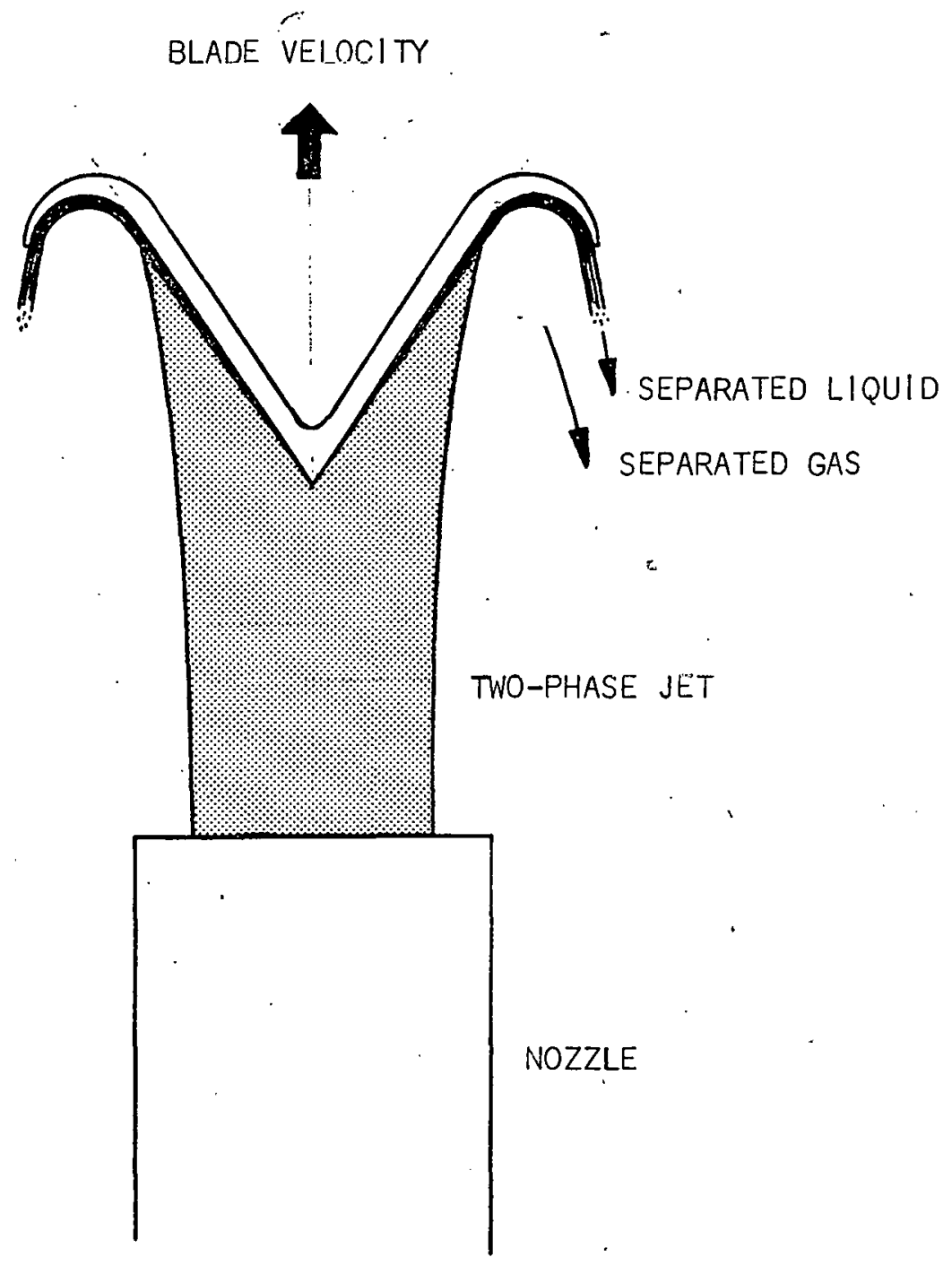

Fi.g. 5 -Schematic of Flow in Two-Phase Impulse Turblne 

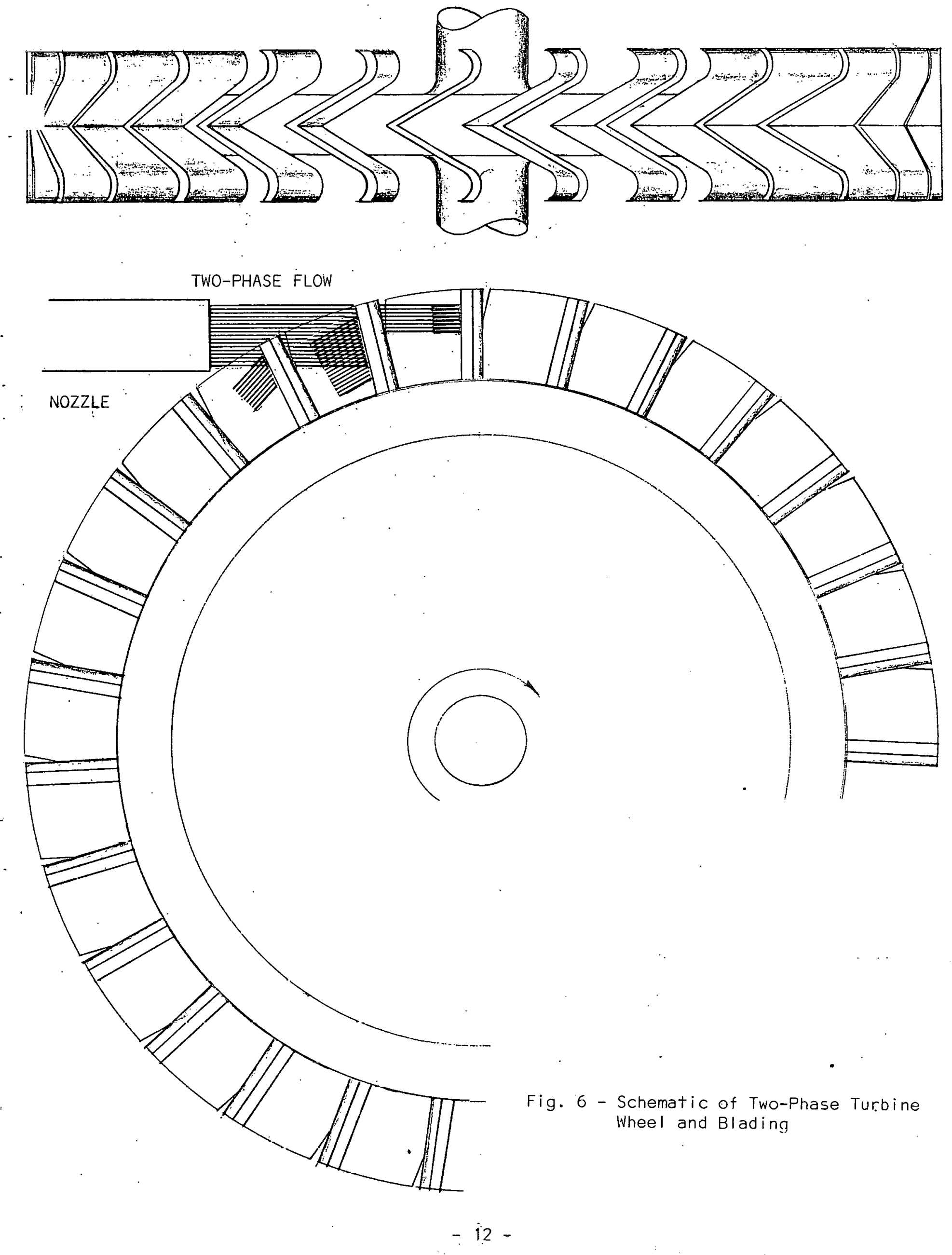


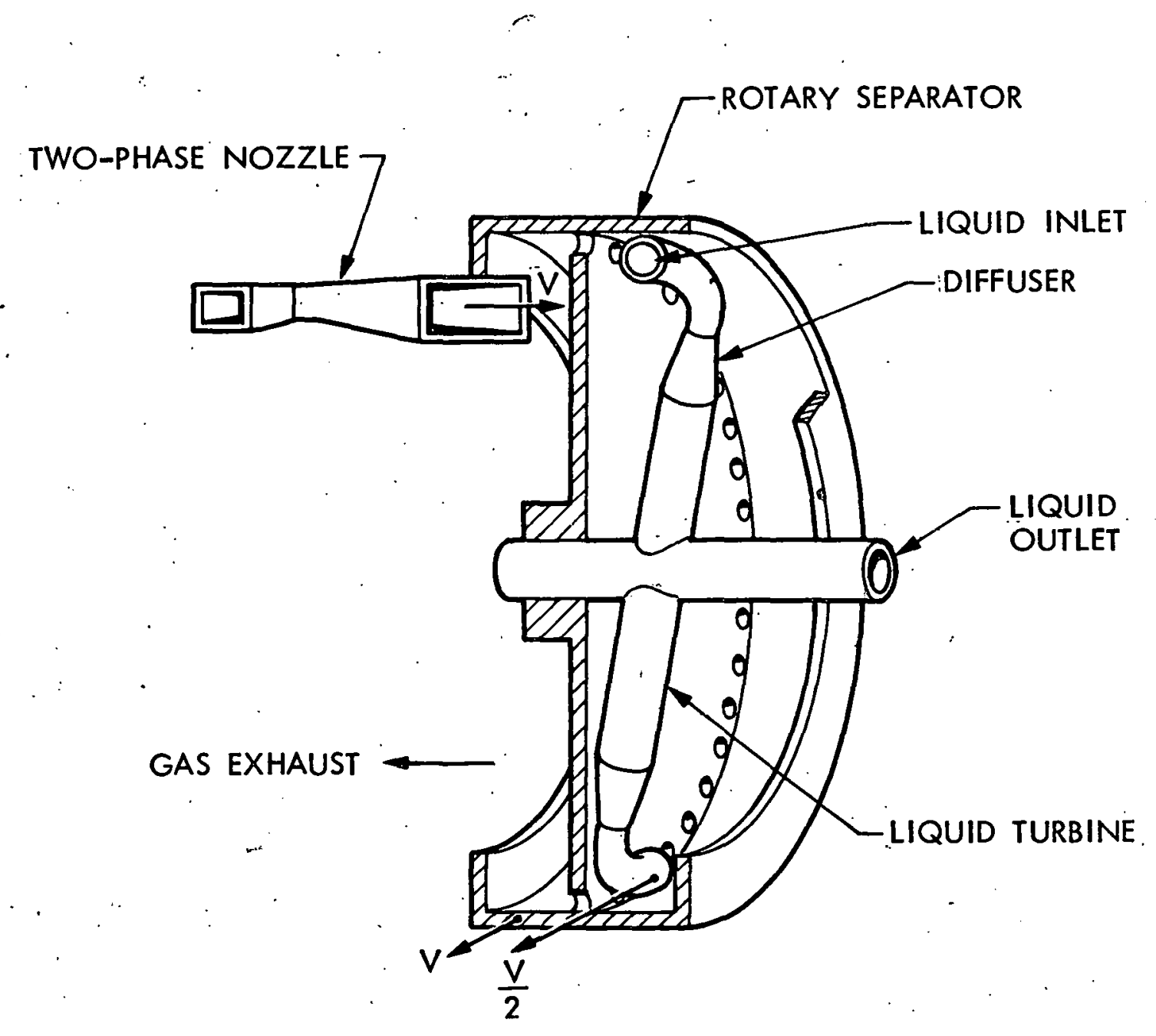

Fig. 7 - Separätor-Turbine with Radial Inflow Liquid Turbine 


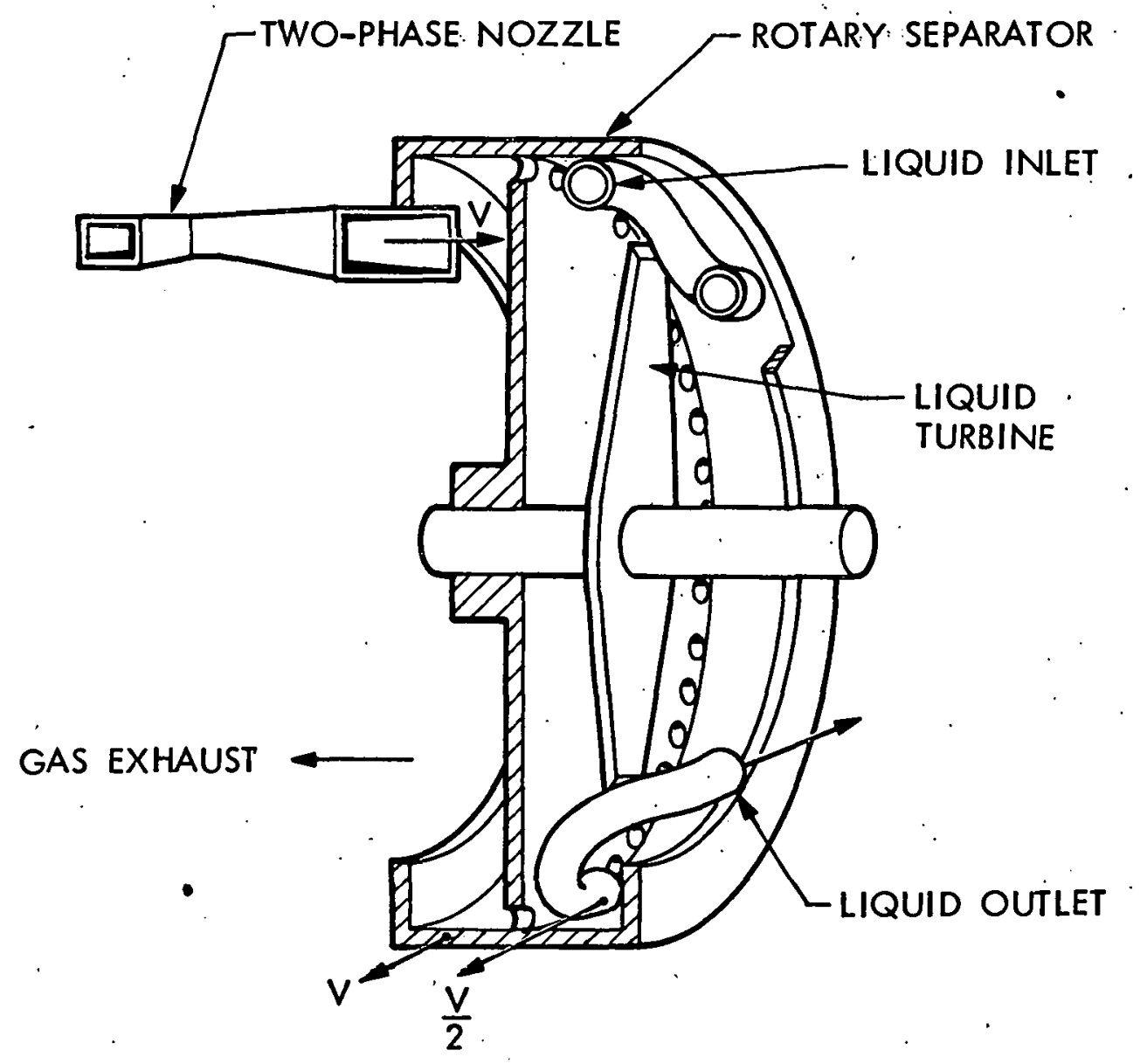

Fig. 8 - Separator-Turbine with U-Tube Liquid Turbine 
The rotation of the separator is impeded only by windage and bearing friction losses, which can be very small. Thus, only a very small relative velocity between the impinging jets and the surface, aided by the torque imparted to the rotating separator by the inward flow of the gas through passages, serves to maintain the speed of the liquid layer at a value nearly. equal to that of the jets.

The liquid flows from the liquid layer through passages in the rotating separator into an annular chamber which forms an integral part of the separator wheel. As a result another liquid layer is formed, held against the surface by centrifugal force. This layer furnishes the fluid energy source for the turbine rotating concentrically within the separator wheel and having turbine inlet passages immersed in the liquid layer.

The turbine may be of any conventional type where the blades or passages can be arranged to intercept the liquid layer. Figure 7 shows a radial flow type of turbine. The turbine wheel rotates at a lower speed than the separator wheel causing liquid from the layer to enter the inlets, flow radially inward through passages, and flow to the liquid outlet pipe through apertures in the wall of the turbine shaft. The shaft is connected to the load to be driven. The turbine is supported on bearings.

The turbine passage can optionally incorporate a diffuser in which the velocity of the liquid entering the inlet can be partially converted to pressure such that, even allowing for the pressure drop in the radial passages due to centrifugal force, the liquid pressure in the discharge pipe is substantially higher than the pressure in the turbine casing and, in fact, greater than the pressure at the nozzle inlets. Thus, the diffusers can supply the necessary pumping of the liquid, el iminating the need for a separate pump to return the liquid to the nozzles. 
For operation with high pressure at the discharge, the leakage of liquid between the shaft and the housing can be reduced by labyrinth seals and drains, which return liquid leakage to the bottom of the housing where the liquid from this and other internal leakage sources is picked up by slinger blades and thrown back into the jets. Leakage to the outside of housing is prevented by a shaft seal.

\section{SINGLE COMPONENT - SINGLE STAGE}

The single component - single stage system is shown in Figure 9. The waste heat from a diesel engine (or gas turbine) enters the heat exchanger at temperature $T_{i}$ with an exhaust flow rate of $\dot{m}_{e}$. The exhaust heat of an amount $Q_{i}$ is transferred to a single phase liquid in a counter current heat exchanger. The exhaust gas exits at temperature $T_{e}$. The heated liquid is flashed in a nozzle and expanded to pressure $P_{2}$ from pressure $p_{1}$. The saturated mixture of vapor and liquid with a quality $x_{2}$ impinges on a rotary separator. The vapor flows through a radial inflow turbine and the liquid flows through a radial inflow turbine, each on a common shaft, producing a net power output $P_{5}$. The vapor exhausts to the condenser where an amount of heat of $Q_{c}$ is rejected. The condensate is pressurized and merged with the high pressure outlet from the liquid turbine. The liquid flows back to the heater, closing the cycle.

Many variations on this basic scheme are possible. For example, the vapor turbine and/or liquid turbine can be impulse type machines with an additional pump to pressurize the liquid. The main advantage lies in the simpler turbine construction, but of course a disadvantage is the presence of another component and a slight loss in efficiency.

SINGLE COMPOINENT - MULTISTAGE

A multistage version of the single component cycle is shown in Figure 10.' 


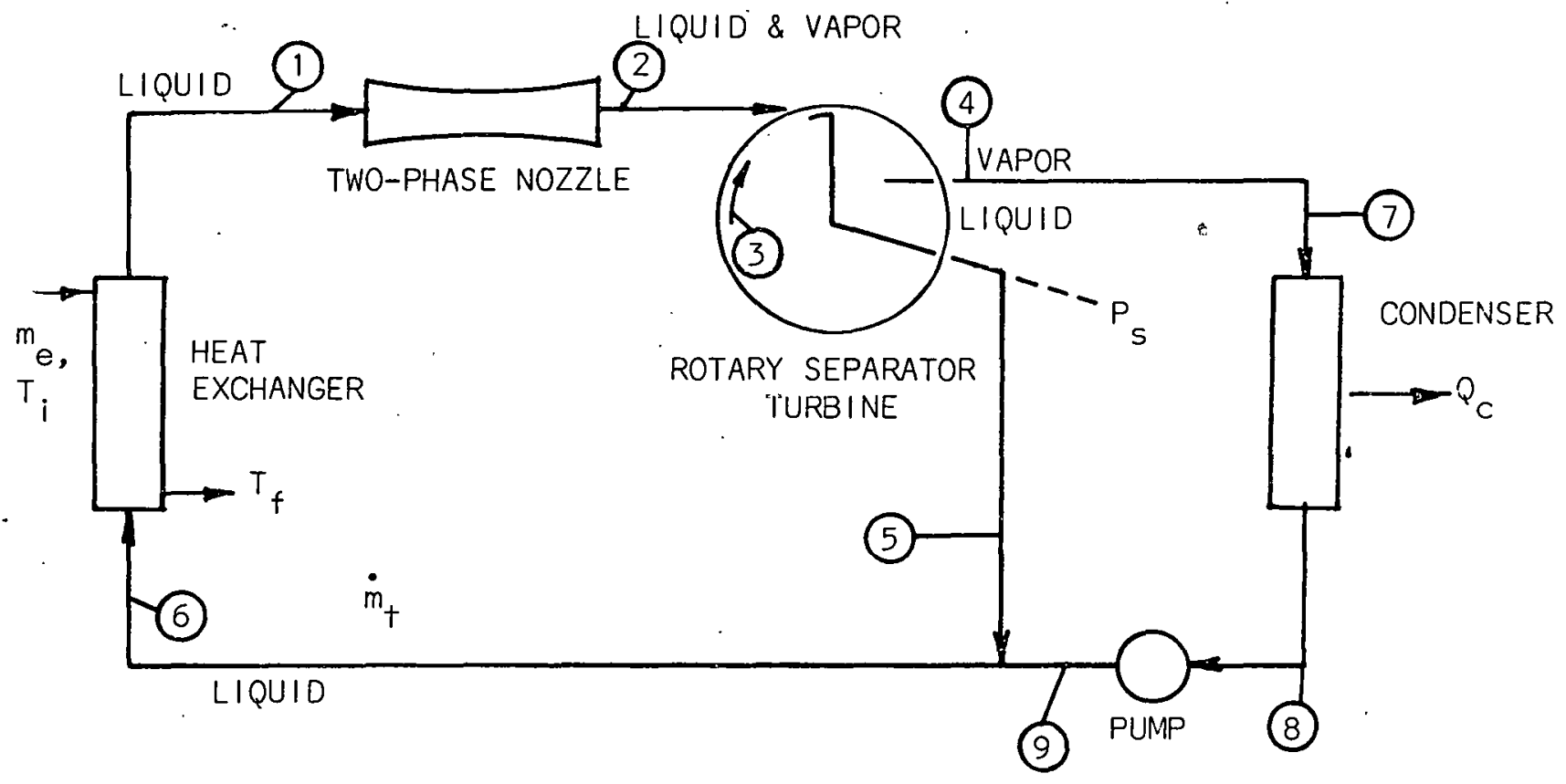

Fig. 9 - Single Component, Two-Phase Bottoming Cycle (Single Stage) 


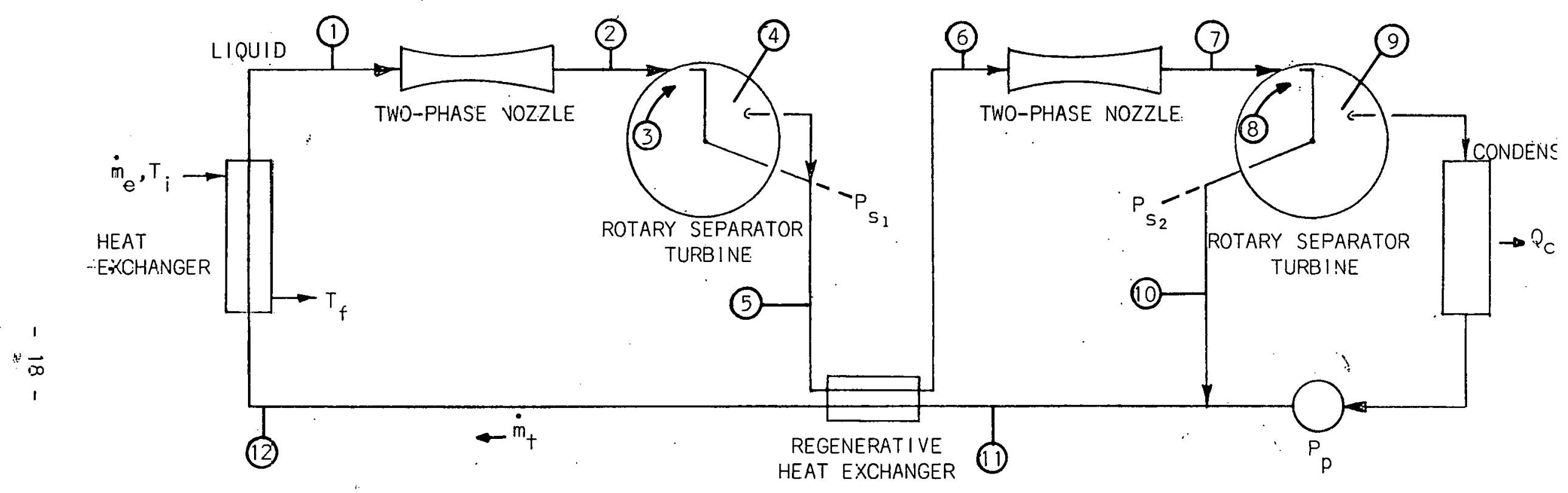

Fig. 10 - Single Component - Multistage Bottoming Cycle 
In this variation; the exit flow from the first stage is remixed and passed through a regenerative heaf exchanger, condensing part of the first stage vapor. The mixture is expanded through the second stage nozzle and turbine (as in the single stage cycle). The condensate and liquid discharge from the final (second) stage is passed through the regenerative heat exchanger increasing the temperature to the minimum dictated by combustor material considerations. The advantage of staging is that lower shaft rpm results and the lower velocities result in more efficient nozzle and turbine operation. Against these gains must be balanced the added complexity and possible interstage losses.

\section{TWO COMPONENT - CONVENTIONAL HEAT EXCHANGER}

The use of two components allows more flexibility in the choice of shaft rpm. A single stage two-component cycle is shown in Figure 11 .

In this cycle the thermodynamic working fluid is component $A$. It is supplied to the nozzle as a liquid and flash vaporizes upon contact with the heated liquid, component B. Another variation of the twocomponent cycle is to mix the condensate (component $A$ ) with the turbine discharge (component B) circulating the mixture through the heater. This variation has the same cycle diagram as the single-component variation.

In either case, the vaporizing component gradually vaporizes in the nozzle as the pressure is reduced. Any degree of superheat can be provided by using large ratios of component "B" to "A", however, in the limit of very large mass ratios, vaporization occurs at a nearly constant temperature. which produces the same thermodynamic limitation as a Rarrkine cyclé.

The resultant two-phase mixture impinges on the rotary separator. Component $A$, the vapor, flows through a radial inflow gas turbine. Component $B$ drives either a radial inflow or impulse liquid turbine. The 


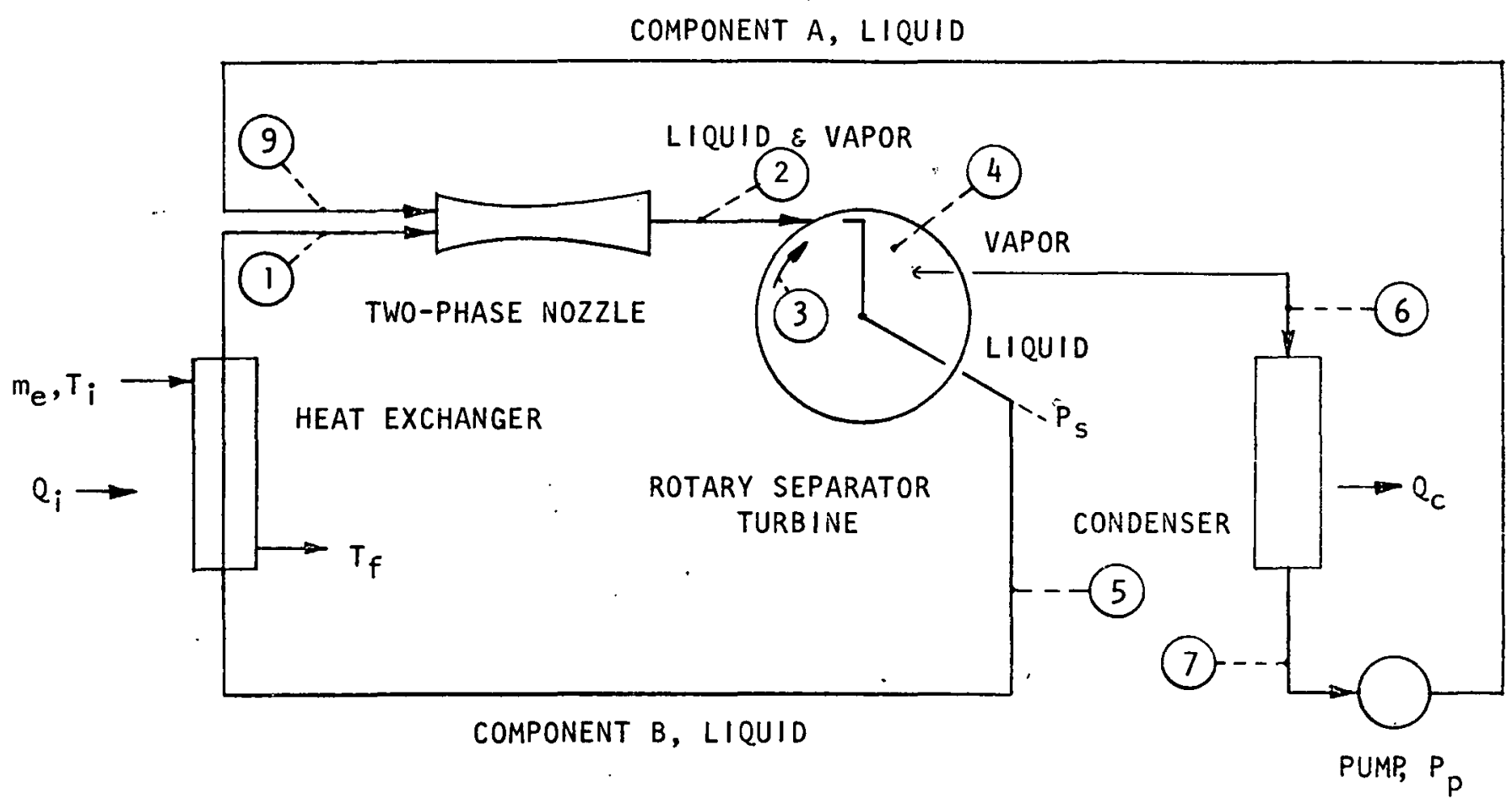

Fig. 11 - Two-Component, Two-Phase Bottoming Cycle with Tube-Fin Heat Exchanger 
vapor, after leaving the gas turbine flows to a regenerator (if superheated) and to the condenser. Affer rejecting the waste heat from the cycle the condensate is pressurized and returned to the nozzle inlet or to the primary heat exchanger. The liquid " $B$ " leaving the liquid turbine is pressurized either by a pump or by conversion of the liquid kinetic energy to head and subsequently return to the primary heat exchanger.

TWO .COMPONENT - CONTACT HEAT EXCHANGER

The final variation to be considered uses two components in a manner to enable the use of a contact heat exchanger for the waste gases. This version is illustrated by the: schematic of Figure 12.

The low vapor pressure liquid, component $B$, is sprayed into a vessel. The resulting droplets contact the hol exhaust gases which flow countercurrent to the falling droplets. The heated liquid is collected at the bottom of the vessel and pumped to the nozzle inlet. The cooled exhaust gas is exhausted (possibly through a mist eliminator) to the atmosphere. The remainder of the cycle is identical to the version with a tube-fin heat exchanger. The heat-exchanger construction is simpler with the high-pressure, tube-fin structure being replaced by a low pressure vessel with spray nozzle, In addition, the physical dimensions of the heat exchanger will be smaller because of the large surface area of the droplets and abscence of $f$ in losses: The pump power $P_{p 2}$ will be about the same required by the diffuser or pump in the cycle of Figure 11, so the efficiency of the two cycles should be similar.

In addition to the basic variations discussed above, other cycle combinations can be used. For example, Figure 12a shows the use of a two-component two-phase cycle to bottom a two-phase cycle. By operating the two-component cycle with a high ratio of "B" to "A" (liquid to gas), 


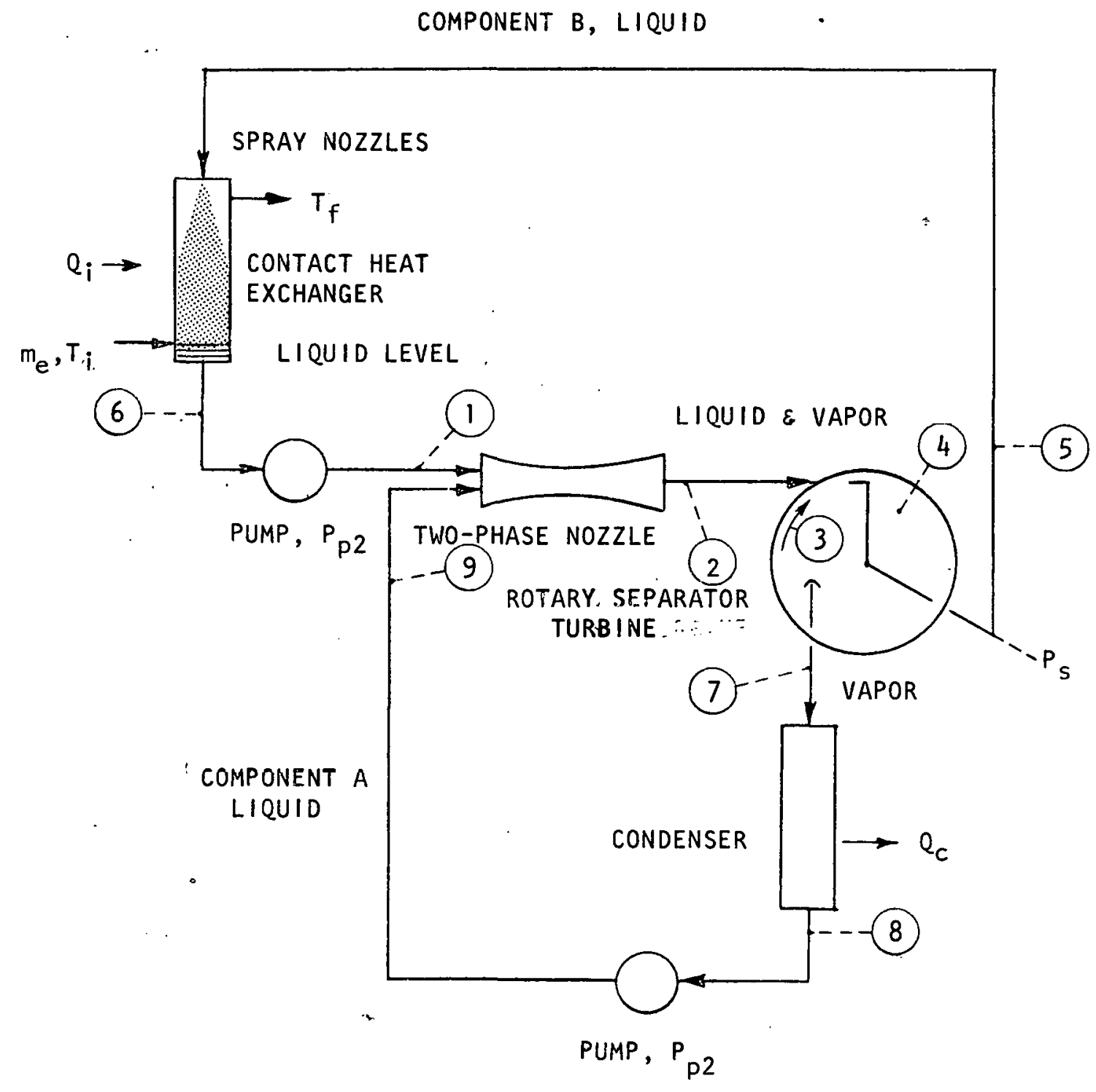

Fig. 12 - Two-Component," Two-Phase Böttoming Cycle whth Contact Heat Exchanger 


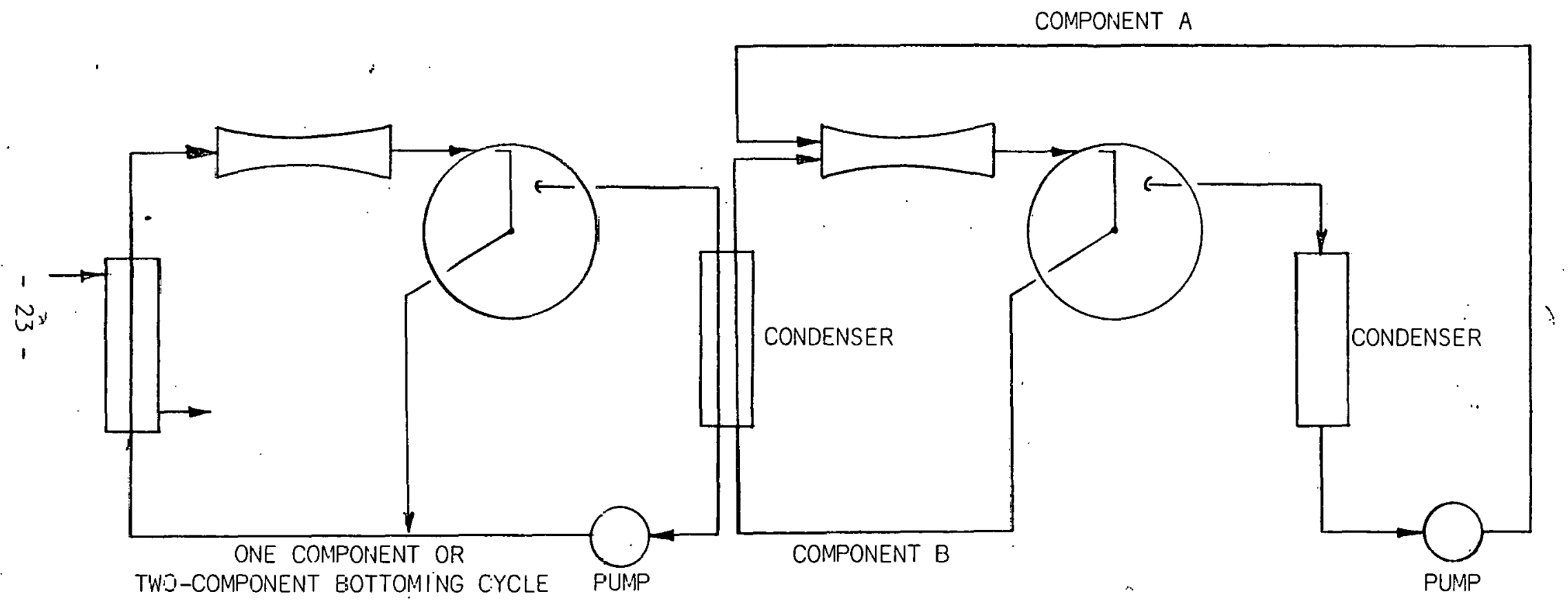

Fig. 12a - Use of Multiple Two-Phase Bottoming Cycles 
heat addition occurs at nearly a constant temperature resulting in effective use of the waste heat from the condenser. This waste heat is rejected at a nearly constant temperature as opposed to the exhaust gas waste heat which occurs over a wide temperature range. In general, the choice of cycle will depend upon the heat source temperature, power level and other factors to be discussed later.

\section{TEMPERATURE - ENTROPY DIAGRAM}

The temperature - entropy diagram for both single and two component cycles is shown in Figure 13. The temperature variation of the exhaust gas for the diesel engine is illustrated by path $A$. The temperature decreases from $719^{\circ} \mathrm{F}$ to $242^{\circ} \mathrm{F}$. In a single component water system this exhaust heat is transferred to pressurized water following path $E$. The water is expanded in the two-phase nozzle following path. $B$, if the process were isentropic, and path $C$ if real flow effects are included. The exit of the nozzle consists of a mixture of steam and water with high kinetic energy. This mixture drives the two-phase turbine. The steam is condensed (path D), pressurized and remixed with the high pressure water leaving the turbine. An alternate method is to extract all of the liquid kinetic energy in the turbine and pressurize that liquid with the condensate pump. As can be seen, the two-phase bottoming cycle maximizes the energy available from the waste heat since the upper temperature of the bottoming cycle continuously increases to match the decrease of the heat source temperature.

In the case of a two-component cycle the thermodynamic working fluid (steam) follows path $F$ during the expansion. The reason the entropy increase is so large is the heat transfer from the all-liquid component into the steam. The net result is that the steam (for the reference. cycle) is slightly superheated at the nozzle exit. In the case of the reference cycle, after separation of the steam from the liquid, it is further expanded from the ngzzle exit pressure, $14.7 \mathrm{psia}$, to a lower 
value, 1.2 psia, through a radial inflow gas turbine, producing added energy. This portion of the cycle diagram is path $G$. The steam is then condensed along path $H$, pressurized and remixed with the liquid from the liquid turbine. The heat input to the steam during the nozzle expansion is derived from the hot liquid which follows path $J$. This curve shows the entropy decrease per unit mass of component "B". However, since there are "r" Ibs. of "B" per lb of "A", the total entropy change is given by path $K$. As can be seen, the areas under curves $K$ and $F$ are equal equating the heat transfer from the liquid into component $B$ into component $A$ during the expansion process. 


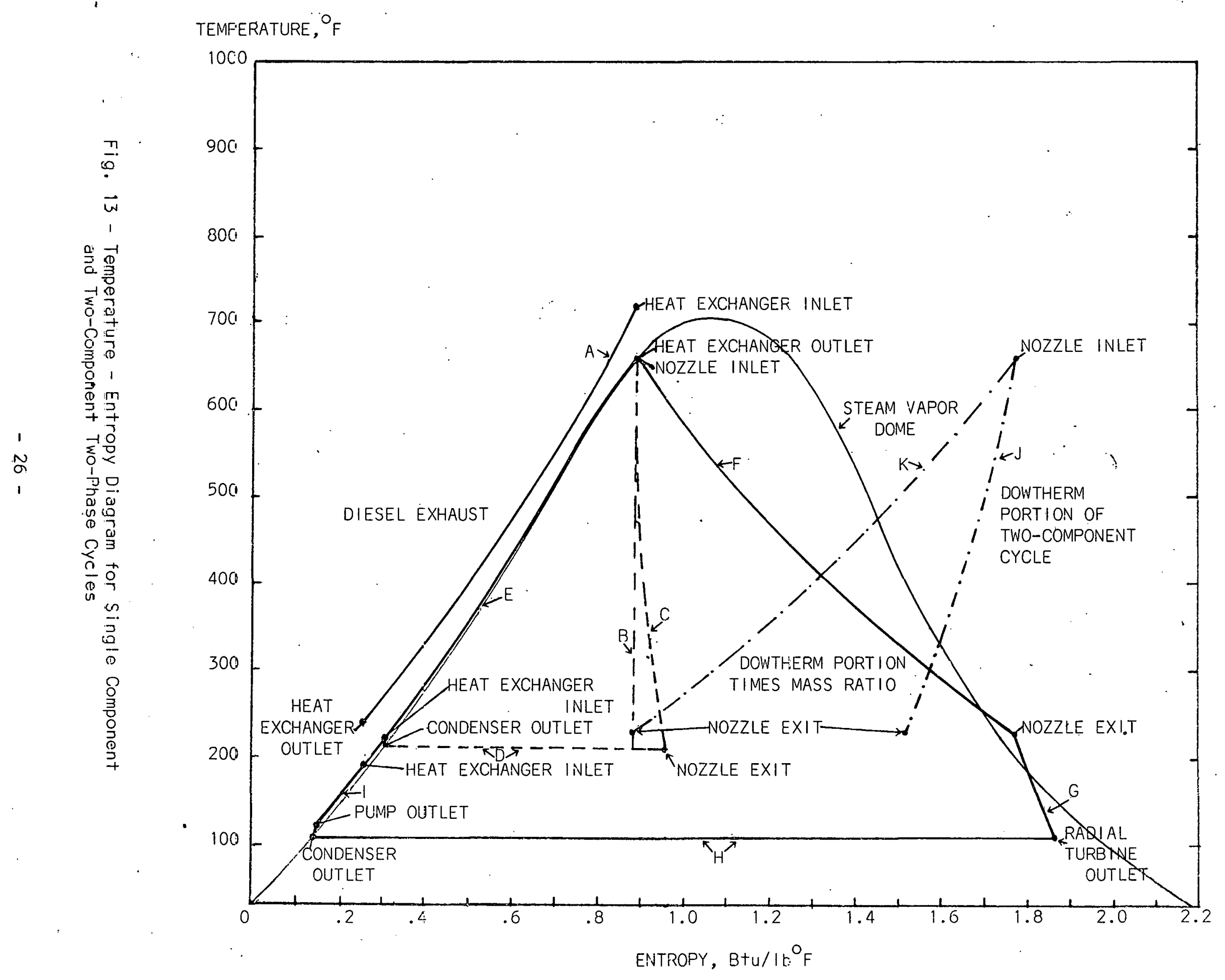




\section{1।1. CYCLE PERFORMANCE}

Performance of the different cycle variations was determined using the two-phase turbine relations of Appendix $A$ and the cycle equations of Appendix B. These calculations were performed for parametric variation of nozzle efficiency, turbine efficiency, rejection temperature and other variables of the power system. The final cycle selected was analyzed in somewhat greater detail as summarized in Section 4.

\section{SINGLE COMPONENT - SINGLE STAGE}

The single component cycle of Figure 9 was analyzed using water as the working fluid. Other possible working fluids considered were Dow-Therm $A$ and $E$ (Dow Chemical), Genetron 133a (Allied Chemical), CP-32 (Monsanto Co.), CP-34 (Monsanto Co.), the Freon family (Du Pont), Trichloroethylene (Dow Chemical), and mercury.

Water obviously has an advantage over the other fluids in terms of cost and the availability of equipment. Consideration of the thermodynamic properties showed most organics to be unsuited for a single component system because of the positive slope of the vapor saturation line. Expansion from pure liquid at a high enough temperature to be of interest for this application (exhaust temperature $=719^{\circ} \mathrm{F}$ ) leads to a superheated vapor rather than a two-phase mixture. This is illustrated in rigure 14 where nozzle expansion for water is compared to a nozzle expansion for CP-32 (pyridine). The starting conditions are $600^{\circ} \mathrm{F}$. With an expansion to $200^{\circ} \mathrm{F}$, the water has a vapor quality of about 0.35 while the pyridine end point is far to the right of the saturated vapor line in the superheated region. *

Mercury, on the other hand, is a very good fluid for a two-phase system. The high ratio of latent heat of vaporization to sensible heat of the liquid $\left(\simeq 4,000^{\circ} \mathrm{F}\right)$ means a large ratio of liquid to vapor results from an 


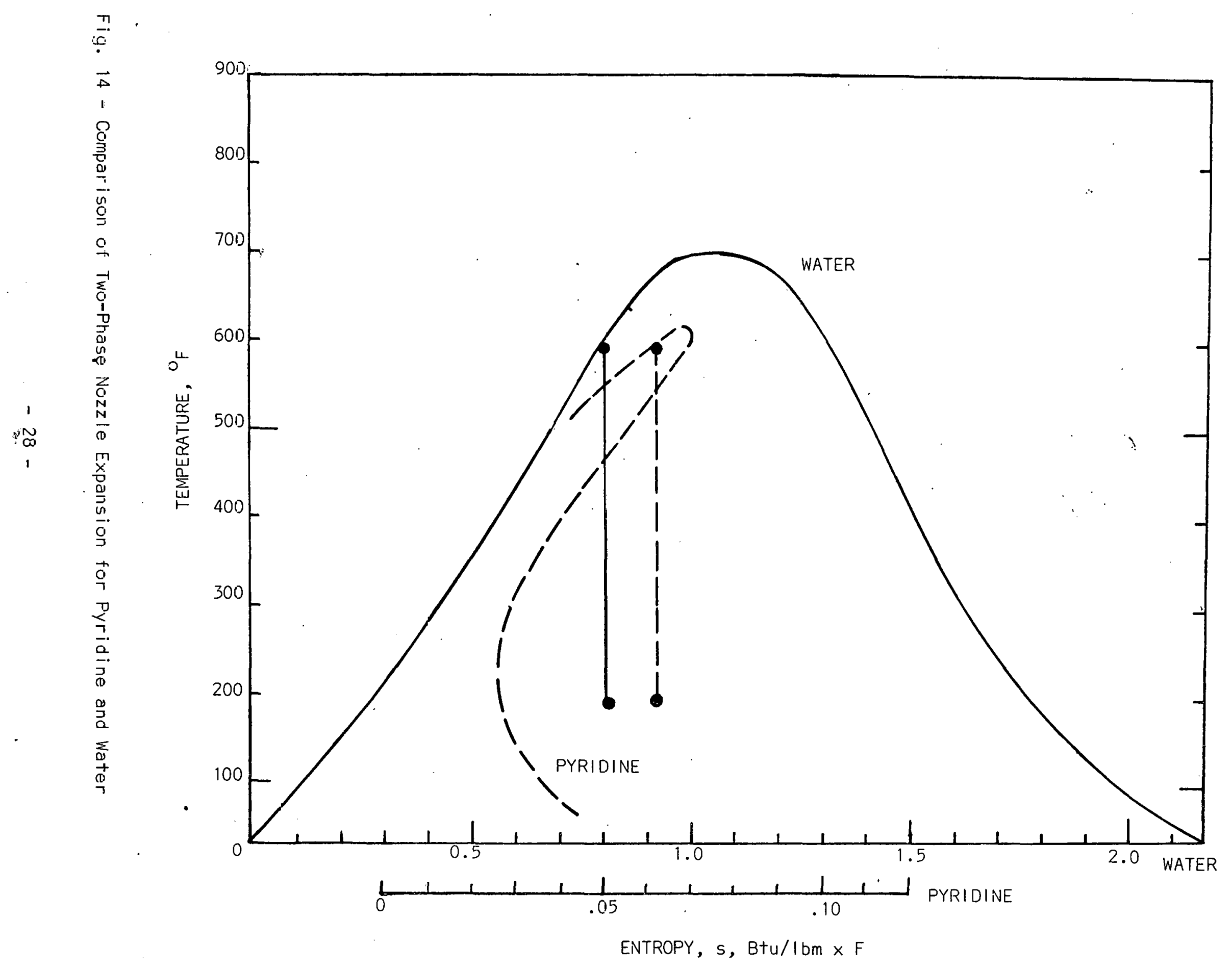


expansion. For example, expansion from liquid at $740^{\circ} \mathrm{F}$ to $240^{\circ} \mathrm{F}$ results in a vapor quality of only about 90 , giving a liquid/vapor ratio of 10 . Expansion of water $\left(L_{v} / C_{p} \simeq 1,000^{\circ} \mathrm{F}\right)$ with a similar temperature drop gives a vapor quality of about .50 , for a liquid to vapor ratio of only one. Thus, the spouting velocity of the mercury nozzle (aside from the obvious molecular weight differences) : would be much less. with a higher mass flow rate and the corresponding two-phase turbine rpm would be much less. Of course, mercury is undesirable as a working fluid because of its cost and toxicity. In addition, the vapor pressure is too low for the application of interest. However, future working fluid searches for single components should concentrate on candidates with a high $L_{v} / C_{p}$ ratio.

The results of calculations for a single stage two-phase bottoming cycle using water are shown in Figures 15 thru 17. In Figure 15, the net cycle efficiency is plotted versus condensing temperature for several values of maximum cycle temperature. A peak efficiency of about $28 \%$ is reached at the maximum cycle temperature of $700^{\circ} \mathrm{F}$ and the condensing temperature of $90^{\circ} \mathrm{F}$. The efficiency is very sensitive to the minimum temperature, decreasing from a value of $28 \%$ at $90^{\circ} \mathrm{F}$ to about $21 \%$ at $212^{\circ} \mathrm{F}$ (rejection temperature). Changing the peak temperature from $700^{\circ} \mathrm{F}$ to $640^{\circ} \mathrm{F}$ at a condensing temperature of $90^{\circ} \mathrm{F}$, reduces the efficiency from $28 \%$ to about $25 \%$. This change is significant because it means dropping the peak pressure from 3100 psia to 2100 psia with attendent lessening of equipment requi rements.

These calculations were all performed for a turbine efficiency of .85 , a nozzle efficiency of .85 , a pump efficiency of .75 and a diffuser efficiency of .85 . The mass ratio of course is a dependent variable as the cycle conditions change.

In order to examine the influence of these component efficiencies (cf. Appendix B) on cycle efficiency, a reference cycle was chosen at 


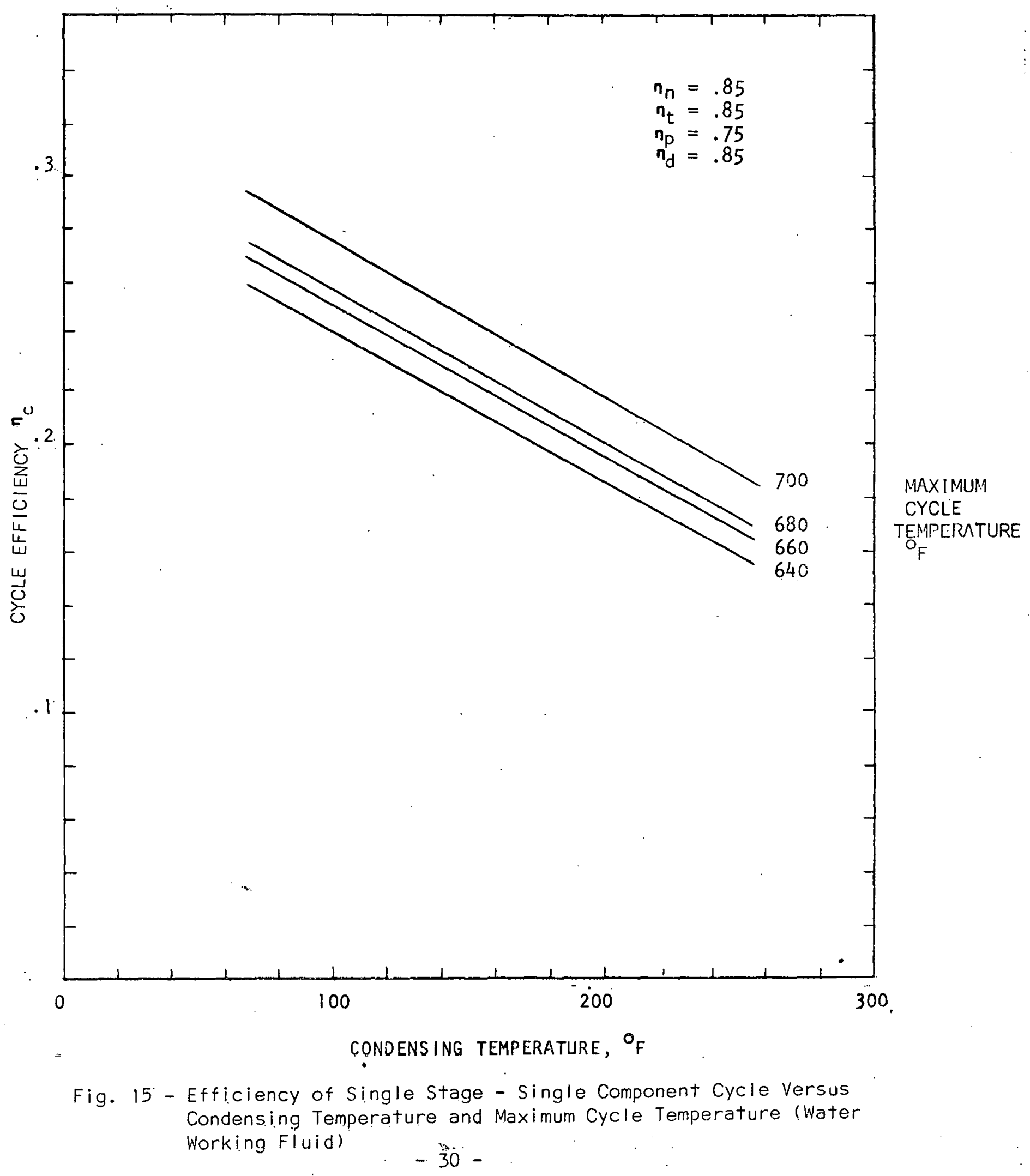




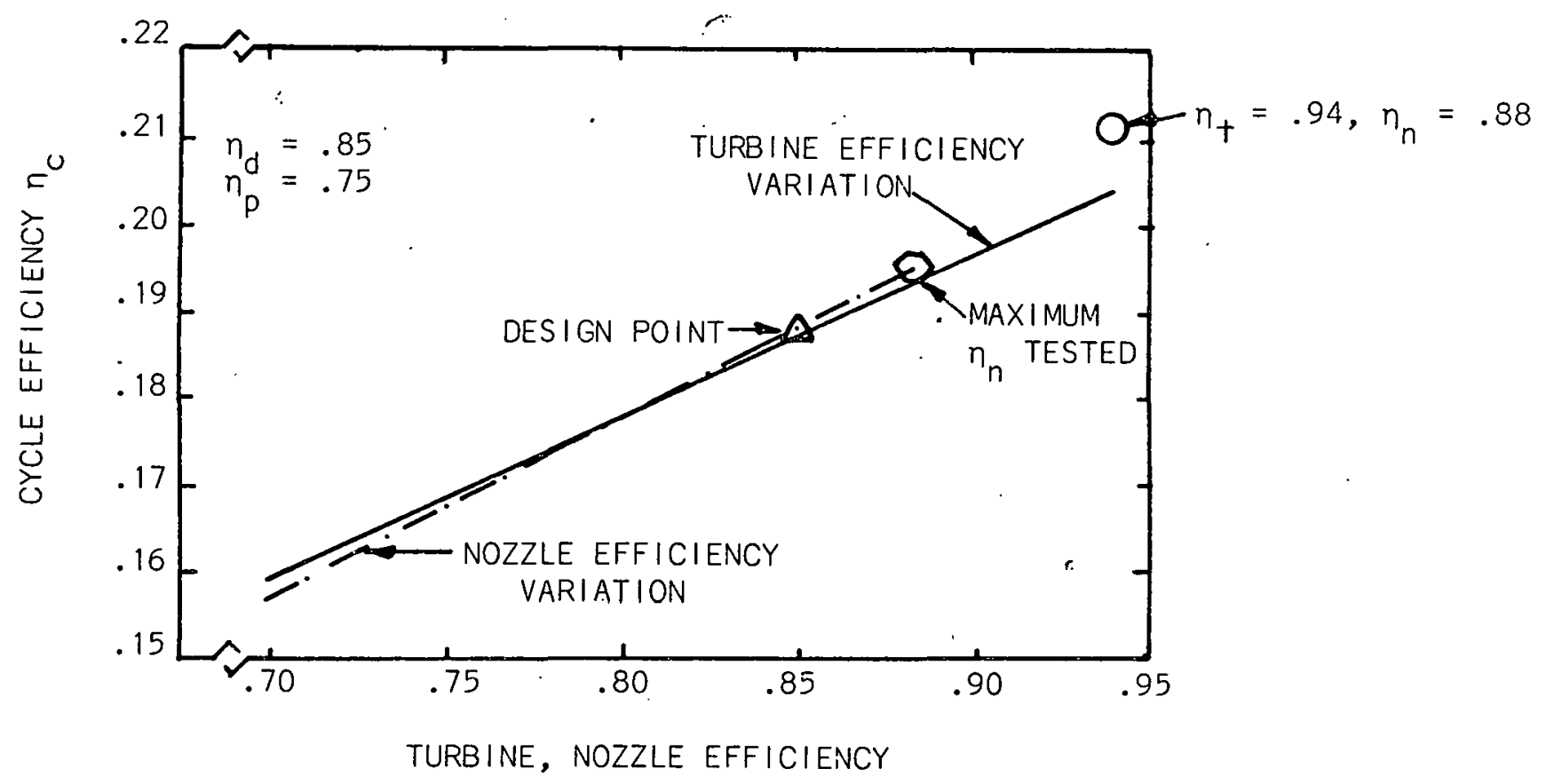

Fig. 16 - Influence of Turbine and Nozzle Efficiencies on Cycle Efficiency $\left(T_{1}=660^{\circ} \mathrm{F}, T_{2}=212^{\circ} \mathrm{F}\right)$

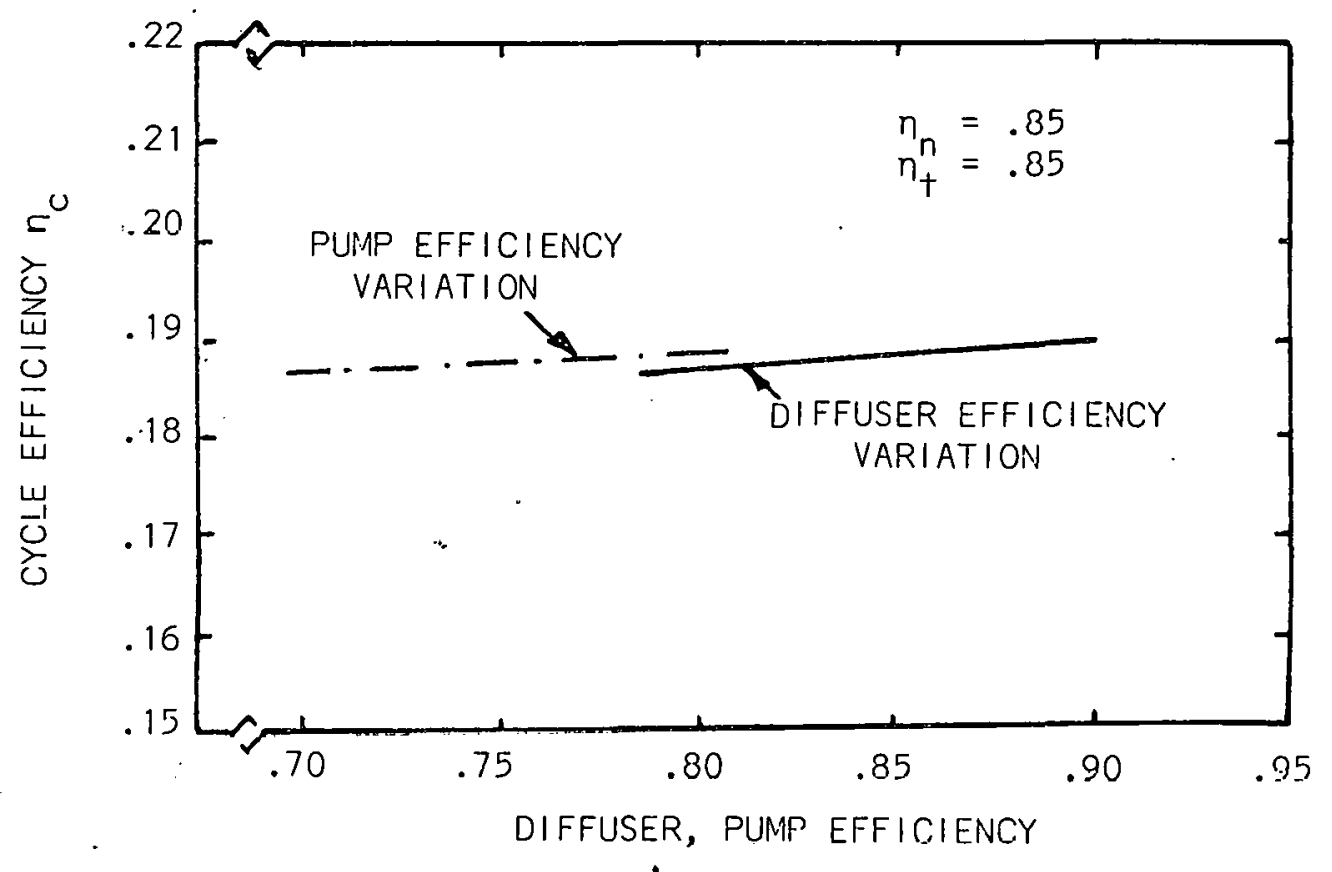

Fig. 17 - Influence of Diffuser and Pump Efticiencies on Cycle Efficiency $\left(\mathrm{T}_{1}=660^{\circ} \mathrm{F}, \mathrm{T}_{2}=212^{\circ} \mathrm{F}\right)$ 
$T_{1}=660^{\circ}$ and $T_{2}=212^{\circ} \mathrm{F}$. The reference cycle efficiency was about $19 \%$ at this point with the above component efficiencies. As seen in Figure 16, variations in nozzle efficiency or turbine efficiency about the design value of .85 , produce a change of about 1 percentage point in cycle efficiency for every 5 percentage points change in component efficiency. The maximum nozzle efficiency previously measured (.88, Ref. 8), would produce a cycle efficiency of about $19 \frac{1}{2} \%$. The same maximum nozzle efficiency with the maximum Pelton wheel efficiency reported (9) would give a cycle efficiency of $21 \%$, a $12 \%$ relative increase above the design point. On the other hand, a nozzle or turbine efficiency of only . 70 would reduce. the cycle efficiency to $16 \%$, which would still be a tolerable value.

Figure 17 shows the cycle efficiency to be less dependent on diffuser and pump efficiency. In this chart, the cycle efficiency changes by only about 1/10 percentage point for every 5 percentage points change in pump or diffuser efficiency. This is particularly significant in the case of the diffuser where the ingestion of vapor can cause efficiency losses.

A key problem with a single component water cycle is the high nozzle exit vapor quality, and hence, high spouting velocity. Nozzle spouting velocities range from $2,600 \mathrm{ft} / \mathrm{s}$ for $212^{\circ} \mathrm{F}$-condensing temperature, to $3,500 \mathrm{ft} / \mathrm{s}$ for a $90^{\circ} \mathrm{F}$-condcnsing tempcraturc. Thesc high valucs negate one of the original advantages of a two-phase cycle - the lower turbine rpm. For a two foot diameter turbine, an rpm range of 12,000 to 17,000 would result. For a Pelton or axial flow turbine the relative liquid impact velocities in the lower range are within turbine current practice $(1,300-1,400 \mathrm{ft} / \mathrm{s}$, Ref. 10), but extreme erosion could be cxpccted to occur at the upper limit of $1,750 \mathrm{ft} / \mathrm{s}$. Thus, it would appear that a lower velocity, such as could be obtained by staging or. the use of two components, would he desirable. 
SINGLE COMPONENT - MULTISTAGE

In order to determine the benefits of staging, the two stage cycle shown in Figure 10 was analyzed and compared to the single stage version. The maximum temperature was chosen as $680^{\circ} \mathrm{F}$ and the rejection temperature was taken as $90^{\circ} \mathrm{F}$. A single stage system analyzed for these conditions gave an efficiency of $27 \%$ with a nozzle spouting velocity of $3,240 \mathrm{ft} / \mathrm{s}$. For a two foot wheel, this would result in an rpm of 15,500 , clearly too high.

Assuming an equal pressure ratio for each stage of the two stage system, with a 10 psi pressure drop between stages, gives an inlet pressure of 40 psia to the second stage. Table 1 summarizes the results of the nozzle calculations using these operating parameters.

TABLE 1

NOZZLE PARAMETERS OF TWO STAGE, SINGLE COMPONENT SYSTEM Inlet Exit Inlet Exit . Spouting

Stage Pressure $\frac{\text { Pressure }}{(p s i a)}$ Quality Quality $\frac{\text { Velocity }}{(\mathrm{ft} / \mathrm{s})}$

$\begin{array}{cccccc}1 & 2710 & 50 & 0 & .42 & 2250 \\ 2 & 40 & .7 & .27 & .33 & 1915\end{array}$

Using these values, the total cycle efficiency becomes 28\% (the slight increase over the single stage is due to the fact that the second stage nozzle is operating at more nearly constant mass ratio). If the pressure ratios were adjusted slightly, to give equal exit velocities, the resulting spouting velocity for the first and second stages would be $2,090 \mathrm{ft} / \mathrm{s}$. For a two foot diameter turbine, an rpm of 9,980 would result. Thus, the beneficial effect of increasing from a single stage to a two stage system would be reduction of the turbine rpm from 15,500 to 9,980 while increasing the cycle efficiency by approximately one percentage point, from $27 \%$ to $28 \%$. The disadvantage is the addition 
of a second nozzle and turbine. To a first approximation, the rpm is inversely proportional to the squáre root of the number of stages. Thus, to reduce the rpm from $n_{1}$ to $n_{2}$, a total of $\left(n_{1} / n_{2}\right)^{2}$ stages would be required.

TWO COMPONENT - SINGLE STAGE

The nozzle exit velocity can also be reduced by the use of a second component " $B$ ", having a lower sensible heat than the liquid phase of the thermodynamic working fluid "A". In order to retain the advantages of a gas to liquid heat exchanger, the amount of the second component must be chosen to give the proper temperature variation in the nozzle and heat exchanger (cf. Appendix B). If too high a flow rate of " $B$ " is used, the nozzle and heat exchanger will approach isothermal operation - the same as if "A" were being vaporized in the heat exchanger. This will reduce the cycle efficiency. If too low a flow rate of " $B$ " is used, the liquid to gas mass ratio will be lower than desired - giving a high nozzle spouting velocity (if the heat source were at a constant temperature, then the mass ratio of " $B$ " to "A" could be freely varied to give the exact nozzle spouting velocity and turbine rpm desired).

Two-component two-phase bottoming systems were analyzed using water as the thermodynamic working fluid and Dow-Therm $A$ as the Iiquid component. Several combinations were examined but the water--Dow-Therm combination had the highest ratio of the latent heat of vaporization to sensible heat of those examined. As will be seen later, the nozzle spouting velocities and turbine rpm are higher than desirable. If a higher molecular weight-thermodynamic working fluid could be found, the turbine rpm could be reduced accordingly.

In order to illustrate the importance of the above parameters, consider a heat source from which it is desired to increase the cycle temperature 
from $T_{2}$ to $T_{1}$. For an isentropic nozzle expansion we have:

$$
\dot{m}_{a} s_{a_{1}}^{\prime \prime}+\dot{m}_{b} s_{b_{1}}^{\prime \prime}=\dot{m}_{a} s_{a_{2}}^{\prime}+\dot{m}_{b} s_{b_{2}}^{\prime \prime}
$$

$$
\text { where } \begin{aligned}
\dot{m}_{a} & =\text { mass flow rate of component } A \\
\dot{m}_{b} & =\text { mass flow rate of component } B \\
s_{a}^{\prime \prime} & =\text { entropy of component } A \text { liquid at the nozzle inlet } \\
s_{b_{1}}^{\prime \prime} & =\text { entropy of component } B \text { liquid at the nozzle inlet } \\
s_{a_{2}}^{\prime} & =\text { entropy of component } A \text { vapor at the nozzle exit } \\
s_{b_{2}}^{\prime \prime} & =\text { entropy of component } B \text { liquid at the nozzle exit }
\end{aligned}
$$

$\dot{m}_{b}$ is selected so that component $A$ is all vaporized and is at saturated conditions at $T_{2}$. Solving for the mass ratio $r=\dot{m}_{b} / \dot{m}_{a}$ :

$$
r=\frac{s_{a_{2}}^{\prime}-s_{a_{1}}^{\prime \prime}}{s_{b_{1}}^{\prime \prime}-s_{b_{2}}^{\prime \prime}}=\frac{s_{a_{2}}^{\prime}-s_{a_{2}}^{\prime \prime}+s_{a_{2}}^{\prime \prime}-s_{a_{1}}^{\prime \prime}}{s_{b_{1}}^{\prime \prime}-s_{b_{2}}^{\prime \prime}}
$$

or

$$
r=\frac{\frac{L_{v a_{2}}}{T_{2}}+C_{p a}^{\prime \prime} \ln \frac{T_{2}}{T_{1}}}{C_{p b}^{\prime !} \ln \frac{T_{2}}{T_{1}}}
$$

$$
\text { where } \begin{aligned}
\mathrm{s}_{\mathrm{a}_{2}}^{\prime \prime} & =\text { entropy of component } A \text { liquid at the nozzle exit } \\
\mathrm{L}_{\mathrm{va}} & =\text { latent heat of vaporization of } A \\
\mathrm{C}_{\mathrm{pa}, \mathrm{b}}^{\prime \prime} & =\text { specific heat of } \mathrm{A}, \mathrm{B}\left(\mathrm{B} / 1 \mathrm{~b}^{\circ} \mathrm{F}\right)
\end{aligned}
$$

Thus, larger $L_{v a}$ and smaller $C_{p b}^{\prime \prime}$ give higher values of mass ratio, which reduces the nozzle velocity.

The two component cycle using water and Dow-Therm was analyzed for variation of the following parameters:

a. Peak Cycle Temperature

b. Rejection Temperaluie

c. Diesel Exhaust Temperature

d. Diesel Exhaust Flowrate

e. Working Fluids ( $C_{p}$ variation)

$$
\begin{array}{rrr}
500^{\circ} \mathrm{F} & \text { to } & 700^{\circ} \mathrm{F} \\
90^{\circ} \mathrm{F} & \text { lo } & 212^{\circ} \mathrm{F} \\
520^{\circ} \mathrm{F} & \text { to } & 720^{\circ} \mathrm{F}
\end{array}
$$$$
15,300 \mathrm{lb} / \mathrm{h} \text { to } 27,300 \mathrm{lb} / \mathrm{h}
$$

steam \& Freon thru polyphenyl ether 
f. Liquid/Gas Mass Ratio

g. Output rpm

$$
\begin{aligned}
3.5 & \text { to } 23.0 \\
5,000 & \text { to } 12,000
\end{aligned}
$$

In the case of the mass ratio and output rpm, independent variation was not always possible because of the interrelation of variables.

The effect of the peak cycle temperature is shown in Figure 18. Operation with a condensing pressure of .7 psia $\left(90^{\circ} \mathrm{F}\right)$ and a nozzle exit liquid temperature of $212^{\circ} \mathrm{F}$, gave a peak cycle efficiency of $30 \%$ at a peak temperature of $700^{\circ} \mathrm{F}$. Reduction of the temperature from $700^{\circ} \mathrm{F}$ to $500^{\circ} \mathrm{F}$ (reduction of the peak pressure from 3,090 psia to 680 psia) reduced the cycle efficiency by only 6 percentage points (to $24 \%$ ). of course, the reduction is much greater in terms of the available energy if the peak exhaust temperature is constant at $719^{\circ} \mathrm{F}$. The significance of this result is that the part load efficiency can be kept at a.high value as the diesel power (exhaust temperature) drops.

The influence of I iquid temperature on cycle efficiency for a constant back pressure (.7 psia) and constant peak cycle temperature $\left(660^{\circ} \mathrm{F}\right)$ is shown in Figure 19. Reduction of the temperature from $240^{\circ} \mathrm{F}$ to $90^{\circ} \mathrm{F}$ results in a reduction of the efficiency from $29 \%$ to $25 \%$. This change results from reducing the mass ratio from 6.5 to 3.9. At the higher mass ratio, more energy is transferred into the liquid phase resulting in the higher efficioncy.

The nozzle back pressure (condensing temperature) has perhaps the greatest effect on cycle efficiency and turbine rpm. Figure 20 shows the cycle efficiency to increase from $18 \%$ to $29 \%$ as the back pressure is decreased from. 14.7 psia to .7 psia. For a constant liquid outlet temperature this results in a simultaneous increase in mass ratio, $r$, and nozzle:spouting velocity. The mass ratio increases from 4.7 to 6.5 while the spouting velocity increases from $1,660 \mathrm{ft} / \mathrm{s}$ to $1,920 \mathrm{ft} / \mathrm{s}$. In addition to the disadvantage of higher turbine rpm, decreasing the 


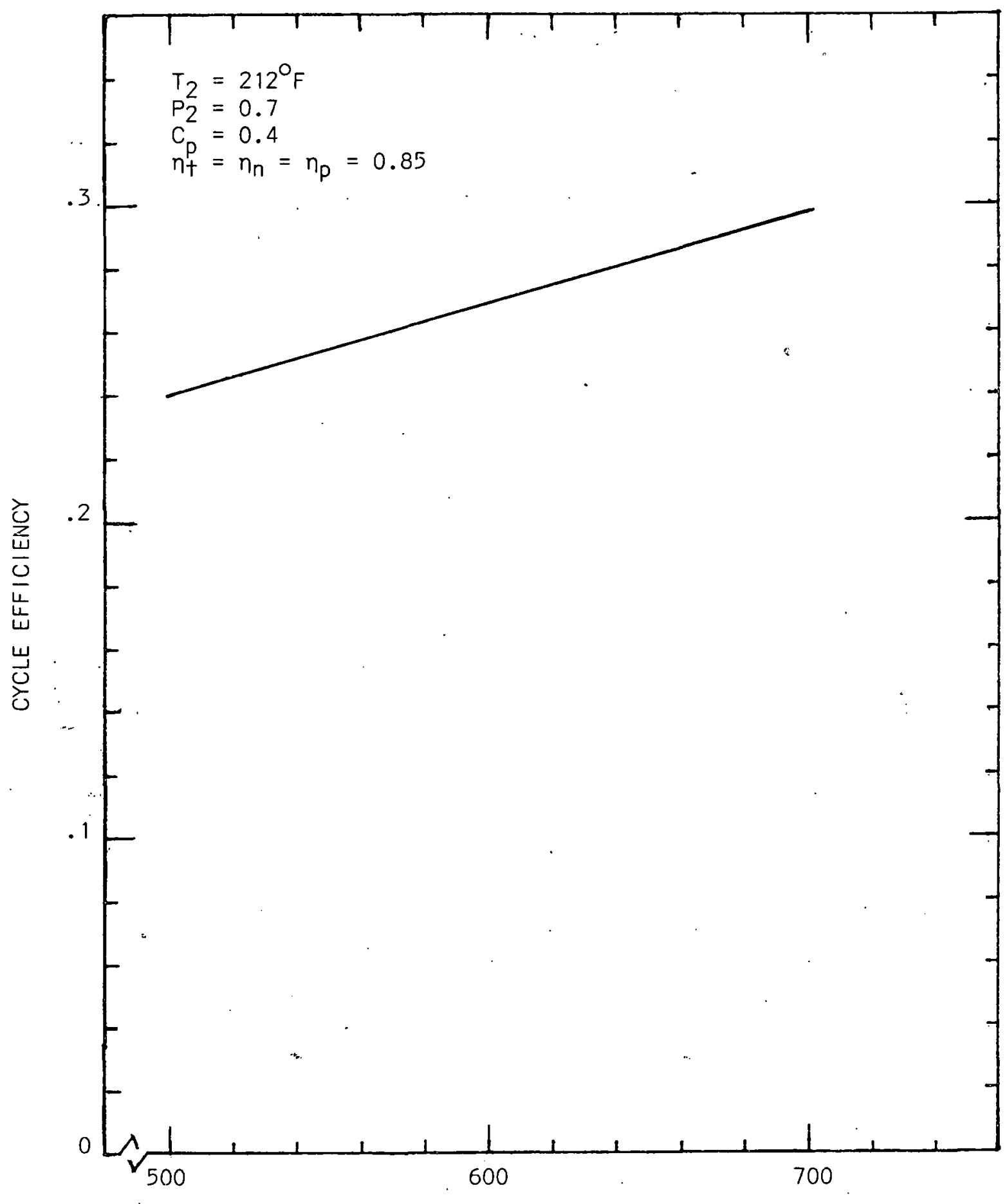

PEAK CYCLE TEMPERATURE, ${ }^{\circ} F$

Fig. 18-Efficiency Versus Peak Cycle Temperature for TwoComponent Bottoming Cycle 


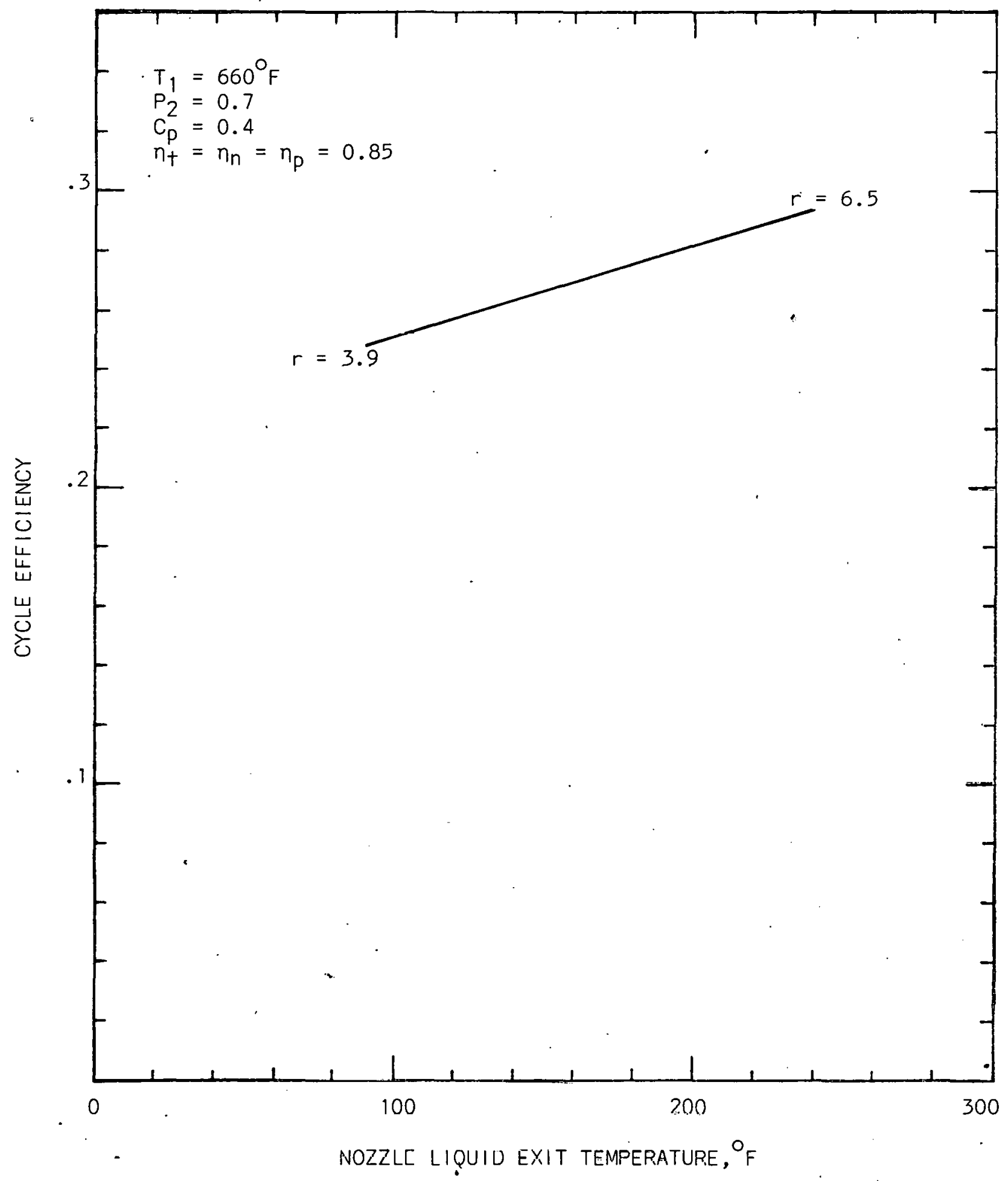

Fig. 19 - Efficiency Versus Nozzle Liquid Exit Temperature for Two-Component Bottoming Cyclo

$$
-38-
$$




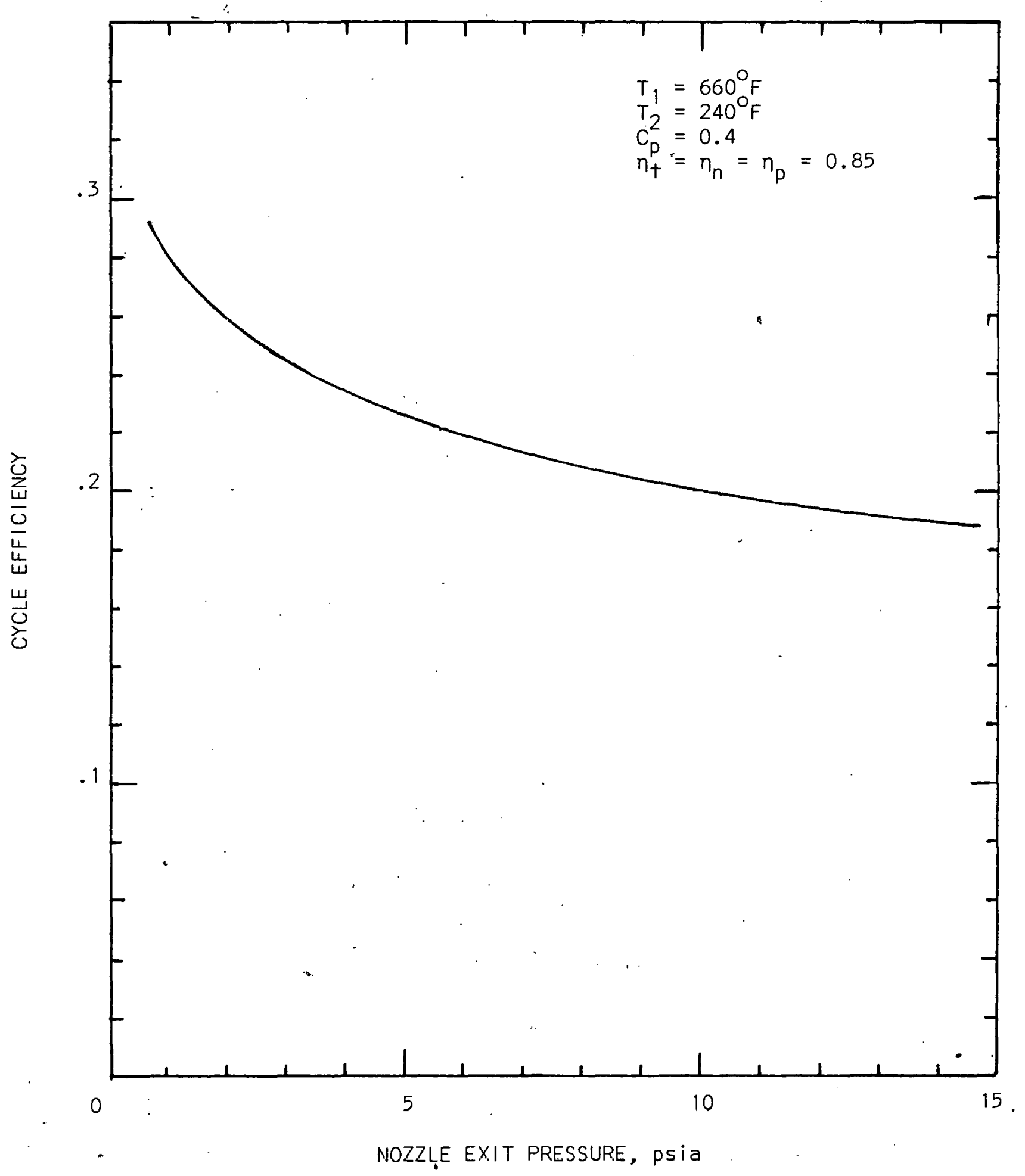

Fig. 20 - Efficiency Versus Nozzle Exit Pressure (Heat Rejection Temperature) for Two-Component Two-Phase Bottoming Cycle

-39 - 
back pressure results in a large increase in nozzle exit area which tends to reduce both the nozzle and the furbine efficiency. Thus, the gains reflected in Figure 20 would be somewhat reduced due to decreasing nozzle and turbine efficiency.

The effect of the liquid working fluid can be seen in Figure 21 through the influence of the sensible heat change. The specific heats of different fluids are indicated on the figure for comparison purposes. As can be seen, a gradual decrease in cycle efficiency occurs as the heat capacity is decreased. For example, decreasing the sensible heat from $.6 \mathrm{~B} / 1 \mathrm{~b}^{\circ} \mathrm{F}$ to $.2 \mathrm{~B} / 1 \mathrm{~b}^{\circ} \mathrm{F}$ reduces the cycle efficiency from $29 \%$ to $27 \frac{1}{2} \%$. However, the mass ratio increases from 3.9 to 11.7 and the nozzle spouting velocity is reduced from $2,350 \mathrm{ft} / \mathrm{s}$ to $1,520 \mathrm{ft} / \mathrm{s}$. This example best illustrates the transformation possible if the mass ratio of liquid to gas can be increased within the thermodynamic constraints available. The reference cycle finally adopted, is operated at a relatively high nozzle exit pressure to limit the nozzle spouting velocity. Howver, if a suitable fluid with a significantly lower $C_{p}$ than that of Dow-Therm $A$ can be used, considerable efficiency improvement should be obtainable.

The above results were generated for constant values of nozzle efficiency, turbine efficiency and pump efficiency. The influence of these parameters on cycle efficiency are shown in Figures 22 through 26 . In general, the liuzzle and lurbine efflclencles have a very strong influence on cycle efficiency, whereas, the pump or diffuser efficiency has a less pronounced effect. For example, increasing the turbine and nozzle efficiencies from the design value of .85 to .90 would increase the cycle efficiency from $28 \%$ to $31 \%$. Decreasing them both to .70 would reduce the cycle efficiency from $28 \%$ to a litule over $20 \%$, which is still a usable value. On the other hand, if the pump efficiency were decreased from .85 to .65 , the cycle efficiency would only drop by less than one percentage point (from 28.4\% to $27.5 \%)$. Thus, a considerable range of useful performance exists whether 


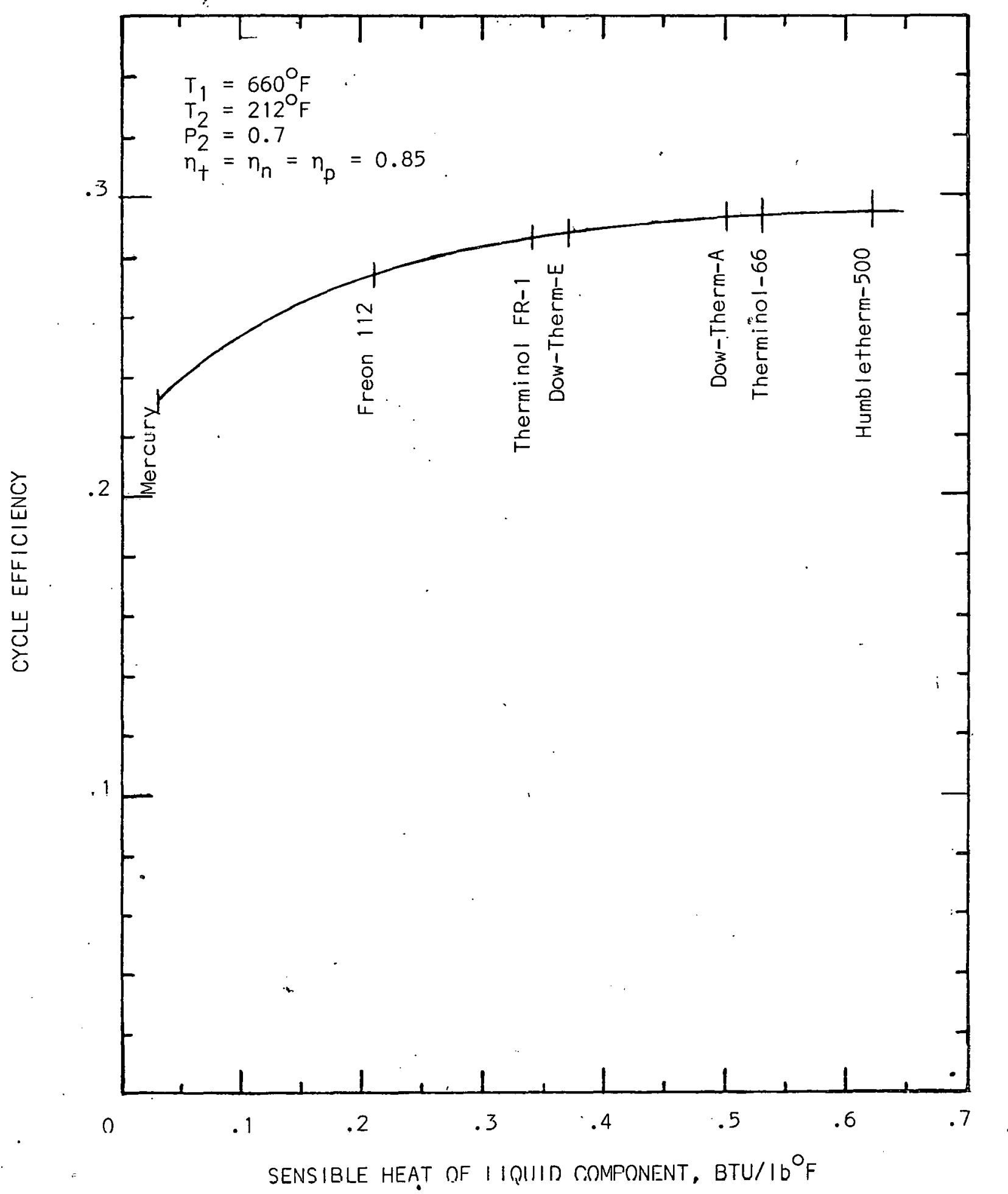

Fig. 21 - Cycle Efficiency Versus Sensible Heat of Liquid compnnent for Two-Component Two-Phase Bottcming Cycle $-4 i-$ 


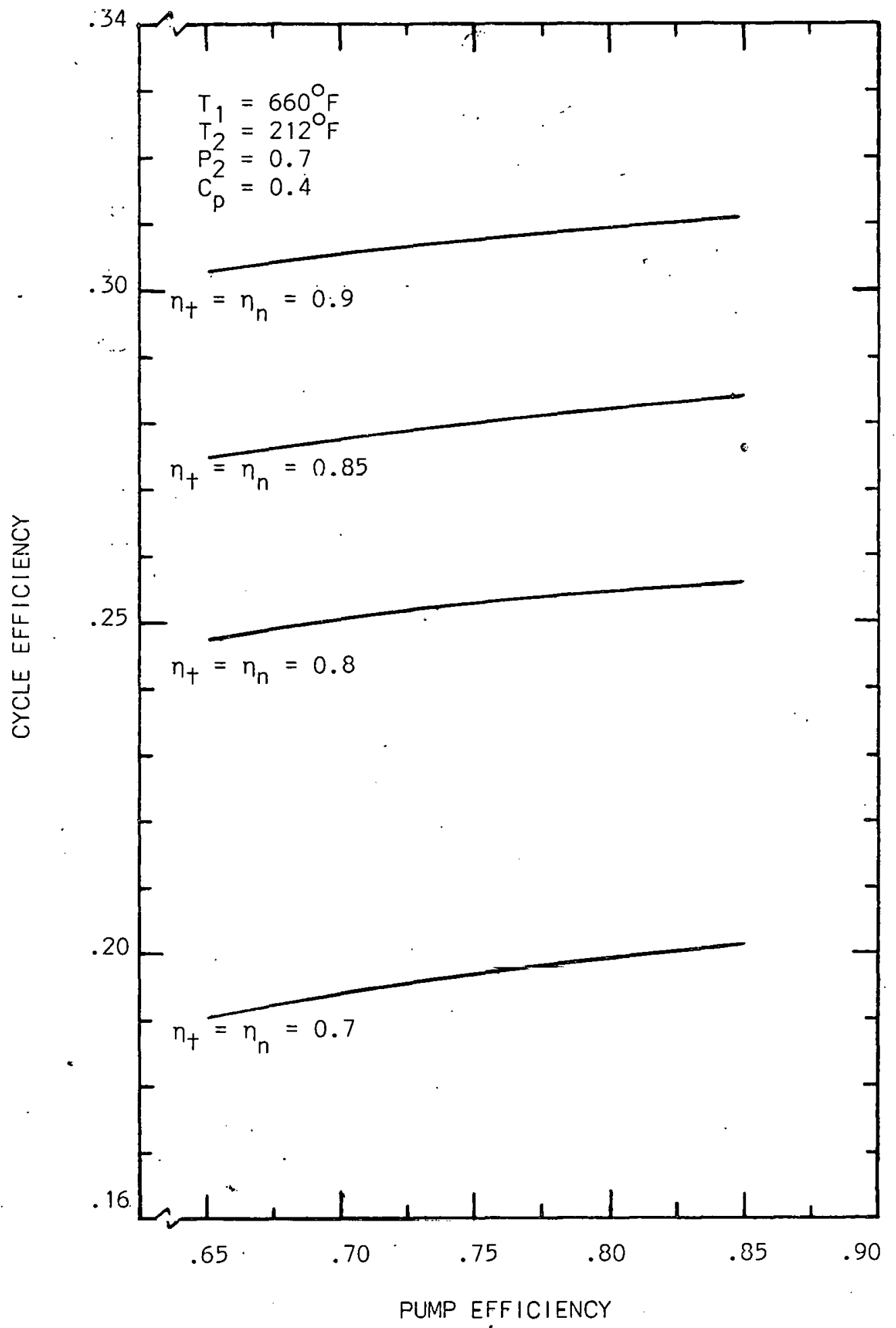

Fig. 22 - Influence of Nozzle, Turbine and Pump Effigiencics on Cyclo Efficiency 


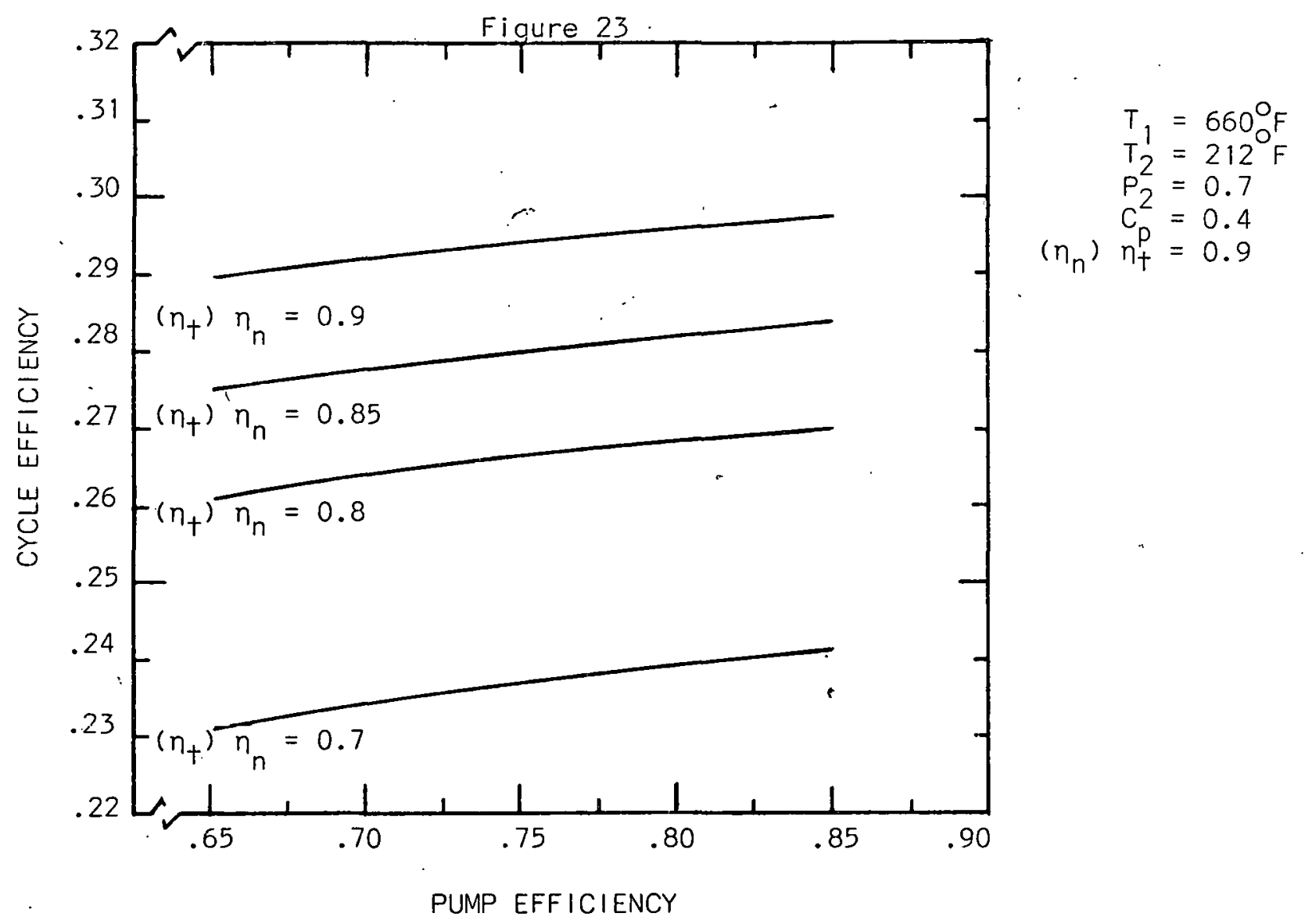

Figs. 23,24:- +nfluence of Nozzle,.. Turb ine and Pump. Efficiencies on Cycle Efficiency.

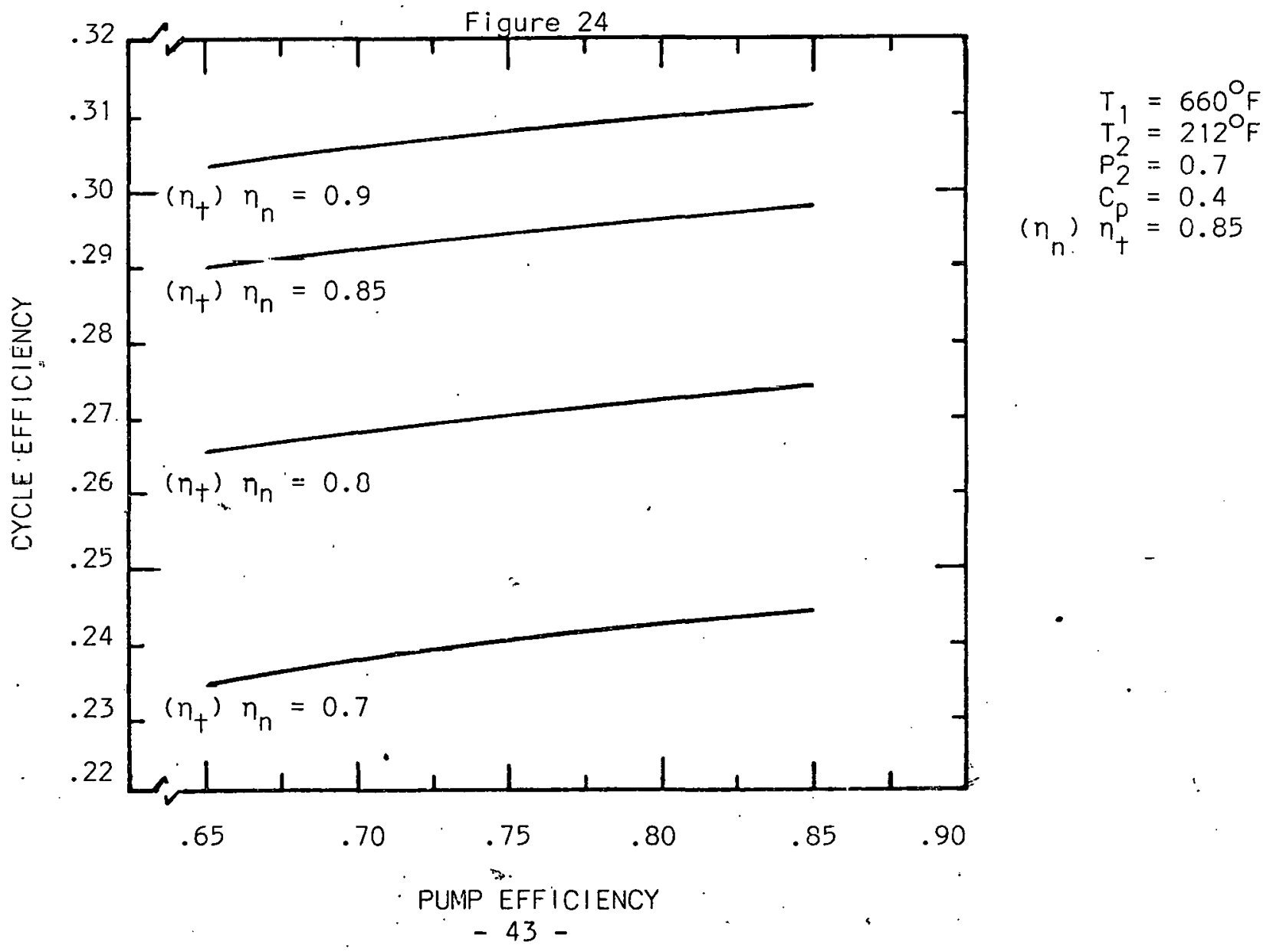




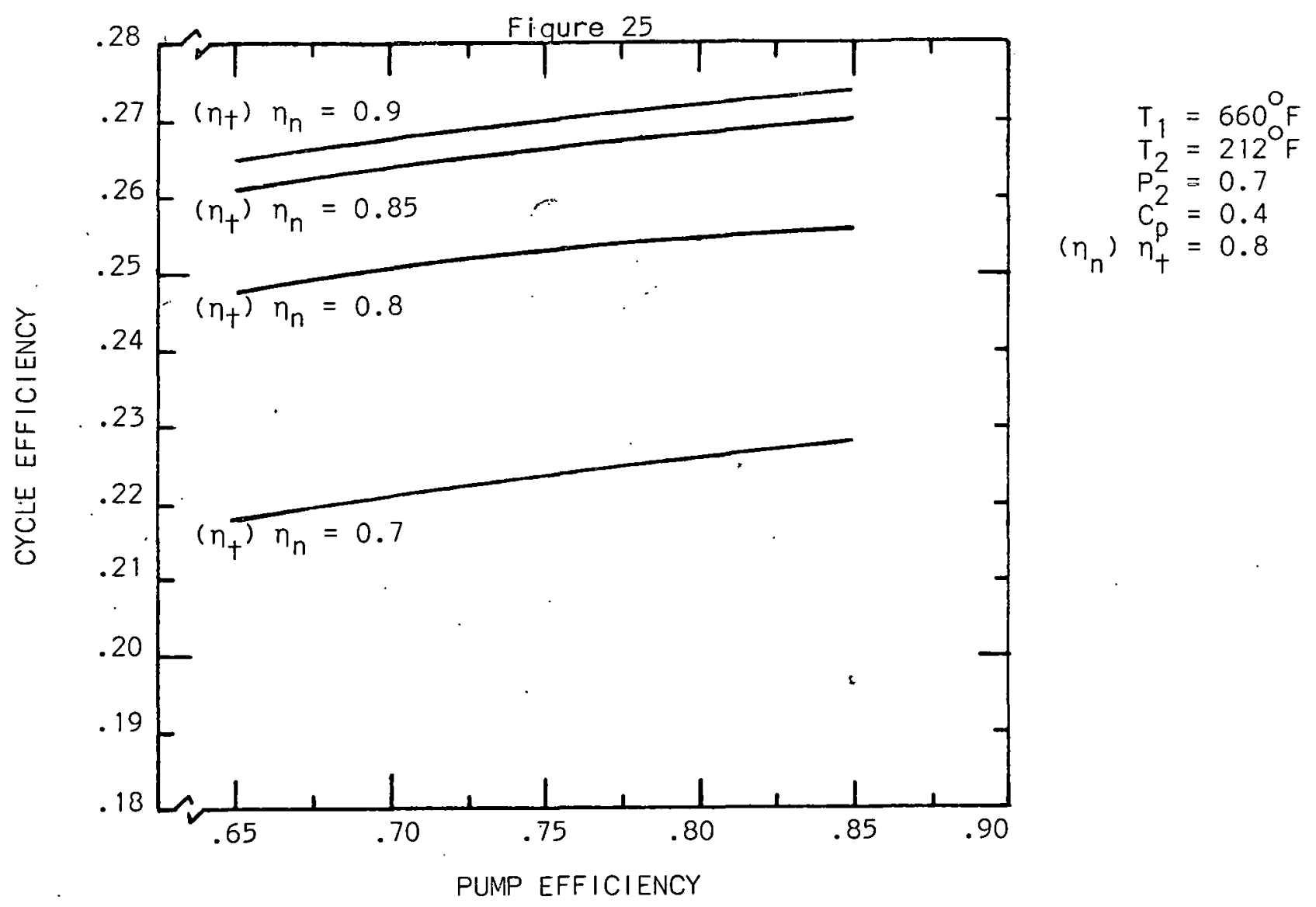

Figs. 25,26 - Influence of Nozzle, Turbine and Pump Efficiencies on Cycle Efficiency

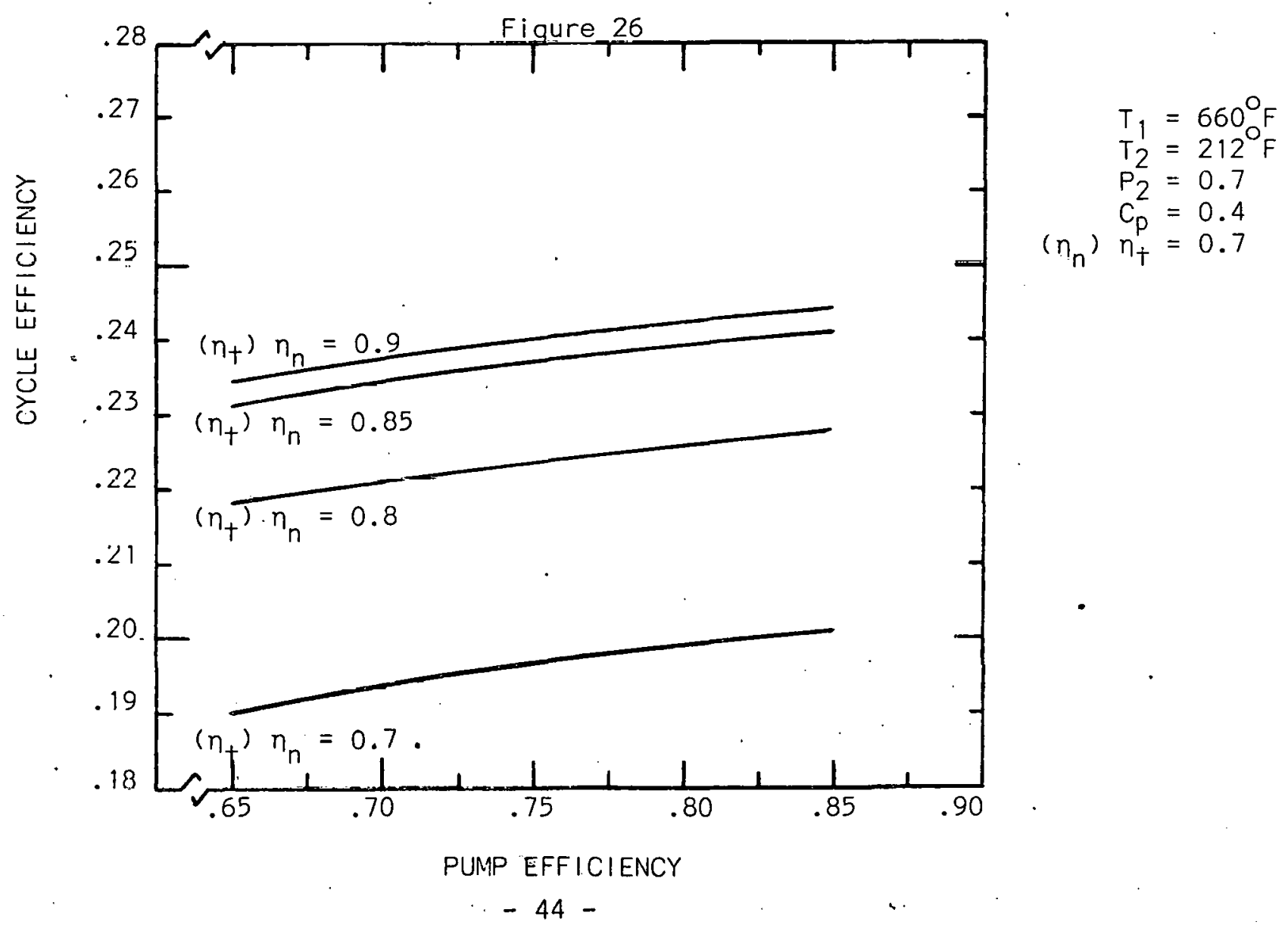


the nozzle, turbine and diffuser attain the highest values tested or calculated $(\sim .9)$ or the lowest varues likely ( $(.7)$.

To summarize, the two-component cycle appears to offer substantially lower turbine rpm and somewhat higher efficiencies than a single component system. It was, therefore, chosen to provide the basis for the reference cycle design. Other variations, such as compound cycles or the contact heat exchanger cycle, can offer substantially the same performance as the above variations while possibly achieving other advan- tages. However, the basic criteria for choice of the reference cycle type and parameters was felt to be simplicity, cost and 'state of the art' components, so a single-stage two-component system was examined. 


\section{REFERENCE CYCLE}

The reference cycle chosen for this design study uses the exhaust from an 1800 HP Colt-Pielstick PC-2 diesel engine to provide heat to the twophase turbine engine. Table 2 (from Ref. 7) summarizes the operating characteristics of the engine over the range of interest. This engine was chosen for the design study because the design power (1800 HP) is large enough to provide a reasonable bottoming cycle efficiency and the engine exhaust temperature $\left(719^{\circ} \mathrm{F}\right)$ is representative of many engines of interest for waste heat recovery. The minimum exhaust temperature $\left(525^{\circ} \mathrm{F}\right)$ was treated in the cycle analysis and the cycle efficiency remained in excess of $20 \%$.

The peak efficiency ( $230 \%$ ) for a bottoming cycle could be obtained by expansion of the two-phase mixture to the lowest possible exhaust pressure (.7. psia for $90^{\circ} \mathrm{F}$ rejection temperature). Use of a liquid component with a low sensible heat would enable operation at this exhaust pressure with a high mass ratio and, therefore, low spouting velocity. However, the lowest sensible heat $\left(\sim .37 \mathrm{~B} / 1 \mathrm{~b}^{\circ} \mathrm{F}\right)$ was found for a 'Therminol' fluid which may have toxicity problems. It was therefore decided to use Dow-Therm $i$ which although having a higher sensible heat ( $\sim .51$ ), is a common heat transfer fluid with no toxicity problems for which commercial equipment is available. With this fluid, the spouting velocity for peak efficiency (29\%) was very high.

In order to limit the rpm to reasonable values ( 8000 ) and to simplify the seals and bearings problems, it was decided to operate the initial system with a nozzle back pressure of one atmosphere. This still produced an acceptably high efficiency (23\%) with a single stage system without any subatmospheric seals. In order to increase the efficiency beyond the normal range for this back pressure (17-18\%), the steam was further expanded (to 1.2 psia) after separation. 
TABLE 2

OPERATING PARAMETERS OF 38TD8-1/8 DIESEL ENGINE

\begin{tabular}{|c|c|c|c|c|c|}
\hline$\%$ of Continuous Rated Power & 110 & 100 & 75 & 50 & 25 \\
\hline BMEP, psi & 139.8 & 127 & 95.3 & 63.5 & 31.8 \\
\hline Input (HHV) & 7117 & 7132 & 7311 & 7861 & 9534 \\
\hline Input ( $L H V)$ & 6687 & 6702 & 6871 & 7386 & 8936 \\
\hline Exh. Sensible, Btu/bhphr & 2200 & 2260 & 2460 & 2860 & 3660 \\
\hline Exh. Latent, Btu/bhphr & 430. & 430 & 440 & 475 & 598 \\
\hline Lube Oil, Btu/bhphr & 700 & 702 & 728 & 808 & 1075 \\
\hline $\mathrm{AC} \& \mathrm{Turbo} \mathrm{H}_{2} \mathrm{O}, \mathrm{Btu} / \mathrm{bhphr}$ & 560 & 512 & 430 & 380 & 349 \\
\hline Cooling $\mathrm{H}_{2} \mathrm{O}$, Btu/bhphr & 460 & 461 & 478 & 530 & 706 \\
\hline Rad. \& Unacc., Btu/bhphr & 222 & 222 & 230 & 263 & 602 \\
\hline Useful Work, Btu/bhphr & 2545 & 2545 & 2545 & 2545 & 2545 \\
\hline Exhaust Temp., ${ }^{\circ} \mathrm{F}$ & 720 & 719 & 701 & 654 & $525^{\circ}$ \\
\hline Air Consumption, $1 \mathrm{~b} / \mathrm{bhphr}$ & 14.2 & 14.8 & 16.3 & 20.5 & 33.5 \\
\hline Fuel Consumption, lb/bhphr & 0.368 & 0.369 & 0.378 & 0.406 & 0.492 \\
\hline Exhaust Gas, lb/bhphr & 14.57 & 15.17 & 16.68 & 20.91 & $33.99^{\circ}$ \\
\hline$\eta(\mathrm{HHV})$ & 0.358 & 0.357 & $0: 348$ & 0.324 & 0.267 \\
\hline$\eta(\mathrm{LHV})$ & 0.381 & 0.380 & 0.370 & 0.345 & 0.285 \\
\hline
\end{tabular}


The final state points and flow conditions for the reference cycle are shown in Table 3. The temperaturés and pressures are well within the state of the art for steam and Dow-Therm systems. The net power output of $276 \mathrm{HP}$, when added to the diesel output of $1800 \mathrm{HP}$ gives an increase of $15 \%$, or on a per unit fuel basis, the same power for $15 \%$ less fuel. For the $1800 \mathrm{HP}$ size, a $40 \%$ basic diesel efficiency, and a fuel price of $\$ 2.00 / \mathrm{million} B$, the annual fuel savings would be $\$ 24,000$ (for an $80 \%$ capacity factor), giving a 3 year payback for about $\$ 300 / \mathrm{kw}$ capital cost of the bottoming system. This cost appears to be a reasonable goal, considering the simplicity.

\section{FLOW CONDITIONS}

The flow conditions were chosen to provide a slight degree of superheat at the exit of the nozzle to avoid the Wilson Line during subsequent expansion of the steam in the radial inflow turbine. For inlet conditions of $660^{\circ} \mathrm{F}$ and 2,365 psia and nozzle exit conditions of $230^{\circ} \mathrm{F}$ and 14.7 psia, the following values result:

$$
\begin{aligned}
& \mathrm{s}_{a_{1}}^{\prime \prime}=.8987 \mathrm{~B} / 1 \mathrm{~b}^{\circ} \mathrm{F} \\
& \mathrm{s}_{a x}^{\prime \prime}=1.7695 \mathrm{~B} / 1 \mathrm{~b}^{\circ} \mathrm{F} \\
& \mathrm{C}_{\mathrm{pb}}^{\prime \prime}=.51 \mathrm{~B} / 1 \mathrm{~b}^{\circ} \mathrm{F} \\
& \mathrm{h}_{\mathrm{a}_{1}}^{\prime \prime}=714.2 \mathrm{~B} / \mathrm{lb} \\
& \mathrm{h}_{\mathrm{ax}}^{\prime}=1159.3 \mathrm{~B} / \mathrm{lb}
\end{aligned}
$$

Substitution in Eq. (3) gives:

$$
r=3.50
$$

Substitution of the enthalpy values in Eq. (28) of Appendix B gives:

$$
V_{2 i}=1,078 \mathrm{ft} / \mathrm{o}
$$

A nozzle efficiency of .85 yields:

$$
V_{2}=1,824 \mathrm{ft} / \mathrm{s}
$$

Entry at $15^{\circ}$, with a radius change of .96 from the nozzle center -line to the separator drum.gives a separator liquid velocity of:

$$
v_{s}=(.96)\left(\cos 15^{\circ}\right)(1,824)=1,691 \mathrm{ft} / \mathrm{s}
$$


TABLE 3

STATE POINTS FOR REFERENCE BOTTOMING CYCLE

\begin{tabular}{|c|c|c|c|c|c|}
\hline State Point & $\begin{array}{c}\text { Temperature } \\
\left(\mathrm{O}_{\mathrm{F}}\right)\end{array}$ & $\begin{array}{c}\text { Pressure } \\
\text { (psia) } \\
\end{array}$ & $\begin{array}{c}\text { Flowrate } \\
(1 \mathrm{~b} / \mathrm{s}) \\
\end{array}$ & $\begin{array}{c}\text { Velocity } \\
(\mathrm{ft} / \mathrm{s}) \\
\end{array}$ & $\begin{array}{l}\text { Liquid/ } \\
\text { Liquid/Gas }\end{array}$ \\
\hline 1 & 660 & 2365 & 2.97 & 30 & L \\
\hline 2 & 230 & 14.7 & 2.97 & 1824 & $L+G$ \\
\hline 3 & 230 & 14.7 & 2.31 & 1691 & L \\
\hline 4 & 107 & 1.2 & .66 & 50 & $L+G^{*}$ \\
\hline 5 & 230 & 14.7 & 2.31 & 30 & $L$ \\
\hline 6 & 100 & 1.2 & .66 & 30 & $L$ \\
\hline 7 & 190 & 2465 & 2.97 & 30 & $L$ \\
\hline 8 & 719 & 15.0 & 7.58 & 50 & $G$ \\
\hline 9 & 242 & 14.7 & 7.58 & 50 & $G$ \\
\hline
\end{tabular}

*Vapor qual ity $=.96$

POWER OUTPUT - 276 HP @ 8075 RPM

CYCLE EFFICIENCY - 23\%

NET POWER INCREASE - 15\%

ABOVE DIESEL OUTPUT 
For a two foot diameter the separator rpm is:

$$
W_{S}=16,150 \mathrm{rpm}
$$

Use of a "U-tube" turbine at an rpm one half of the separator rpm gives a turbine rpm of:

$$
W_{t}=8,075 \mathrm{rpm}
$$

The liquid turbine tip speed in $845.5 \mathrm{ft} / \mathrm{s}$. The torque on the turbine due to momentum change is:

$$
\begin{aligned}
& L_{t m}^{\prime \prime}=2 \dot{m}_{b}\left(v_{s}-v_{t}\right) r_{t} \\
& L_{t m}^{\prime \prime}=121: 32 b f t
\end{aligned}
$$

The drag on the liquid turbine is given by:

$$
F_{t d}^{\prime \prime}=\frac{C_{d} \rho_{b}^{\prime \prime}\left(v_{s}-v_{t}\right)^{2}}{-2} A_{i}
$$

or

$$
F_{t d}^{\prime \prime}=c_{d} \frac{\dot{m}_{b}\left(v_{s}-v_{t}\right)}{2} .
$$

where $C_{d}=$ the drag coefficient for the liquid pickup

$$
A_{i}=\text { the inlet area }
$$

A: value of $C_{d}=1$ appears attainable for an inlet with base ventilation! (11). Substitution in. Eq. (6) gives:

$$
F_{+d}^{\prime \prime}=3.031 t
$$

Since a 1 foot radius is found at this location the drag torque on the inlet is:

$$
L_{\text {fd }}^{\prime \prime}=3.0310 \mathrm{ft}
$$

The total torque on the liquid turbine is:

$$
L_{t}^{\prime \prime}=124.3 \mathrm{lbft}
$$

The power is therefore:

$$
P_{t}^{\prime \prime}=\frac{(121.3)(845.5)}{(550)}=191 \mathrm{HP}
$$


The power loss due to the drag of the inlet is:

$$
P_{S_{1}}=\frac{(3.03)(1,691)}{(550)}=9.3 \mathrm{HP}
$$

The windage loss of the separator was estimated considering the rim to be a flat plate with the width equal to the separator width and the length equal to the circumference.

The Reynolds Number is:

$$
\operatorname{Re}_{x}=\frac{v_{s} L_{s}}{v_{a}^{\prime}}
$$

For steam at $230^{\circ} \mathrm{F}$ and 14.7 psia, $v_{a}^{\prime}=2.3 \times 10^{-4} \mathrm{ft} / \mathrm{s}$

$$
\operatorname{Re}_{x}=\frac{(1,691)(6.28)}{\left(2.3^{\prime} \times 10^{-4}\right)}=4.55 \times 10^{.7}
$$

The friction factor is ${ }^{(12)}$ :

$$
f_{p m}=.0024
$$

The drag on the separator is:

$$
F_{s}=f_{p m} \frac{\rho_{a}^{\prime} V_{s}^{2}}{2} L_{s} w_{s}
$$

where $w_{s}=$ separator width

$$
F_{S}=4.04 \mathrm{lb}
$$

Tho power loss due to wirlaye is:

$$
P_{S_{2}}=\frac{(4.04)(1,691)}{(550)}=12.4 \mathrm{HP}
$$

Allowing $1.3 \mathrm{HP}$ loss in the bearings and seals, gives a total separator loss of:

$$
P_{0}=23 H P
$$

The net power from the radial inflow turbine obtained by expansion to 1.2 psia is estimated in Appendix $D$ to be:

$$
P_{t}^{\prime}=137 \mathrm{HP}
$$


The pumping power required to return the liquid through the heat exchanger to the nozzle is:

$$
P_{p}=\frac{\left(Q_{a}+Q_{b}\right) \Delta p}{\eta_{p}}
$$

where $Q_{a}=$ volume flowrate of $A$

$$
\begin{aligned}
Q_{\mathrm{b}} & =\text { volume flowrate of } \mathrm{B} \\
\Delta \mathrm{p} & =\text { pressure rise }=2,450 \mathrm{psi} \\
\eta_{\mathrm{p}} & =\text { pump efficiency }=.75 \\
P_{p} & =28.9 \mathrm{HP}
\end{aligned}
$$

The net power is given by:

$$
P_{n}=P_{t}^{\prime}+P_{t}^{\prime \prime}-P_{s}-P_{p}
$$

Substitution of the above values gives:

$$
P_{n}=137+191-23-29=276 \mathrm{HP}
$$

The heat rejection is:

$$
Q_{c}=\dot{m}_{a} L_{v a} \times_{v a}
$$

where $x_{v a}=$ the exit quality from the steam turbine

Substitution of the appropriate values gives:

$$
Q_{c}=654.4 \mathrm{~B} / \mathrm{s}
$$

The cycle efficiency is:

$$
n_{c}=\frac{P_{n}}{P_{n}+Q_{c}}
$$

or

$$
n_{c}=.23
$$


OPERATION

The schematic diagram of Figure 27 shows a configuration of the reference cycle where the exhaust from the diesel is passed through a jacket to preheat the inventory. Startup is then achieved by a ramp injection of the hot charge downstream of a check valve. This type of startup technique was successfully used in a similar two-phase cycle ${ }^{(13)}$ where the power was extracted in a magneto-hydrodynamic generator instead of a turbine. In that case, steady state operation with a flow of $150 \mathrm{lb} / \mathrm{s}$ of Nak was achieved in 2-3 seconds. 


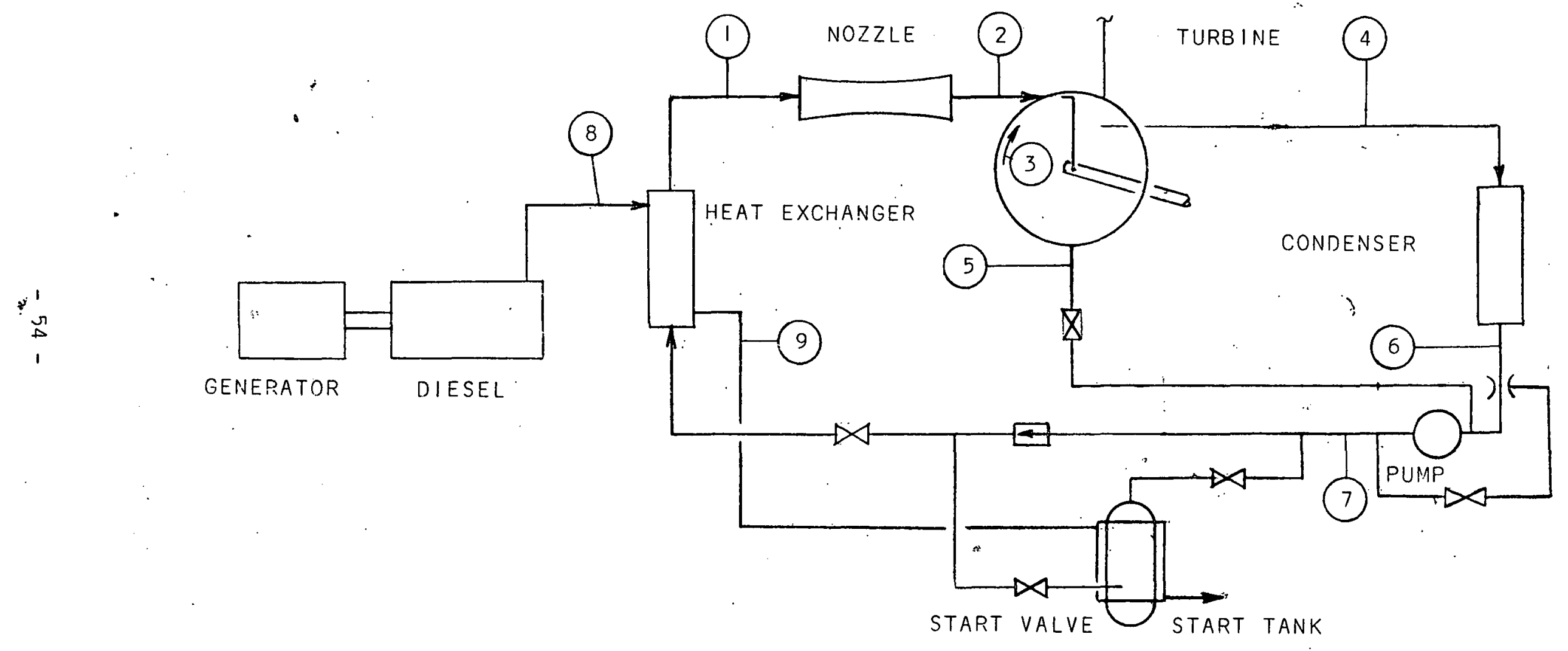

Fig. 27 - Schematic of Reference System 


\section{TURBINE DESIGN}

The design configuration of the two-phase turbine resulting from the analysis for the reference bottoming application summarized in Section IV, is given in Figures 28 and 29 . The basic procedures used in the mechanical design are summarized in Appendix $C$. The steam turbine design is described in Appendix $D$.

The turbine has a single stage expansion of the two-phase mixture in the 12 inch nozzles. The mixture impinges on the inside surface of the free wheeling drum, forming a liquid layer traveling at $1,691 \mathrm{ft} / \mathrm{s}$. The layer drives a liquid turbine to $845 \mathrm{ft} / \mathrm{s}(8,075 \mathrm{rpm})$ for the "U-tube" version shown in Figure 28. The discharge from the U-tube is collected in an annular tube and exits from the hot well of the turbine. The separator drum free wheels on the turbine shaft and is held in place by clips and retainers as shown. The separator drum and turbine are overhung from the $35 \mathrm{~mm}$ shaft. The bearings are standard grease packed double seal bearings. A simple mechanical sliding seal is used to isolate the low temperature $\left(230^{\circ} \mathrm{F}\right.$ ) steam at atmospheric pressure from ambient.

The separated steam flows radially inward from the drum through a twostage turbine to the exhaust pressure of 1.2 psia. The radial inflow turbine is keyed to the same shaft as the liquid turbine and thus has the same rpm, 8,075. As summarized in Appendix D, a total of $137 \mathrm{HP}$ is added by the steam turbine to the liquid turbine output of $191 \mathrm{HP}$. Expansion of the total two-phase mixture to the lower pressure would result in a greater fraclion of the power being available in the liquid phase. The turbine blading is conventional radial design and could probably be castw in quantity for $\$ 75-100$.

Figure 29 shows the nozzle detail and the detail of a counter-balanced radial inflow liquid turbine: The nozzle is built up of two conical sections and a throat, in accordance with past design practice (14). 


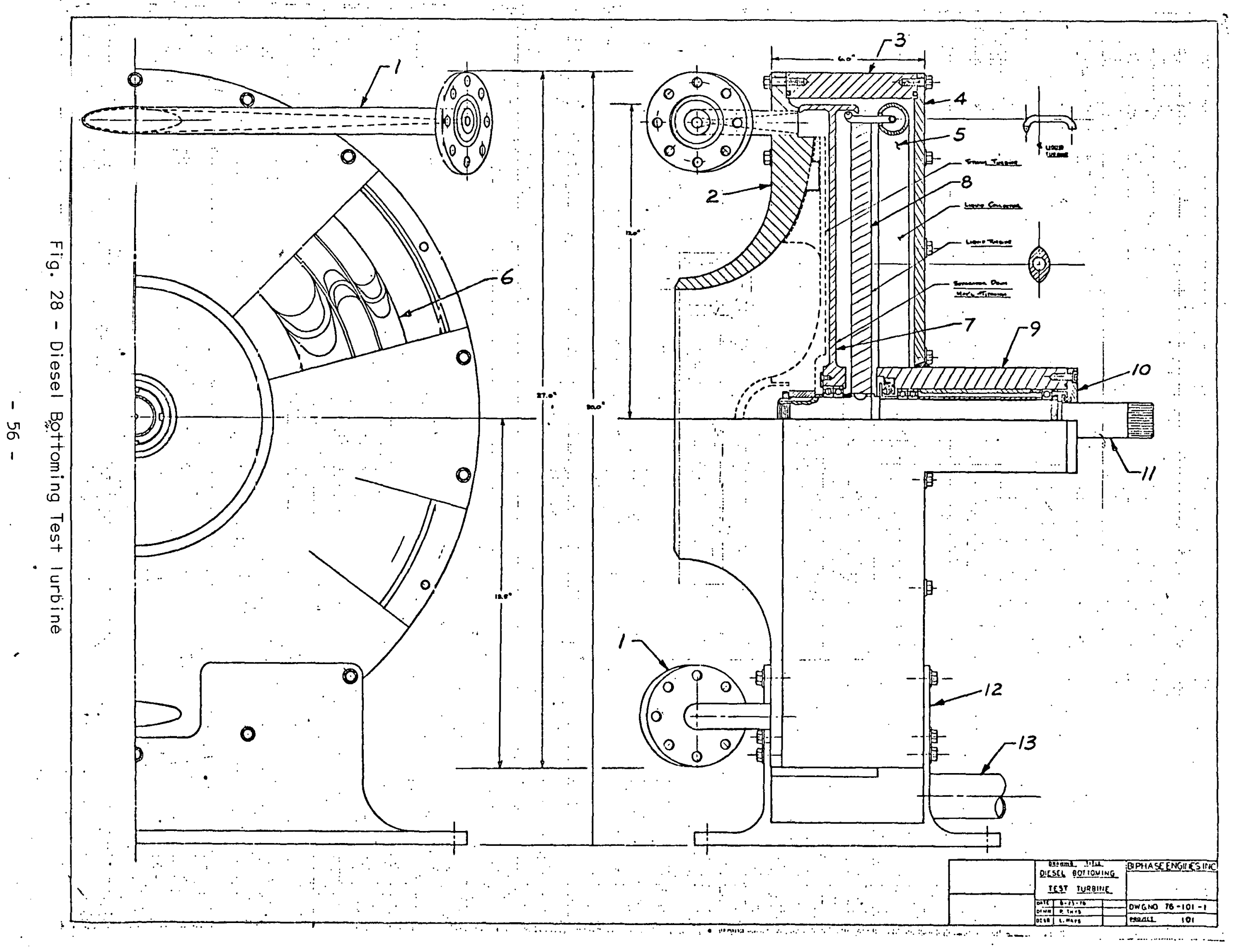




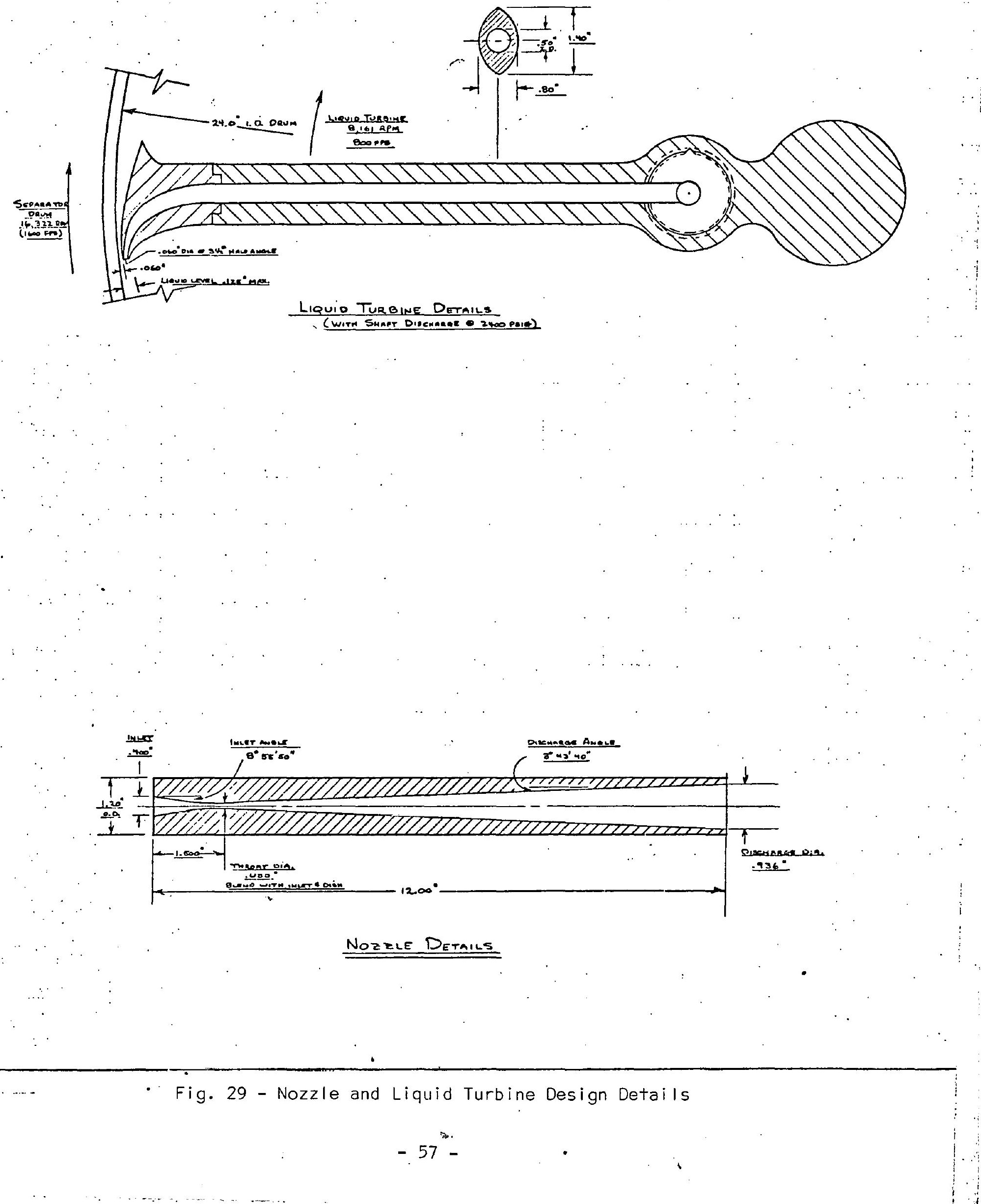


Recent cost estimates have been obtained for hydroforming these nozzles for a price of about $\$ 150$ in quantity ${ }^{(15)}$. The liquid inlet design on the liquid turbine is similar to configurations used for high pressure, pitot pumps $(16)$.

Thus, the turbine and nozzle components appear to be basically low cost units.

The materials are entirely conventional alloys except for the drum which is titanium for this design. Table 4 summarizes the materials for major components of the assembly.

To summarize, the nozzle and turbine assembly is a simple, low cost design which can be mass produced for much less than a multi-stage axial flow gas turbine with high speed bearings and seals. Increases in the mass ratio, made possible through using a liquid with lower sensible heat would enable a lower separator drum rpm and the use of low carbon steel. Staging the nozzle expansion would have a similar influence but with an increase in the total number of components. 
TABLE 4

MATERIALS LIST FOR MAJOR TURBINE COMPONENTS

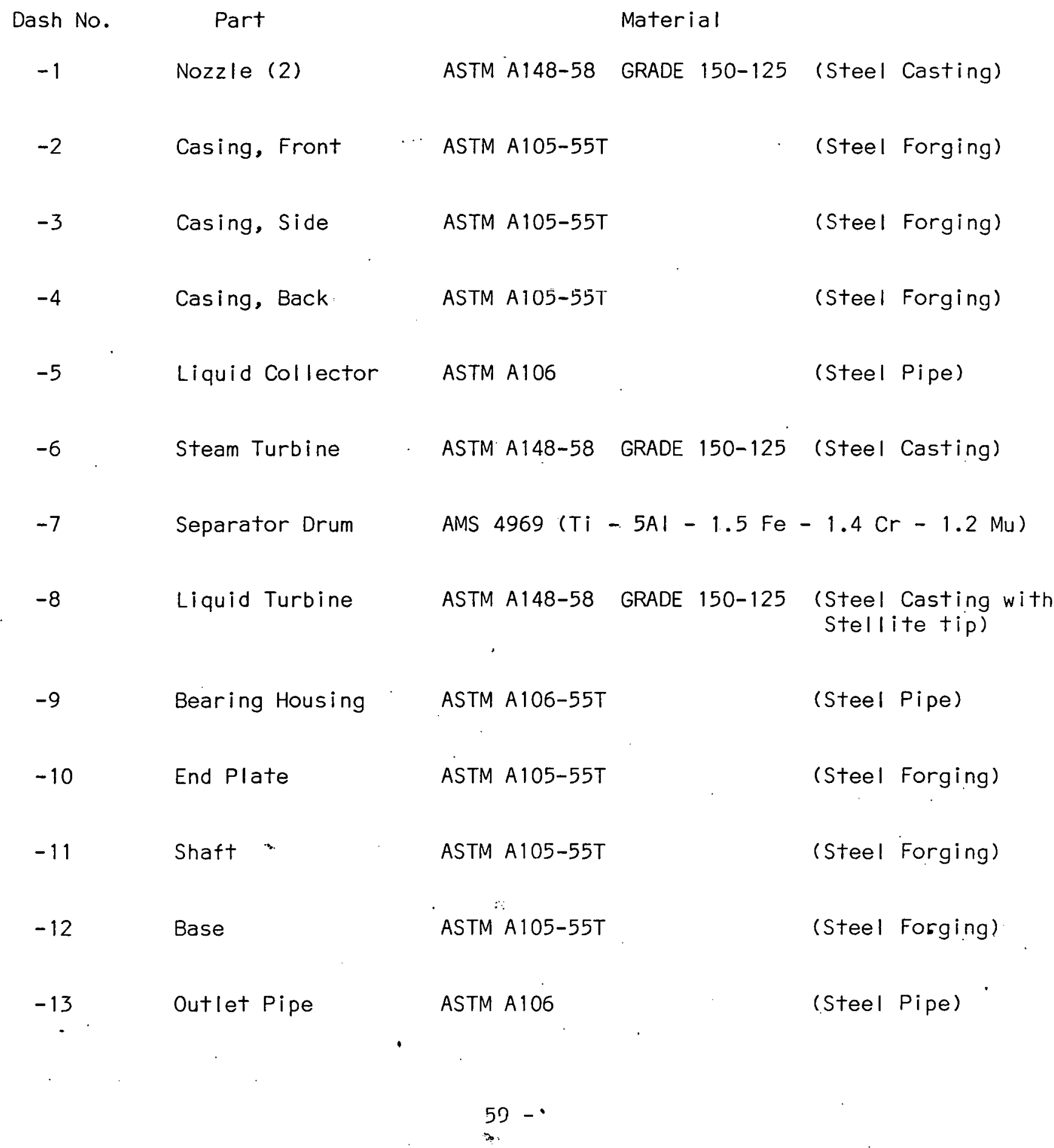




\section{SYSTEM SPECIFICATIONS}

Components of the two-phase turbine cycle chosen for this application are all well within the state of the art. Common fluids were chosen for the first system (water and Dow-Therm A). The temperatures for the pumps and valves are in the range of $90-250^{\circ} \mathrm{F}$. The peak temperature for the exhaust gas-liquid heat exchanger is that of the diesel exhaust, $719^{\circ} \mathrm{F}$. The pressures required are high $(2,500$ psia, maximum) but are within normal practice for both steam and hydraulic systems. The only "exotic" materials required are stellite tip on the inlet of the liquid turbine to minimize erosion and, for the initial system, a titanium drum for the separator. Use of a liquid with a lower specific heat than Dow-Therm would reduce the separator and turbine rpm, simplifying the bearing and seal requirements further: However, the values for the reference cycle $(16,150$ and $8,075 \mathrm{rpm})$ are within the range of commercially available seals and bearings. In order to enable preliminary assessments to be made of the system cost and complexity, specifications for the major components are given below:

\section{PRIMARY HEAT EXCHANGER}

$\begin{array}{lc}\text { Design - tube-fin construction, heliarc welded joints } \\ \text { Material - ASTM Al05-55T, Al06-55T (carbon steel) } \\ \text { Inlet liquid temperature (tube side) } & 190^{\circ} \mathrm{F} \\ \text { Inlet liquid pressure } & 2,465 \mathrm{psia} \\ \text { Inlet gas temperature (fin side) } & 719^{\circ} \mathrm{F} \\ \text { Outlet liquid temperature } & 660^{\circ} \mathrm{F} \\ \text { Outlet liquid pressure } & 2,365 \mathrm{psia} \\ \text { Outlet gas temperature } & 242^{\circ} \mathrm{F} \\ \text { Gas pressure drop } & 10^{\prime \prime} \mathrm{H} O \\ \text { Liquid flowrate } & 2.97 \mathrm{lb} / \mathrm{s} \\ \text { Gas flowrate } & 7.58 \mathrm{lb} / \mathrm{s} \\ \text { Heat transfer rate } & 654 \mathrm{~B} / \mathrm{s} \text { (net) }\end{array}$


The type of construction to be used can be very similar to the unit shown in Fig. 30. Some decrease in construction costs relative to a vapor generator should be realized because of the smaller flow area (hence, tube size) required by the liquid.

\section{CONDENSER}

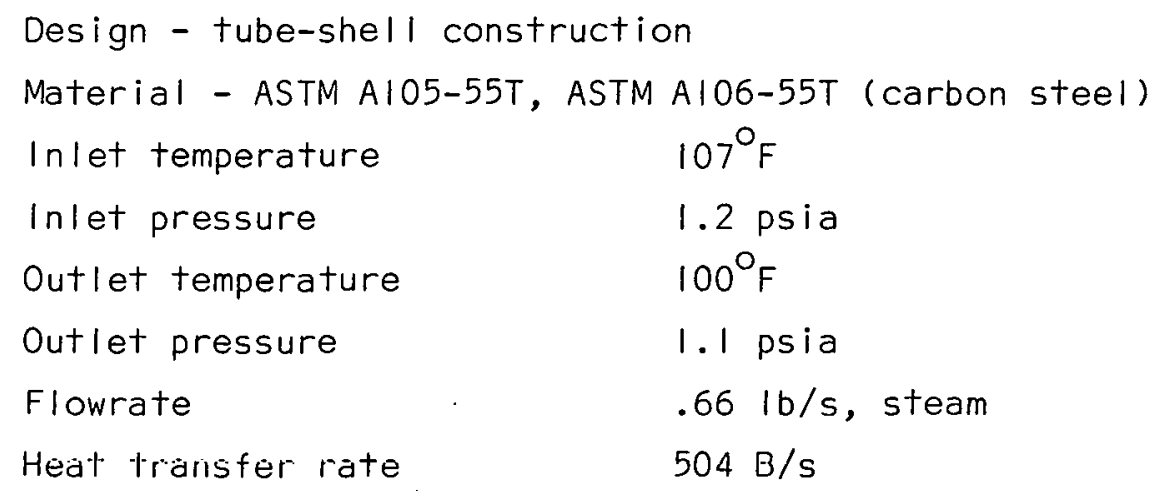

Figure 31 is a isometric drawing of a condenser used in a diesel bottoming application. A smaller surface area would be possible for the two-phase bottoming cycle because of the higher condensing coefficients of the steam (relative to organic vapor).

START AND DUMP TANK

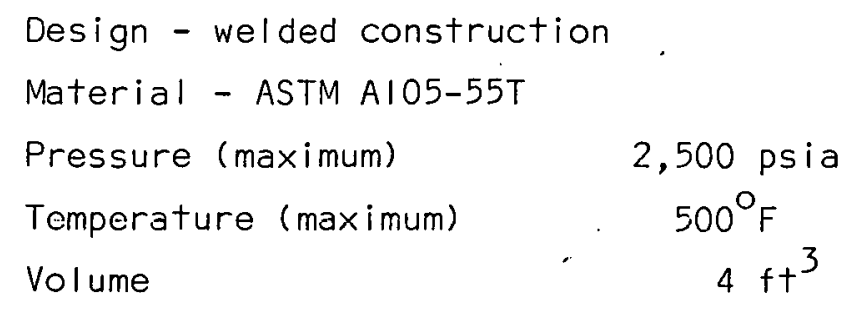

FUMP

Pressure rise

Flowrate

Efficiency
3

2,500 psia

$3 \mathrm{lb} / \mathrm{s}$, water - Dow-Therm A mixture. .75 

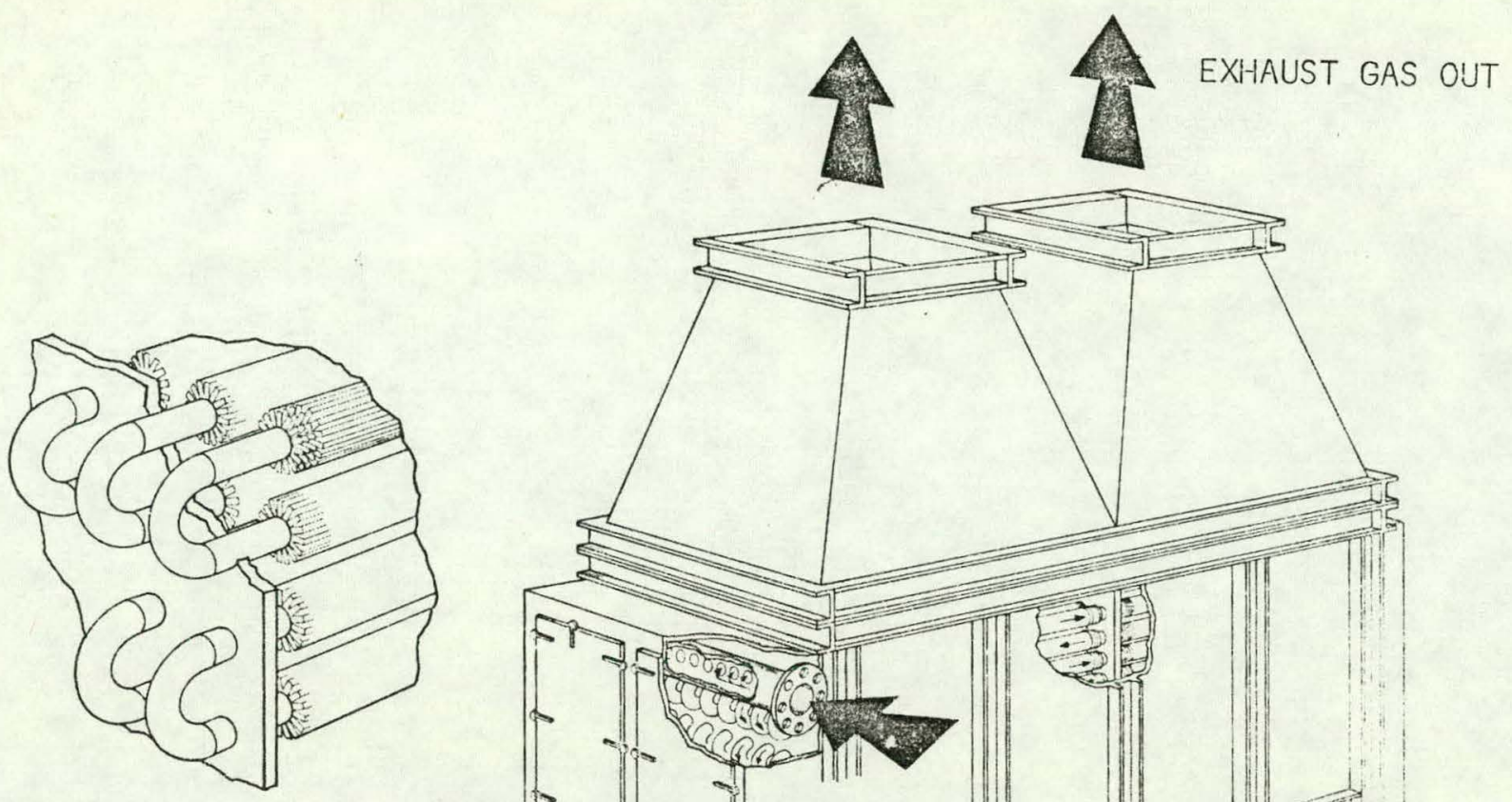
. 


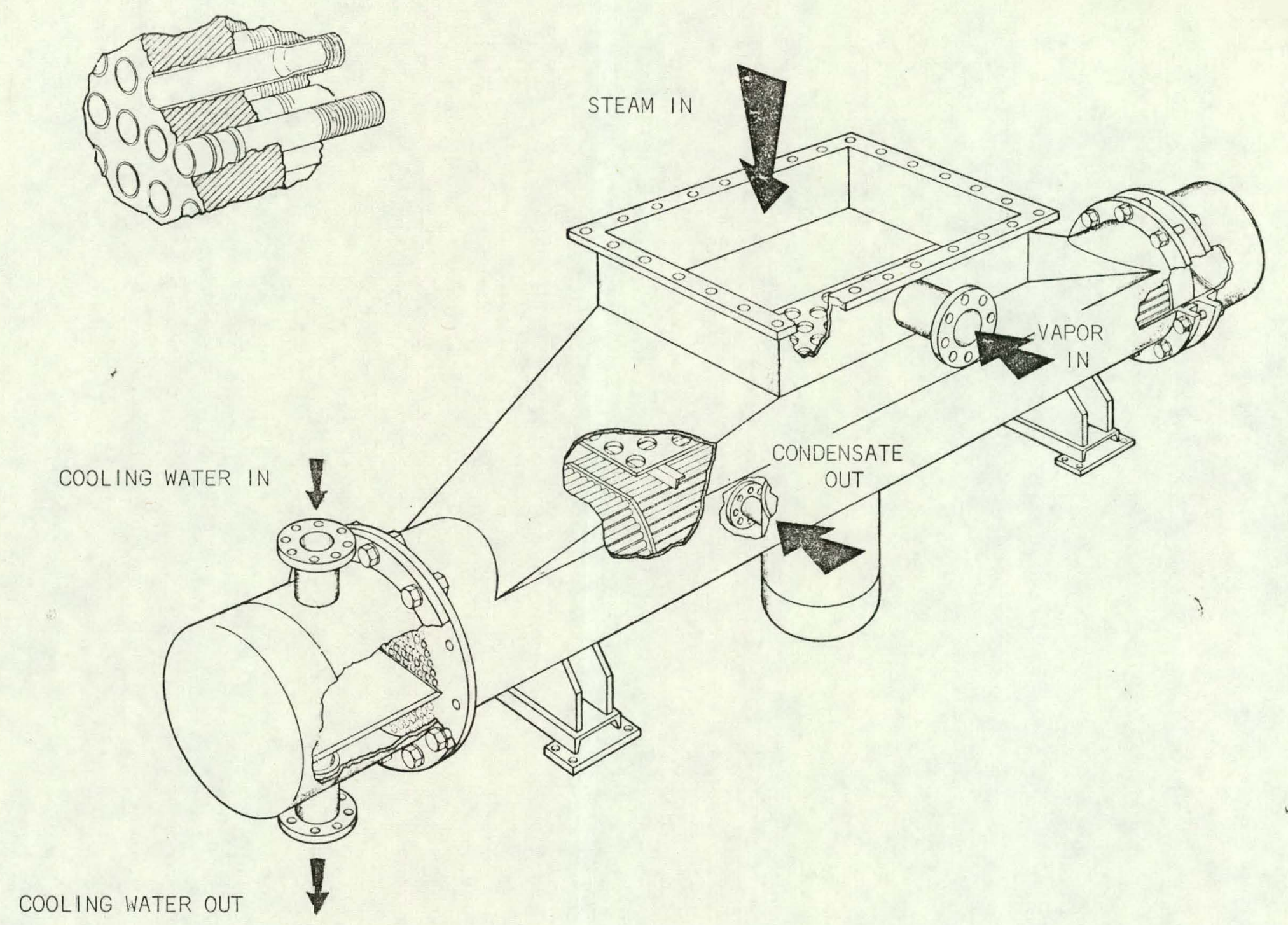

Fig. 31 - Isometric IIIustration of a Typical Condenser (After Ref. 7) 
CONTROL VALVES AND START VALVE

Type - high pressure globe

Material - ASTM A217 Grade WC6 or ASTM A182 Grade F11

Pressure

2,500 psia

Temperature (maximum) $660^{\circ} \mathrm{F}$

Size

$1 "$

CHECK VALVE

Type - swing or lift

Materia.l - ASTM A335-55T Grade P11 or ASTM 217 Grade WC6

Pressure

2,500 psia

Temperature (maximum) $660^{\circ} \mathrm{F}$

Size

$1 "$

PIPING, HIGH TEMPERATURE

Seamless Chrome - Moly Steel, ASTM A369

Pressure 2,500 psia

Temperature (maximum) $\quad 660^{\circ} \mathrm{F}$

Diameter

$1 ", 1 / 2^{\prime \prime}$

PIPING, LOW TLMHERATURE

Seamless Carbon Steel, ASTM A106

Pressure

2,500 psia

Temperature (maximum)

$250^{\circ} \mathrm{F}$

Diameter .

$1 ", 1 / 2 ", 1^{\prime}$

$\therefore$ 


\section{BEARINGS}

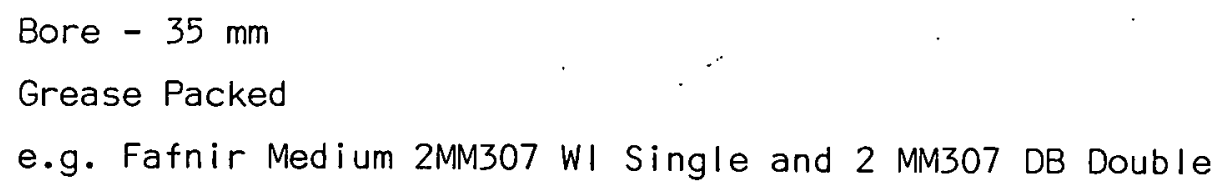

Carbon Face Seal, Bellows Loading

(Design Equivalent to Chicago Rawhide Manf. Co. No. B33-90 66 T1) 
VII. PROGRAM PLAN

A program culminating in the demonstration of a two-phase bottoming system was developed for the reference design cycle. The main objective of the plan is to demonstrate the technology of two-phase turbine bottoming systems in sufficient depth to provide a firm basis for commercial applications. The time required, 3 years, and the estimated cost, $1.3 \mathrm{milli}$ ion dollars, are very reasonable values for demonstration of a new technology which has the potentially large industrial impact of the two-phase turbine.

The first year's program is summarized in Figure 32. The basic objective of the first year is to demonstrate performance of the nozzle and turbine for the actual flow conditions of the bottoming system. A simple blowdown test will be conducted with steam alone and with a mixture of steam and a second fluid. The major portion of the blowdown test facility will be available from capital equipment and government furnished equipment. The system is sized to provide $50 \mathrm{HP}$ output power for a 10 minute duration. The testing of both steam alone and steam and oil, will provide sufficient data for either single component or two-component systems. The end of the first year provides a convenient, low cost $(\$ 230 K)$, decision point for continuing the effort. The level of performance attainable will have been demonstrated for the fluids and temperatures of interest. Performance and economic analyses based on the actual test performance will have been completed.

The second year's program will demonstrate performance of the complete twophase bottoming system using a hot gas generator to simulate the exhaust from a diesel engine. The estimated schedule is summarized in Figure 33. The power output from the system will bc in excess of $200 \mathrm{HP}$ on a continuous basis.' The bottoming system will be designed for eventual long term operation to verify reliability. 
MONTHS AFTER INCEPTION OF CONTRACT

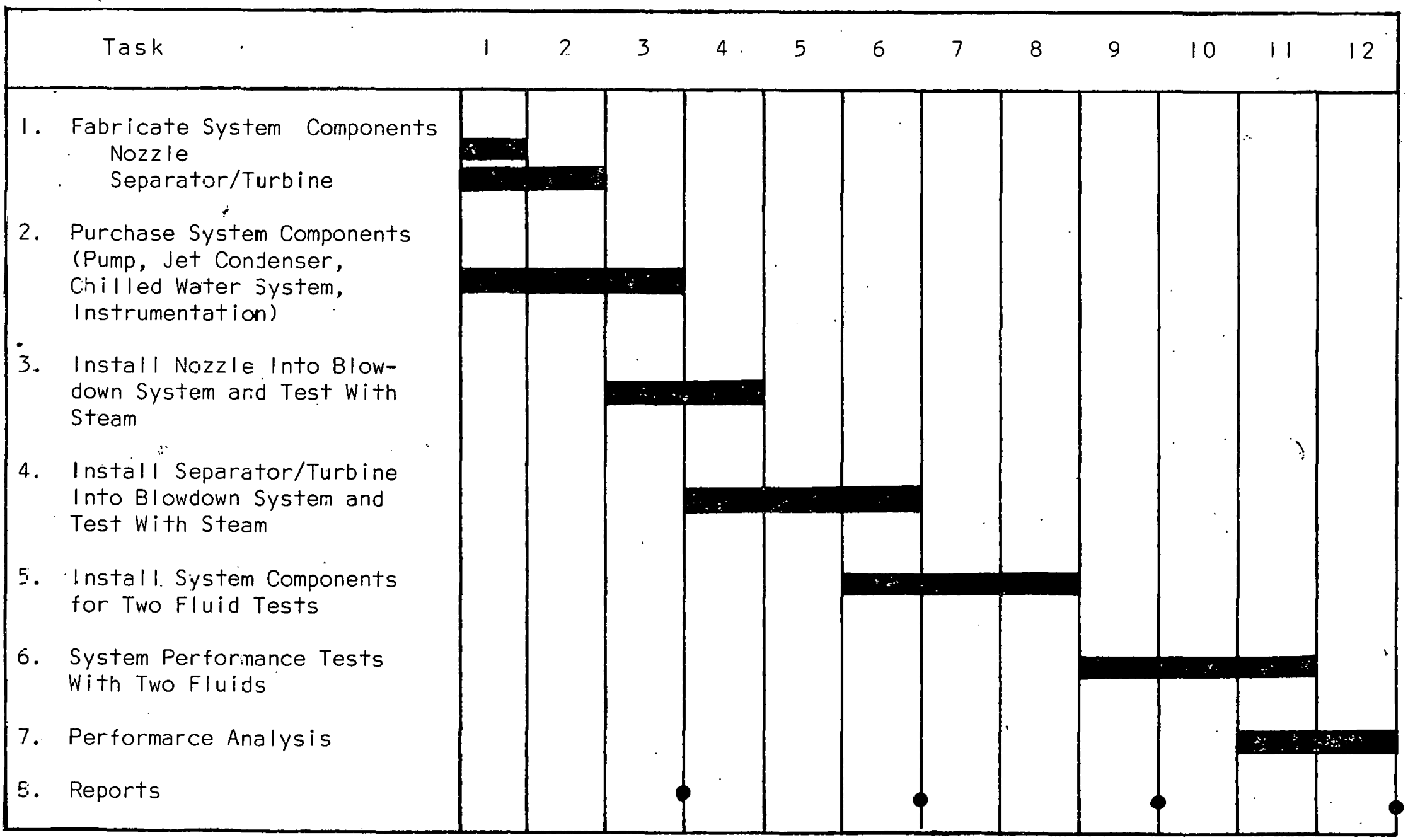

Fij. 32 - Schedule for Demonstration of a Biphase Bottoming Cycle - Year 1 
MONTHS AFTER INCEPTION OF CONTRACT

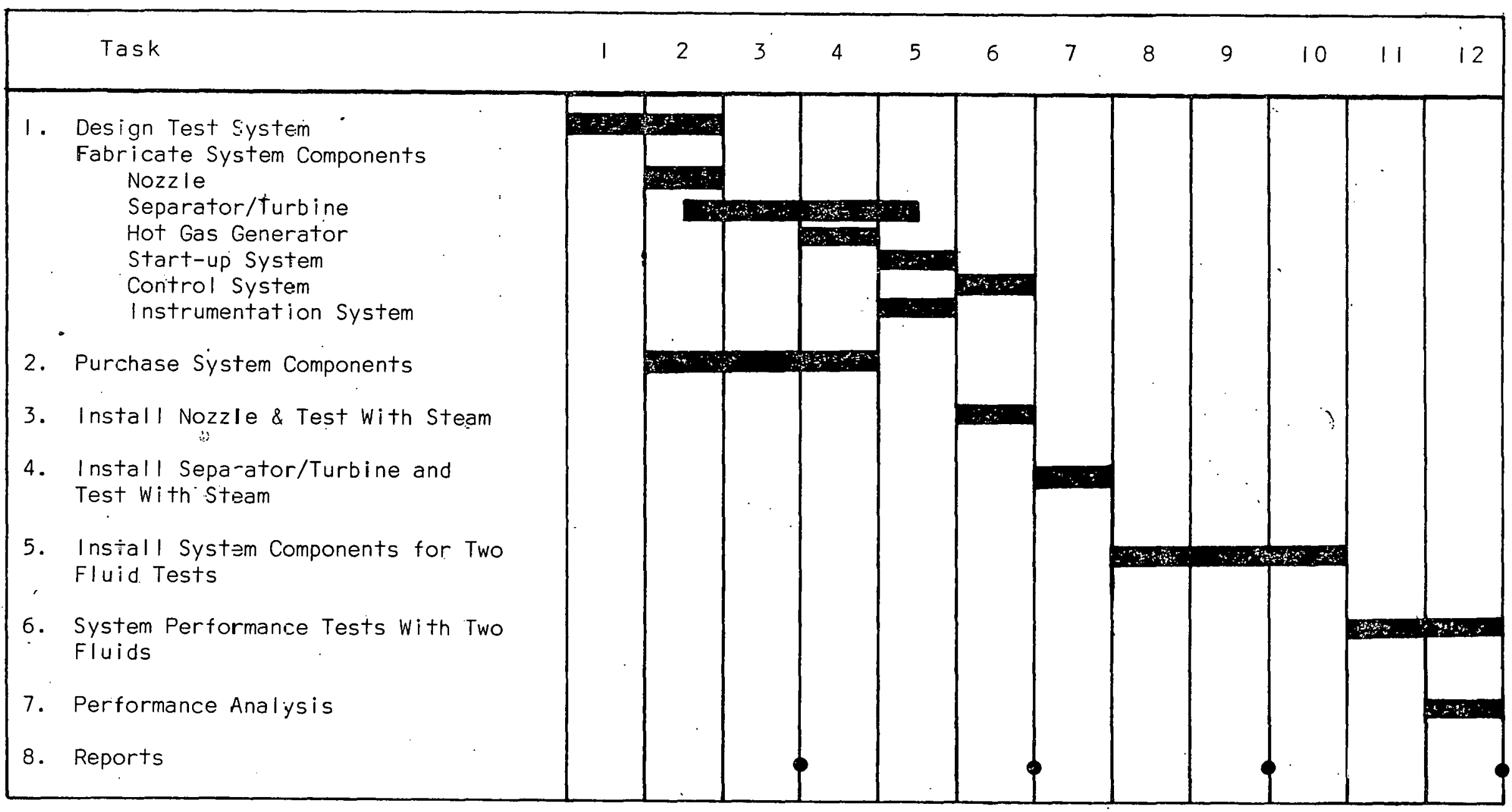

$\cdot$

Fic. 33 - Schedule for Demonstration of a Biphase Bottoming Cycle - Year 2 
The third year's program, shown in Figure 34, will consist of endurance testing of the hot gas laboratory system and field testing of the final two-phase bottoming system. Thus, reliability of the rotating unit and performance of the complete system will both be demonstrated. The power level of the final field test unit will depend upon the available diesel engine for the demonstration. The program. plan assumes availability of a large industrial diesel or spark ignition engine in the Southern California area. Likely candidates that have such engines are the Southern California Gas Company, Lomita Gas Company, the seven major refineries, Southern Cal ifornia Edison and the Los Angeles Department of Water and Power.

A cost breakdown for the 1.3 million dollar demonstration program is shown in Tables 5, 6 and 7. The costs are based on 1976 dollars with an expected annual salary increase of $10 \%$ and an overhead increase of five percentage points per year. 
MONTHS AFTER INCEPTION OF CONTRACT

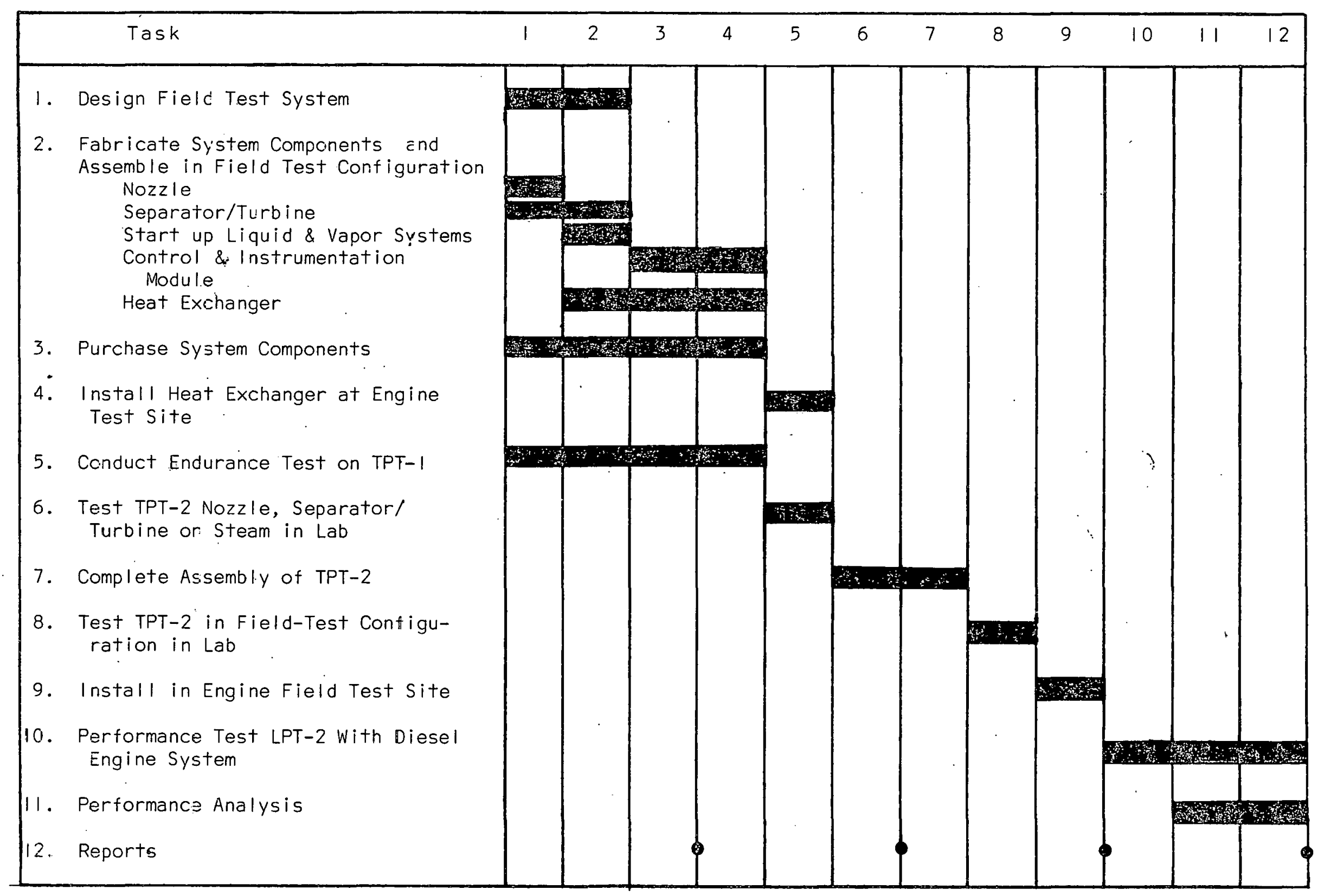

Fig. 34 - Schedule for Demonstration of a Biphase Bottoming Cycle - Year 3 


\section{COST SUMMARY OF FIRST YEAR'S PROGRAM}

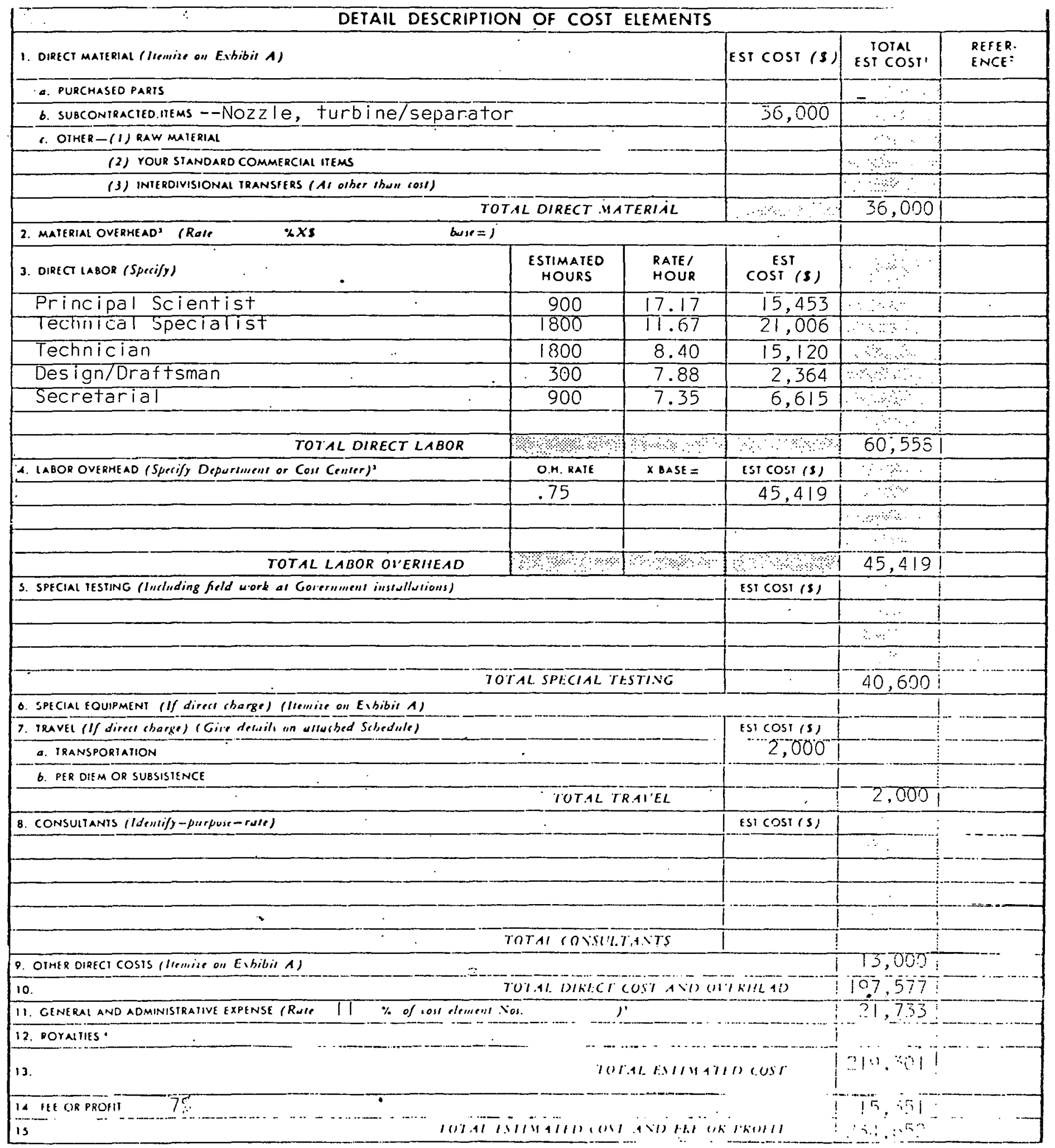


TABLE 5 - continued

$r$

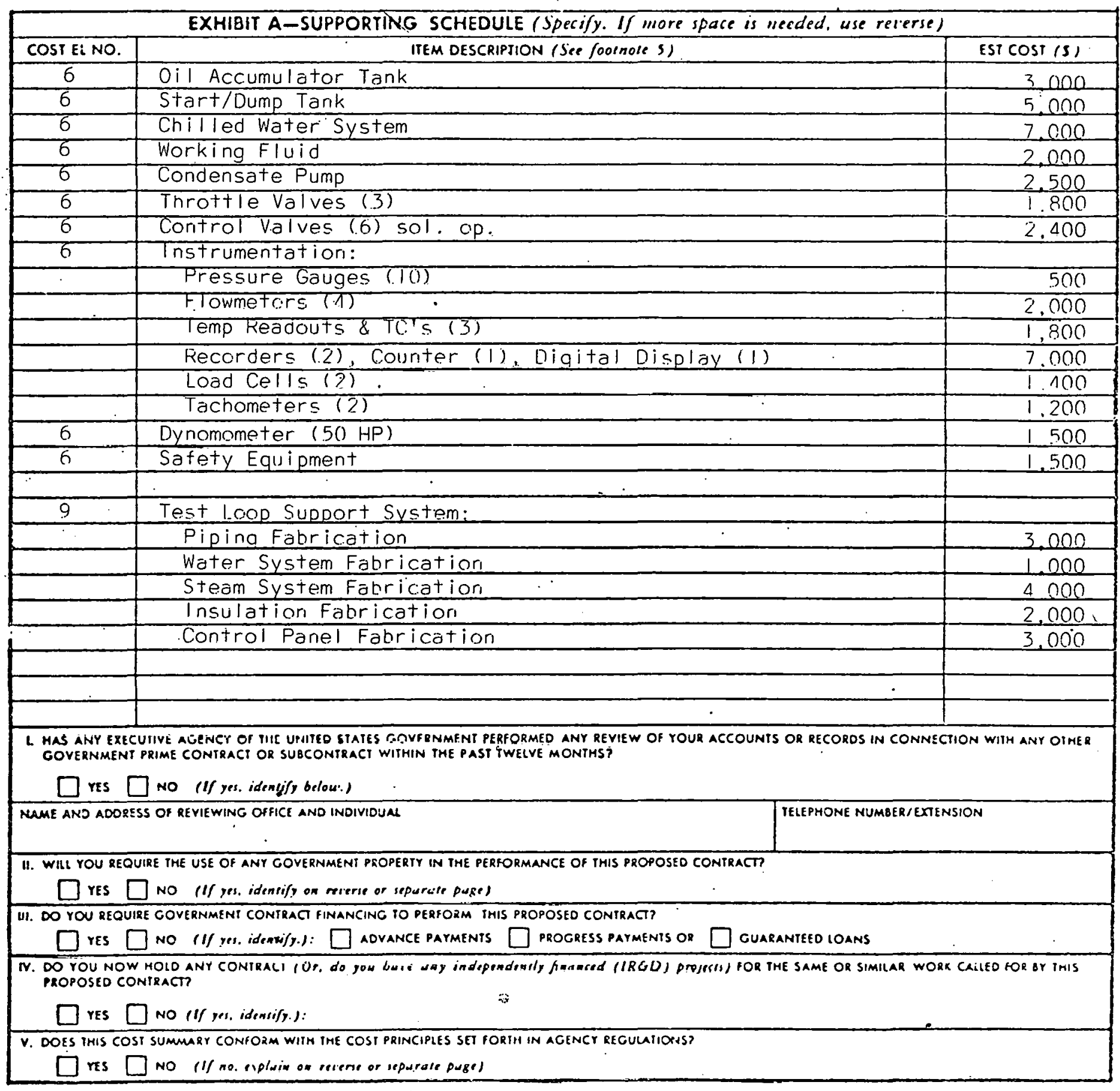


TABLE 6

COST SUMMARY OF SECOND YEAR'S PROGRAM

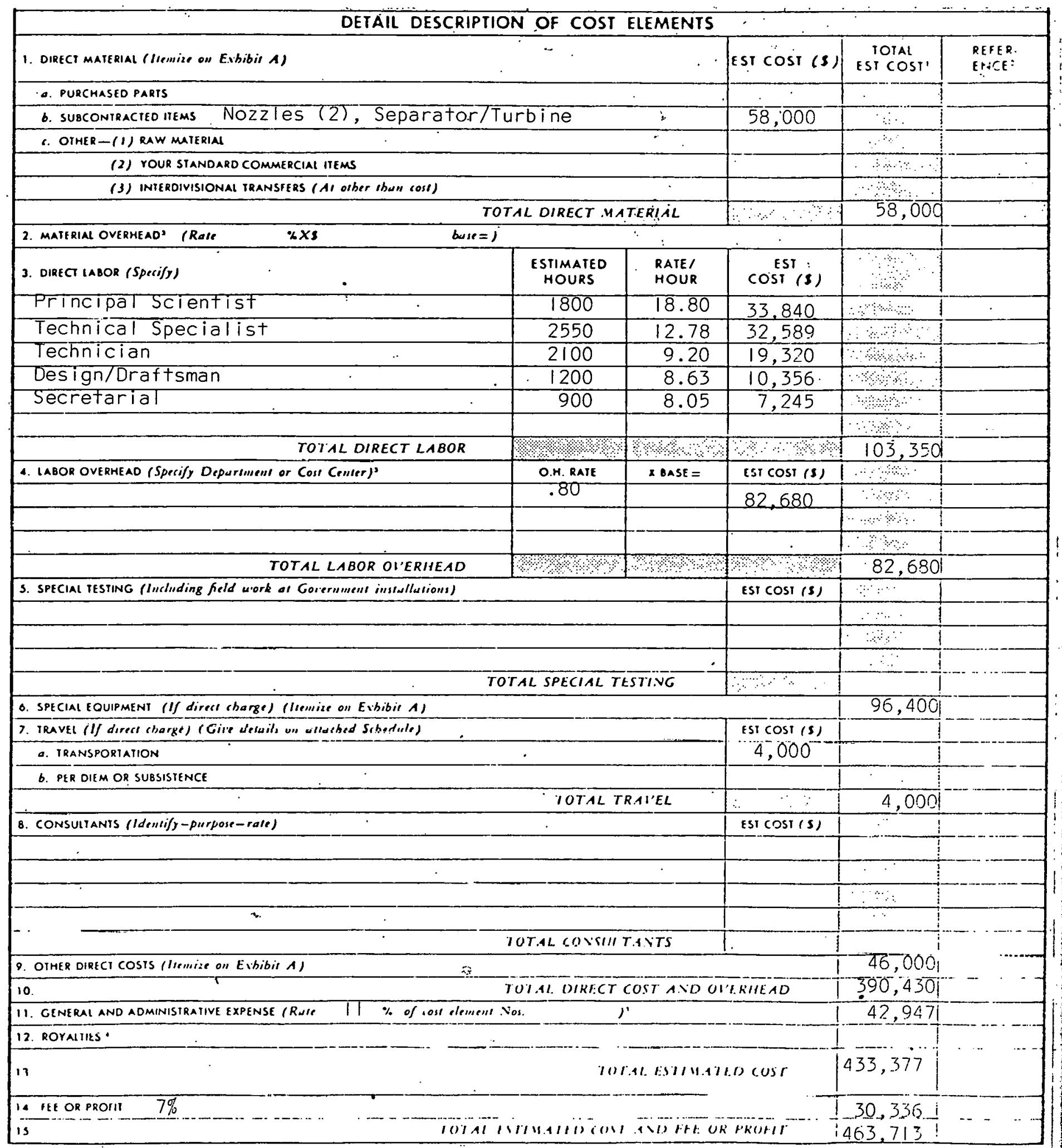


TABLE 6 - continued

?

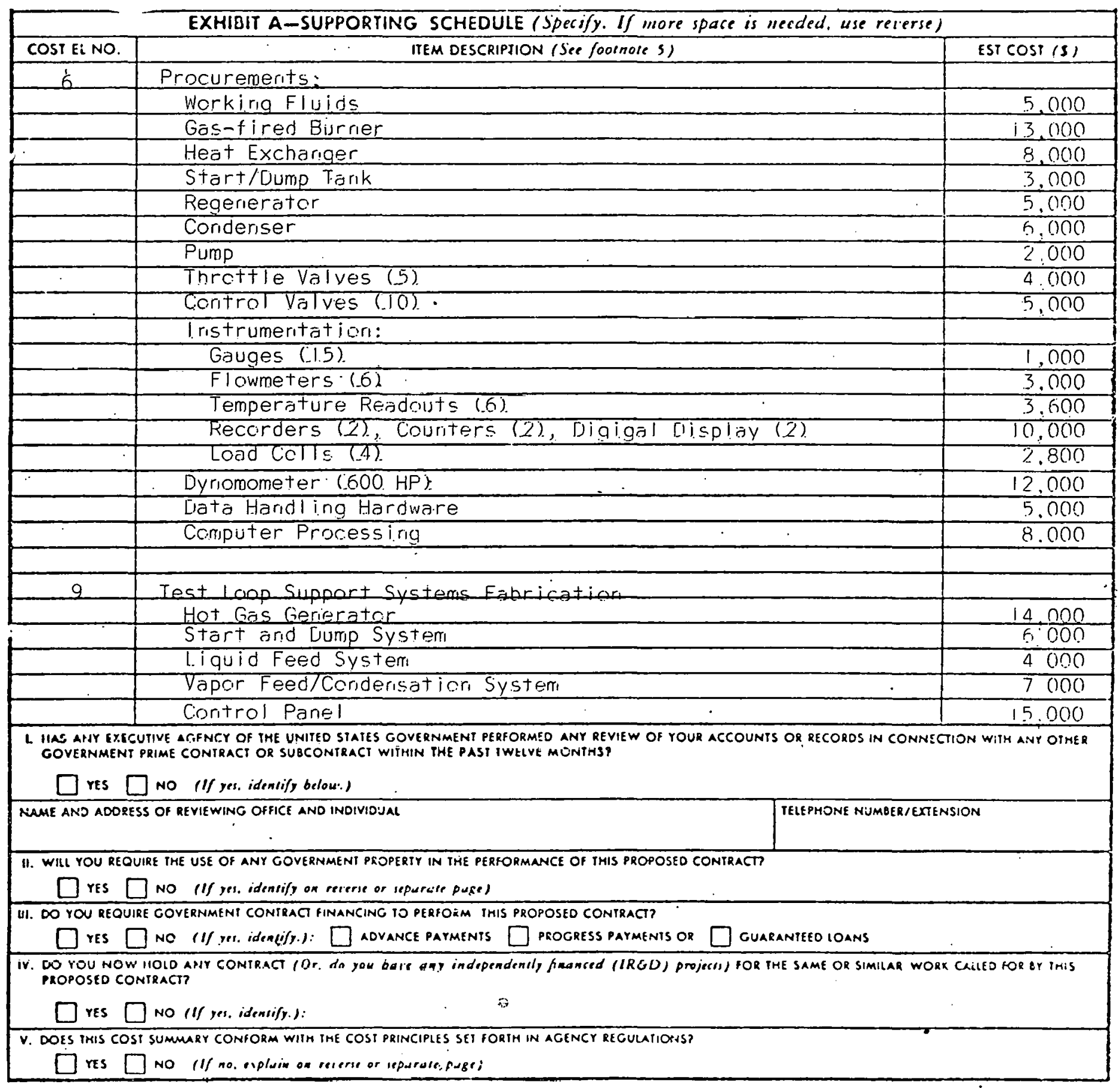


TABLE 7

COST SUMMARY OF THIRD YEAR'S PROGRAM

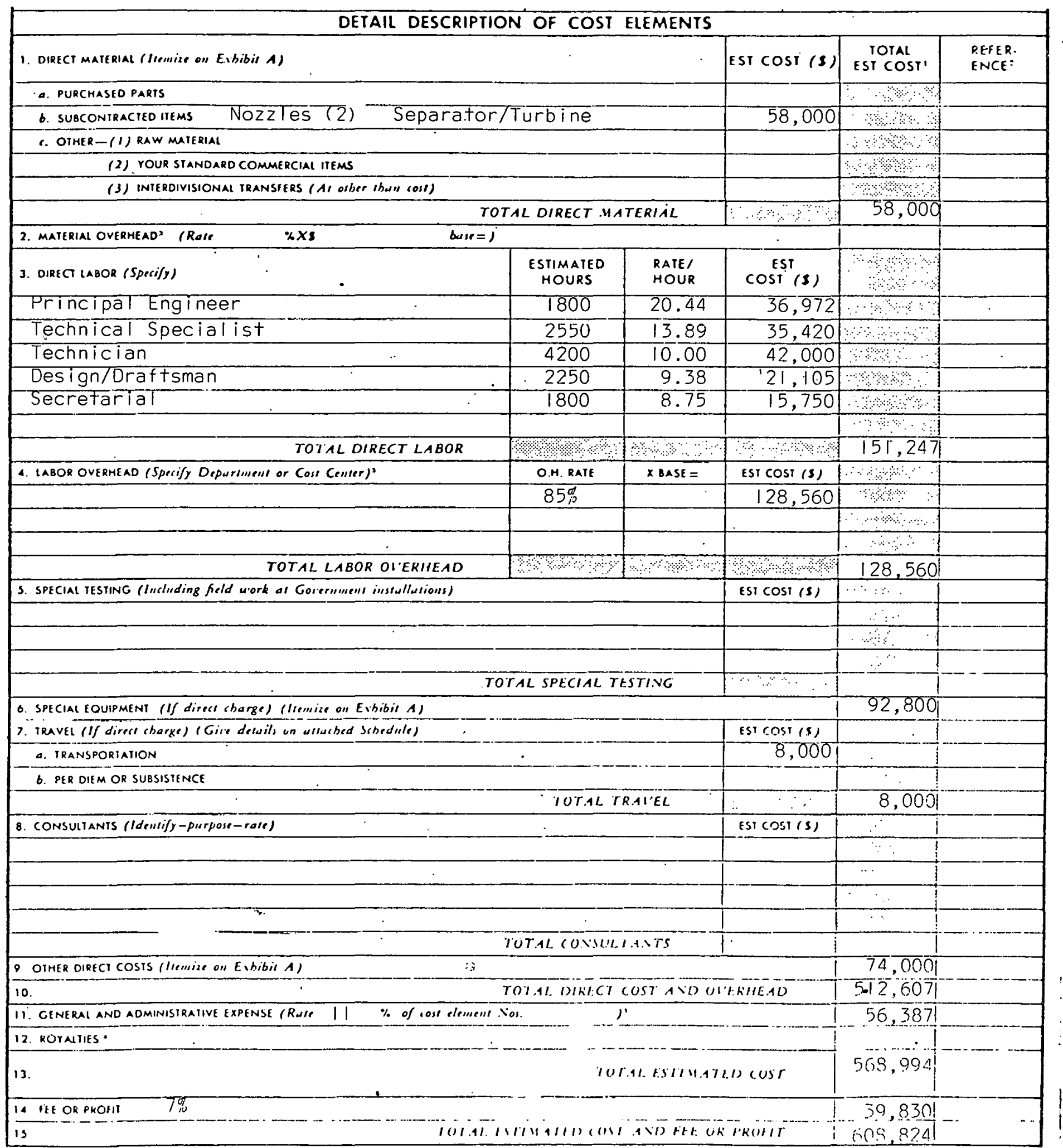


TABLE 7 - continued

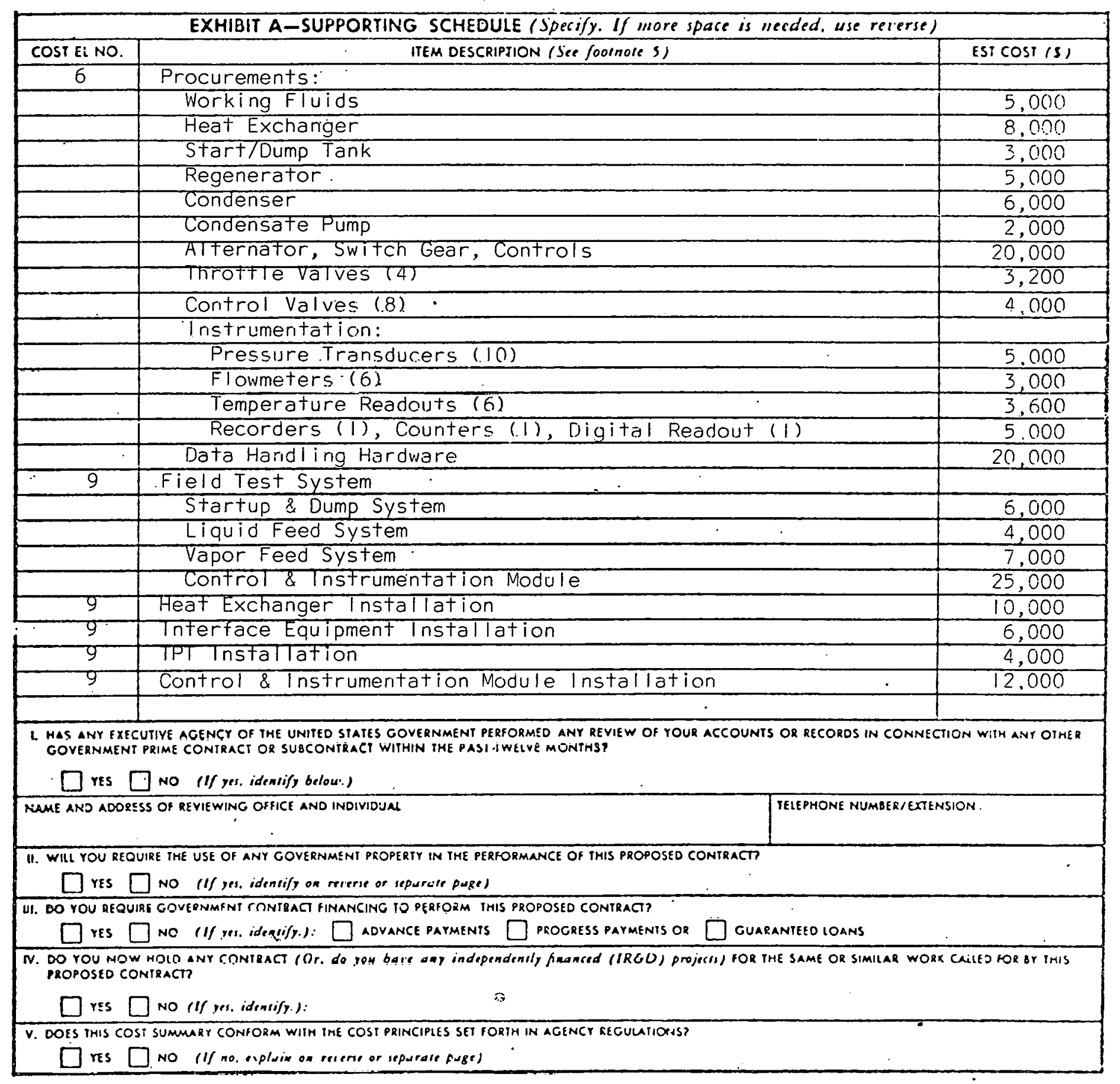




\section{CONCLUSIONS}

Cycle calculations for the two-phase turbine bottoming system showed the efficiency to be superior to, or competitive with, organic vapor turbine systems, depending on the assumptions of the analysis. The two-phase turbine appears to be much simpler than an organic or steam vapor turbine because of the following reasons:

(1) One stage versus four stages

(2) $8,100 \mathrm{rpm}$ versus 14,700 to $26,000 \mathrm{rpm}$

(3) Simple construction with very few close tolerances

Other advantages for the designed two-phase system relative to an organic Rankine cycle are:

(1) No regenerator.

(2) No toxic fluids (the working fluids of candidate organic systems are toluene and FS-85, both of which are toxic)

(3) Smaller, simpler condenser (steam condensing instead of organic vapor)

The main disadvantages appear to be:

(1) The required pump is larger than for an organic vapor system

(2) The state of development is low relative to organic or steam Rankine cycles

Because of the advantages cited it appears that the two-phase bottoming system has the potential of early commercialization. This seems to be particularly true if the cost savings and reduction in fouling that would result from the use of a contact heat exchanger, could be realized. A demonstration program of the type outlined should be sufficient for industry to gain the confidence level necessary for widespread application of this technology.

Research topics which could materially aid in improving performance and reducing cost are: 
(1) Development of low vapor pressure, low sensible heat fluids

(2) Low loss inlet optimization for the liquid turbine

(3) Investigation of other moving surface geometries for I iquid-gas separation

(4) Improved atomization techniques for the two-phase nozzle

\begin{abstract}
Institution of these improvements should result in increases in system efficiency, from the 23-25\% range to the $30 \%$ range, and in reduction of ' turbine rpm, from the 8,000 to 10,000 range to the 3,000 to 4,000 range. However, as summarized above, the two-phase turbine bottoming system appears to offer enough advantages in its present form to warrant the pursuit of this technology.
\end{abstract}




\section{REFERENCES}

八.

1. Hays, L., Design Study of a Two-Phase. Turbine Bottoming Cycle, Report 101-M1, Biphase Engines, Inc., Santa Monica, California, April 1976.

2. Diamant, R., Total Energy, Pergamon Press, Oxford, 1970.

3. Smith, A. J. and Crabtree, L. C., "Salt Grass - 300 MW Combined Cycle," 16th Annual International Gas. Turbine Conference, American Society of Mechanical Engineers, March 1971.

4. The Westinghouse Pace 260 Combined Cycle Power Plant, Synoptic Presentation M271S, Westinghouse Electric Corporation, Philadelphia.

5. Advanced Automotive Power Systems Contractors Coordination Meeting, Seventh Summary Report, Washington D.C., 1975.

6. Stengel, R. F., "'Freon' Engine Boosts IC Engine Fuel Economy," Design News, February 17, 1975.

7. Morgan, D. T. and Davis, J. P., High Efficiency Decentralized Electrical Power Generation Utilizing Diesel Engines Coupled with Organic Working Fluid Rankine Cycle Engines Operating on Diesel Reject Heat, Report TE4186-27-75, ThermoElectron Corporation, Boston, Massachusetts, November November 1974.

8. Alger, T. W., The Performance of Two-Phase Nozzles For Total Flow Geothermal Impulse Turbines, UCRL - 76417, Lawrence Livermore Laboratory, Livermore, Cali fornia, May 1975.

9. Csanady, G. T., Theory of Turbomachines, McGraw-Hill, New York, 1964.

10. Pouchot, W. D., Basic Investigation of Turbine Erosion Phenomena, WANL - TME - 1977, Westinghouse Astronuclear Laboratory, Pittsburg, Pennsylvania, January 1971.

11. Sherman, P.M. and Lincoln, F. W., "Rain Inlet Systems for Waterjet Propulsors," AIAA 2nd Advanced Marine Vehicles and Propulsion Meeting, Paper No. 69-418, Seattle, Washington, May 1969.

12. Eckert, E. R. G. and Drake, S. M., Heat Transfer, McGraw-Hill.

13. Cerini, D. J., "Circulation of Liquids for MHD Power Generation," SM - 107/40, EZectricity from MHD, 1968, Volume III. International * Atomic Energy Agency, Vienna, 1968. 
14. Elliott, D. G. and Weinberg, E. W., Acceleration of Liquids in TwoPhase Nozzles, Technical Report 32-987, Jet Propulsion Laboratory, Pasadena, California, July 1968.

15. Aircraft Hydroforming, Inc., Personnal Communication.

16. Kobe Pump, Sales Literature. 


\section{PAGES 81 to 83 WERE INTENTIONALLY LEFT BLANK}


APPENDIX A

\section{EXPANDER RELATIONS}

Nomenc Lature

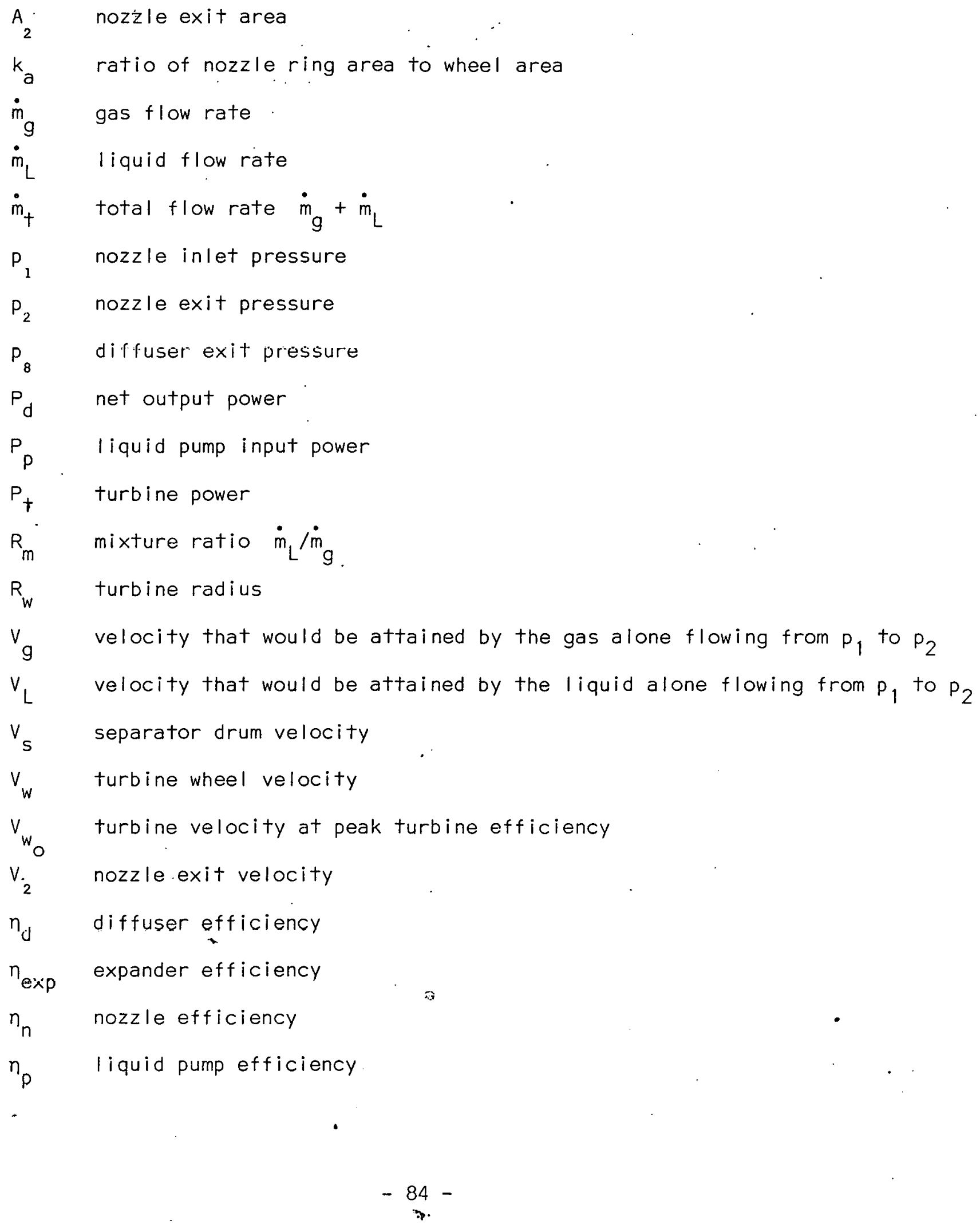




$\begin{array}{ll}n_{S} & \text { separator efficiency } \\ n_{+} & \text {turbine efficiency } \\ \rho_{g_{1}} & \text { gas density at. nozzle inlet } \\ \rho_{g_{2}} & \text { gas density at nozzle exit } \\ \rho_{L} & \text { liquid density } \\ \Theta & \text { nozzle angle relative to plane of rotation }\end{array}$


As shown previously, the kingtic energy attained in isentropic two-phase nozzle flow at mixture ratios high enough to give negligible temperature drop, is the sum of the kinetic energies that would be attained by the gas and liquid phases alone. The liquid energy would be:

$$
\dot{\mathrm{m}}_{L} V_{L}^{2} / 2=\dot{\mathrm{m}}_{L}\left(\mathrm{P}_{1}-\mathrm{P}_{2}\right) / \rho_{L}
$$

and the gas energy would be:

$$
\dot{m}_{g} v_{g}^{2} / 2=\dot{m}_{g} p_{1} \log \left(p_{1} / p_{2}\right) / \rho_{g 1}
$$

The two-phase jet energy is the sum of these two energies times the nozzle efficiency $n_{n}$, which is determined from existing algorithms of Biphase Engines, Inc.

$$
\dot{m}_{+} v_{2}^{2} / 2=\eta_{n}\left(\dot{m}_{g} v_{g}^{2}+\dot{m}_{L} v_{L}^{2}\right) / 2
$$

The ratio of two-phase jet velocity $V_{2}$ to liquid-alone velocity $V_{L}$ is given by:

$$
\left(v_{2} / V_{L}\right)^{2}=\left(n_{n} \dot{m}_{L} / \dot{m}_{+}\right)\left[\left(V_{g} / V_{L}\right)^{2} / R_{m}+1\right]
$$

where $R_{m}$ is the mass ratio of liquid to gas

\section{Turbine Expander}

\section{Wheel velocity}

An Impulse turbine has pook officiency, when the blade speed is $v_{w}=v_{2} / 2$. From Eq. (4), neglecting the small difference between $\dot{m}_{+}$. and $\dot{m}_{L}$ at high mixture ratios, the wheel speed is given by: 


$$
\left(V_{w} / V_{L}\right)^{2}=\left(n_{n} / 4\right)\left[\left(V_{g} / V_{L}\right)^{2} / R_{m}+1\right] .
$$

Thus, the mixture ratio $R_{m}$ required for a specified ratio of wheel velocity $V_{w}$ to liquid velocity $V_{L}$ is given by:

$$
\therefore\left(V_{g} / V_{L}\right)^{2} / R_{m}=\left(4 / n_{n}\right)\left(V_{w} / V_{L}\right)^{2}-1
$$

\section{Efficiency}

The turbine output power is:

$$
P_{t}=n_{t} \dot{m}_{t} v_{2}^{2} / 2
$$

where $\eta_{+}$is calculated from existing algorithms of Biphase Engines, Inc.

The Ilquid pump input power is:

$$
P_{p}=\dot{m}_{L}\left(p_{1}-p_{2}\right) / n_{p} \rho_{L}=\dot{m}_{L} V_{L}^{2} / 2 n_{p}
$$

The net output, or drive, power is:

$$
P_{d}=P_{t}-P_{P}
$$

Substituting $V_{2}$ from Eq. (4), the net power is:

$$
P_{d}=\dot{m}_{L} V_{L}^{2}\left\{n_{t} n_{n}\left[\left(V_{g} / V_{L}\right)^{2} / R_{m}+1\right]-\left(1 / n_{p}\right)\right\} / 2
$$

The available input power to the expander is the gas energy $\dot{m}_{g} V_{g}{ }^{2} / 2$ from Eq. (2). The expander efficiency is:

$$
\eta_{\text {exp }}=P_{d} / \dot{m}_{g}{ }^{2} v_{g}{ }^{2} / 2
$$

Substituting $P_{d}$ from Eq. (10) and replacing the expression $R_{m}\left(V_{g} / V_{L}\right)^{2}$ by the expression in terms of $V_{w} / V_{L}$ from Eq. ( 6$)$, the turbopump expander efficiency as a function of the ratio of wheel veloclty $v_{w}$ lu liquid-alone volocity is:

$$
n_{\exp }=\frac{4 n_{t}\left(V_{w} / V_{L}\right)^{2}-1 / \eta_{P}}{4\left(V_{w} / V_{L}\right)^{2} / n_{n}-1}
$$


This expression gives the efficiency only at a turbine speed $V_{w}$ equal to half the jet speed $v_{2}$. As $V_{w}$ and $v_{2}$ are reduced, a point is reached where further reduction in $v_{w}$ can more efficiently be accomplished by reducing $V_{w}$ and leaving $V_{2}$ fixed; the added turbine loss is less than the increased liquid pumping loss. As $V_{W}$ is reduced below $v_{2} / 2$, the torque increases approximately by the factor $\left(2-v_{w} / v_{w_{0}}\right.$ ) where $v_{w_{0}}=v_{2} / 2$. Therefore, the efficiency decreases by the factor:

$$
\eta_{\exp }=\left\{\left.n_{\exp }\right|_{v_{w}}=v_{w_{0}}\right\}\left(2-v_{w} / v_{w_{0}}\right)\left(v_{w} / v_{w_{0}}\right)
$$

The attainable expander efficiency is the larger of the two values given by Eqs. (12) and (13).

\section{Rotopitot Expander}

\section{Wheel velocity}

The separator efficiency $n_{S}$ is defined as the ratio of the liquid energy in the separator to the two-phase jet energy and can be calculated from previously determined two-phase flow relations. Thus, the separator velocity $v_{s}$ is given by:

$$
\dot{m}_{L} v_{S}^{2} / 2=n_{S} \dot{m}_{+} v_{2}^{2} / 2
$$

Substituting $V_{2}$ from Eq. (4), the ratio of separator velocity $v_{s}$ to liquid-alone velacity $V_{L}$ is given by:

$$
\left(V_{s} / V_{L}\right)^{2}=n_{n} n_{s}\left(V_{g} / V_{L}\right)^{2} / R_{m}+1
$$

The pressure at the exit of the diffuser is:

$$
P_{B}=P_{2}+\eta_{d} \rho_{L}\left(V_{s_{0}}-V_{w}\right)^{2} / 2
$$


The pressure at the liquid outlet, which must be equal to $P_{1}$, is $p_{8}$ minus the centrifugal pressure.

$$
P_{1}=p_{8}-\rho_{L} V_{W}{ }^{2 / 2}
$$

Combining Eqs. (16) and (17) and replacing $\left(p_{1}-p_{2}\right) / p_{L}$ by $V_{L}{ }^{2} / 2$, the ratio of wheel velocity to separator drum velocity is given by:

$$
\left(V_{L} / V_{s}\right)^{2}=n_{d}\left(1-2 V_{w} / V_{s}\right)-\left(1-n_{d}\right)\left(V_{w} / V_{s}\right)^{2}
$$

which can be solved for $V_{w}$ using the quadratic formula.

\section{Efficiency}

The liquid flow $\dot{m}_{L}$ of velocity $v_{s}$ is brought to rest in passing radially inward through the turbine. Therefore, the torque on the . turbine is $\dot{m}_{L} v_{s} R_{w}$, and the power output, equal to torque times angular velocity, is:

$$
P_{d}=\dot{m}_{L} V_{S} V_{w}
$$

The expander efficiency is:

$$
\begin{aligned}
\eta_{\text {exp }} & =P_{d} / \dot{m}_{g} V_{g}{ }^{2 / 2} \\
& =2 R_{m} V_{s} V_{w} / V_{g}{ }^{2} \\
& =2 R_{m}\left(V_{s} / V_{L}\right)^{2}\left(V_{w} / V_{s}\right)\left(V_{L} / V_{g}\right)^{2}
\end{aligned}
$$

Substituting the expression. for $R_{m}\left(V_{L} / V_{g}\right)^{2}$ in terms of ' $\left(V_{s} / V_{L}\right)^{2}$ from Eq. (15) and the expression for $\left(V_{S} / V_{L}\right)^{2}$ in terms of $V_{w} / V_{S}$ from Eq. (18), the rotopitot expander efficiency is:

$$
\left.n_{\exp }=n_{m}+\left[\left(1 / \eta_{n} n_{s}\right)-n_{d}\right] /\left(v_{w} / v_{s}\right) 2+\left(1-n_{d}\right)\left(v_{w} / v_{s}\right) / 2\right\}^{-1}
$$

The dependence of $n_{\text {exp }}$ on $V_{W} / V_{\hat{L}}$ can be found by choosing a value. of $v_{w} / V_{s}$ (between 0 and $1 / 2$ ), finding the efficiency from Eq. (21), the 
ratio $V_{L} / V_{S}$ from Eq. (18), and then determining $V_{w} / V_{L}$ from:

$$
v_{W} / V_{L}=\frac{v_{W} / V_{s}}{V_{L} / V_{S}}
$$

\section{Flow Rate and Power Limitations}

If the nozzle ring is confined to a fraction $k_{a}$ of the turbine wheel area and the nozzles are tilted at an angle $\theta$ relative to the plane of rotation, then the allowable nozzle exit area is:

$$
A_{2}=\pi R_{w}^{2} k \sin \theta
$$

The fraction of the nozzle exit area used by the liquid can be neglected, at least for the low pressure stages where flow area limitations are a problem. Hence, the gas flow rate is:

$$
\dot{m}_{g}=\rho_{g_{2}} V_{2} A_{2}
$$

The output power is: .

$$
P_{d}=n_{\exp } \dot{m}_{g} V_{g}^{2} / 2
$$

Substituting $V_{g}$ from Eq. (2), $\dot{m}_{g}$ from Eq. (24), and $A_{2}$ from Eq. (23), the area-limited output power is:

$$
P_{d}=n_{\exp } k_{a} \sin \theta \pi R_{w}{ }^{2} v_{2} p_{2} \log \left(p_{1} / p_{2}\right)
$$


APPENDIX B

ANALYSIS OF TWO-PHASE CYCLES

Two-Phase Bottoming Cycles

The single component-single stage system is shown in Figure 4 . The waste heat from a diesel engine (or gas turbine) enters the heat exchanger at temperature $T_{i}$ with an exhaust flow rate of $\dot{m}_{e}$. The exhaust heat of an amount $Q_{i}$ is transferred to a single phase liquid in a counter current heat exchanger. The exhaust gas exits at temperature $T_{e}$. The heated liquid is flashed in a nozzle and expanded to pressure $p_{2}$ from pressure $p_{1}$. The saturated mixture of vapor and liquid with a quality $x_{2}$ impinges on a rotary separator. The vapor flows through a radial inflow turbine and the liquid flows through a radial inflow turbine, each on a common shaft, producing a net power output $P_{S}$. The vapor exhausts to the condenser where a heat of $Q_{C}$ is rejected. The condensate is pressurized and merged with the high pressure outlet from the liquid turbine. The liquid flows back to the heater, closing the cycle.

A multistage version of the single component cycle is shown in Figure 5 .

In this version, the exit flow from the first stage is remixed and passed through a regenerative heat exchanger, condensing part of the first stage vapor. The mixture is expanded through the second stage nozzlc and turbine (as in the single stage cycle). The condensate and liquid discharge from the final (second) stage is passed through the regenerative heat exchanger, increasing the temperature 
to the minumum dictated by combustor material considerations. The advantage of staging is that lower shaft rpm results and the lower velocities result in more efficiefit nozzle and turbine operation. Against these gains must be balanced the added complexity and possible inter-stage losses.

The use of two components allows more flexibility in the choice of shaft rpm. A single stage two component cycle is shown in Figure 6 .

In this cycle the thermodynamic working fluid is component A. It is supplied to the nozzle as a liquid and flash vaporizes upon contact with the heated Iiquid, component B. Another variation of the two-component cycle is to mix the condensate (component A) with the turbine discharge (component B) circulating the mixture through the heater. This variation has the same cycle diagram as the singlecomponent variation.

The final variation considered uses two components in a manner to enable the use of a contact heat exchanger for the waste gases. This version is illustrated by the schematic of Figure 7 .

Component B is sprayed into the contact heat exchanger vessel and flows counter to the direction of the exhaust gases, picking up heat in the process. The hot liquid is collected in the bottom of the vessel and is pressurized by a pump, and injected into the nozzle. The thermodynamic working fluid $A$ is vaporized upon contact with the component $B$ and the mixture is expanded through the nozzle. Component B i.s separated in the rotary separator turbine driving the hydraulic turbine. Sufficient pressure is left in $B$ to return it to the vessel and spray it into the contact heat exchanger. The vapor exhaust from the rotary. separator is cunderised, pressurized and roturnod to the nozzle. 


\section{Single Component - Single Stage Analysis}

Consider Figure 4, the heat rejected is given by:

$$
Q_{C}=x_{v_{7}} \dot{m}_{T} L_{v_{7}}+\left\{\left(1-\phi_{s}\right)\left(\cdot T-x_{v_{7}}\right)+x_{v_{7}}\right\}\left\{\dot{m}_{T} C_{p_{7}}^{\prime \prime} \Delta T T_{s c}\right\}
$$

where $Q_{C}=$ cycle heat rejection.

$$
\begin{aligned}
& x_{V_{7}}=\text { vapor quality at condenser inlet } \\
& L_{V_{7}}=\text { latent heat at condenser inlet } \\
& \phi_{S}=\text { separation efficiency }=\dot{m}_{5} /\left(1-x_{V_{4}}\right)\left(\dot{m}_{T}\right) \\
& \dot{m}_{T}=\text { total mass flow rate } \\
& \dot{P}_{P_{7}}^{\prime \prime}=\text { liquid specific heat at condenser inlet } \\
& \Delta T_{S C}=\text { subcooling }
\end{aligned}
$$

The maximum power output from the turbine is:

$$
P_{+}=\Psi_{V} \eta_{T}^{\prime} x_{V_{4}} \dot{m}_{T}\left(v_{2}^{\prime}\right)^{2} / 2 g_{C} J+\phi_{S} \eta_{+}^{\prime \prime}\left(1-x_{V_{4}}\right) \dot{m}_{T}\left(V_{2}^{\prime \prime}\right)^{2} / 2 g_{C} J
$$

where $\Psi_{V}=$ fraction of gas energy extracted in turbine, 0 or 1

$$
\begin{aligned}
& n_{+}^{\prime}=\text { efficiency of gas turbine } \\
& x_{v_{4}}=\text { vapor quality at } 4 \\
& v_{2}^{\prime}=\text { vapor exit velocity from nozzle } \\
& g_{C}=32.16 \mathrm{ft} / \mathrm{s}^{2} \\
& J \quad=778 \mathrm{~B} / 1 \mathrm{~b} \cdot \mathrm{ft} \\
& n_{+}^{\prime \prime}=\text { liquid turbine efficiency }
\end{aligned}
$$

The liquid pumping work is given by:

$$
P_{p_{1}}=\frac{\phi_{S}\left(1-x_{V_{4}}\right) \dot{m}_{T}\left(p_{6}-p_{4}\right)(144)}{n_{d} p_{4}^{\prime \prime J}}
$$

where $n_{d} \equiv$ diffuser efficiency

$$
\begin{aligned}
& p_{6}=\text { heater inlet pressüre } \\
& p_{4}=\text { separator casing pressure } \\
& \rho_{4}^{\prime \prime}=\text { liquid density at liquid turbine inlet temperature }
\end{aligned}
$$


This power must be subtracted from the liquid turbine power if it is recovered in the diffuser of a radial inflow turbine. The pumping power required for the condensate is:

$$
P_{p_{2}}=\frac{\left\{\left(1-\phi_{S}\right)\left(1-x_{v_{4}}\right)+x_{v_{4}}\right\}\left(p_{9}-p_{8}\right)(144) \dot{m}_{T}}{\eta_{p} p_{8}^{11 J}}
$$

The net power available from the turbine is:

$$
\begin{aligned}
& P_{n}=\frac{\Psi_{V} \eta_{f}^{\prime} x_{V_{4}} \dot{m}_{T}\left(V_{2}^{\prime}\right)^{2}}{2 g_{C}^{J}}+\frac{\eta_{t}^{\prime \prime} \phi_{S}\left(1-x_{V_{4}}\right) \dot{m}_{T}}{g_{C}^{J}}\left[\frac{\left(V_{2}^{\prime \prime}\right)^{2}}{2}-\frac{(144)\left(p_{6}-p_{4}\right)_{C}}{\eta_{d} \rho_{4}^{\prime \prime}}\right] \\
& -\frac{(144)\left\{\left(1-\phi_{5}\right)\left(1-x_{V_{4}}\right)+x_{V_{4}}\right\}\left(p_{9}-p_{8}\right) \dot{m}_{T}}{n_{p} p_{8}^{\prime \prime J}}
\end{aligned}
$$

The cycle efficiency is given by:

$$
n_{c}=\frac{P_{n}}{P_{n}+Q_{c}}
$$

If an exhaust gas to working fluid temperature difference of $\Delta T_{\text {he }}$ is maintained, then the heat input is given by:

$$
Q_{i_{0}}=\eta_{h e} \dot{m}_{e} C_{p e}\left(T_{i}-T_{f}\right)
$$

and

$$
\begin{aligned}
& T_{1}=T_{i}-\Delta T_{h e} \\
& T_{f}=T_{0}+\Delta T_{h e}
\end{aligned}
$$

where $n_{\text {he }}=$ heat exchanger efficiency

$\dot{\mathrm{m}}_{\mathrm{e}}=$ exhaust gas mass flow rate, $\mathrm{lb} / \mathrm{s}$

$\mathrm{C}_{\mathrm{pe}}=$ exhaust gas specific heat, $\mathrm{B} / 1 \mathrm{~b}^{\circ} \mathrm{F}$

$\mathrm{T}_{i}=$ sexhaust gas initial temperature, ${ }^{\circ} \mathrm{F}$

$T_{f}=$ exhaust gas final temperature, ${ }^{{ }} \mathrm{F}$

The engine efficiency is then:

$$
n_{e}=n_{h e} n_{c}
$$


If the exhaust gases are cooled below the dew point, then

$$
Q_{i_{1}}=\eta_{h e} \dot{m}_{e}\left\{C_{p e}\left(T_{i}-T_{f}\right)+x_{w} L_{v w}\right\}
$$

The nozzle exit velocities $\underset{2}{V^{\prime \prime}}$ and $V_{2}^{\prime \prime}$ can be estimated as:

$$
\therefore v_{2}^{\prime} \simeq V_{2}^{\prime \prime}=\int_{n} V_{2 i}
$$

where $V_{2} i$ is the isentropic expansion velocity for the saturated liquid from $T_{1}$ to $T_{2}$

$$
n_{n}=\text { nozzle energy efficiency }(0.7 \text { to } 0.88)
$$

The vapor quality at the nozzle exit is determined by the approximation

$$
x_{v_{2}} \simeq x_{v_{2} i}+\left(1-n_{n}\right) \frac{v_{2} i^{2}}{2 g_{c} J C_{p}^{\prime \prime}} \frac{1}{L_{v_{2}}}
$$

where $x_{v_{2} i}=$ the isentropic expansion exit quality

$$
L_{v_{2}}=\text { latent heat at Station 2, nozzle exit }
$$

The rpm is given by:

$$
\begin{aligned}
& w=P_{n} / L \\
& L=\frac{\dot{m}_{T} V_{2}^{\prime} r_{t}}{g_{C}}
\end{aligned}
$$

\section{Single Component - Multistage}

In the two-stage system shown in Figure 5, the exit flow from the first stage is passed through a regenerative heat exchanger to reduce the quality to the second stage in order to reduce the spouting velocity and to increase the heat exchanger inlet temperature to a value above the dewpoint of the exhaust gases.

The heat rejected from the condenser is:

$$
Q_{C}=x_{v_{9}} \dot{m}_{T} L_{v_{9}}+\left\{\left(1-\phi_{S_{2}}\right)\left(\hat{\eta}-x_{v_{g}}\right)+x_{v_{9}}\right\} C_{p_{9}}^{\prime \prime} \Delta T_{s C} \dot{m}_{T}
$$

The power output from the first stage turbine is:

$$
\begin{gathered}
P_{t_{1}}=\frac{\Psi_{v_{1}} n_{t_{1}}^{\prime} x_{v_{4}} \dot{m}_{T_{T}}\left(v_{2}^{\prime}\right)^{2}}{2 g_{C} J}+\frac{\phi_{s_{1}} n_{t_{1}}^{\prime \prime}\left(1-x_{v_{4}}\right) \dot{m}_{T}\left(v_{2}^{\prime \prime}\right)^{2}}{2 g_{C} J} \\
-95-
\end{gathered}
$$


The change in temperature through the regenerator in the flow to the heater is given by:

$$
\dot{m}_{T}\left(x_{v_{5}}-x_{v_{6}}\right) L_{v_{5}}=\dot{m}_{T} C_{\ddot{p}_{11}^{\prime \prime}}^{\prime}\left(T_{12}-T_{11}\right) \text {. }
$$

where $T_{12}=$ minimum metal surface temperature for exhaust gas ( $\equiv 217^{\circ} \mathrm{F}$ from Ref. 7)

or

$$
x_{v_{6}}=\frac{L_{v_{5}} x_{v_{5}}-C_{p_{11}}^{\prime \prime}\left(T_{12}-T_{11}\right)}{L_{v_{5}}}
$$

The power output from the second stage is:

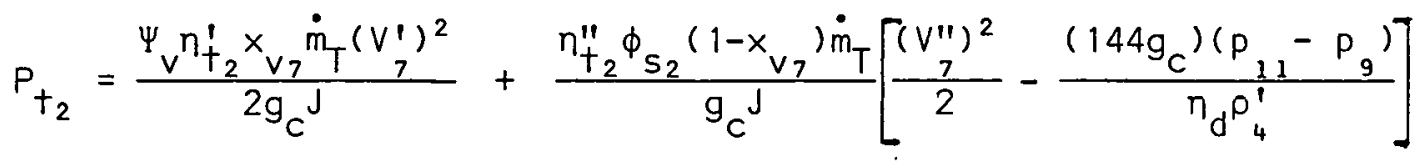

$$
\begin{aligned}
& -\frac{(144)\left\{\left(1-\phi_{S_{2}}\right)\left(1-x_{V_{7}}\right)+x_{V_{7}}\right\}\left(p_{11}-p_{9}\right)\left(\dot{m}_{T}\right)}{n_{p} p_{11}^{\prime \prime} J}
\end{aligned}
$$

where the nozzle exit parameters $\dot{x}_{v}, v_{7}^{\prime}$, and $v_{7}^{\prime \prime}$ are found by considering an isentropic expansion of the saturated liquid-vapor mixture from quality $x_{v_{6}}$ at temperature $T_{6}$ to a pressure of $p_{7}$; and subsequently applying corrections for the actual nozzle efficiency, $n_{n_{2}}$.

The cycle efficiency is subsequently given by:

$$
r_{c}=\frac{P_{t_{1}}+P_{t_{2}}}{P_{t_{1}}+P_{t_{2}}+Q_{c}}
$$

Methods of determining engine efficiency and other parameters follow those outlined in the single component single stage analysis. 


\section{Two-Component - Conventional Heat Exchanger}

The most efficient two-component system is achieved by circulating both components through the heater. Considering the cycle diagram of Figure 4 with components $A$ and $B$, the heat rejected in the condenser is given by:

$$
\begin{aligned}
Q_{C} \simeq & \frac{\dot{m}_{T} L_{v a}}{(1+r)}\left[1+\frac{C_{1}}{1-C_{1}} \frac{L_{v b}}{L_{v a}}+\frac{C_{p a}^{\prime \prime} \Delta T}{L_{v a}}+\frac{C_{1}}{1-C_{1}} \frac{C_{p b}^{\prime \prime} \Delta T_{S C}}{L_{v a}}\right. \\
& \left.+\frac{\left(1-\phi_{S}\right)(1+r) C_{p b}^{\prime \prime} \Delta T_{S C}}{L_{v a}}\right] \\
\simeq & \frac{\dot{m}_{T}}{(1+r)}\left\{L_{v a}+\frac{C_{1}}{1-C_{1} L_{v b}}+C_{p a}^{\prime \prime} \Delta T_{s c}+\left[\frac{C_{1}}{1-C_{1}}+\left(1-\phi_{s}\right)(1+r)\right] C_{p b}^{\prime \prime} \Delta T_{s c}\right\}
\end{aligned}
$$

where $L_{v a, b}=$ latent heat of vaporization of $A, B(B / / b)$

$$
\begin{aligned}
& r=\text { mass flow ratio of } B \text { to } A \\
& C_{1}=\text { vapor fraction of } B \text { in gas }=\frac{W_{b_{7}} P_{b_{7}}}{W_{7} P_{7}} \\
& W_{b_{7}}=\text { molecular weight of } B \text { at } T_{7} \text { ( } 1 \mathrm{~b} / \mathrm{lb} \text { mole) } \\
& \mathrm{p}_{b} \quad=\text { vapor pressure of } \mathrm{B} \text { at } T \text { (psia) } \\
& \mathrm{W}_{7}=\text { molecular weight of gas at } T_{7} \text { ( } \mathrm{lb} / \mathrm{lb} \text { mole) } \\
& P_{7}=\text { condenser inlet pressure (psia) } \\
& \mathrm{C}_{\mathrm{pa}, \mathrm{b}}^{\prime \prime}=\text { specific heat of } \mathrm{A}, \mathrm{B}\left(\mathrm{B} / 1 \mathrm{~b}^{\circ} \mathrm{F}\right) \\
& \phi_{S}=\text { separator efficiency for } 1 \text { iquid }=\frac{\dot{m}_{b_{5}}}{m_{\dagger}} \frac{(1+r)}{r} \\
& \Delta T_{S C}=\text { subcooling }=T_{7}-T_{8},\left({ }^{O} \mathrm{~F}\right)
\end{aligned}
$$

The exit velocity from the nozzle is given by:

$$
\begin{aligned}
& v_{2}=v_{2}=\sqrt{\eta_{n}} v_{2} i \\
& \text { where } v_{2 i}=\text { the isentropic exit velocity }
\end{aligned}
$$


The power output is given by:

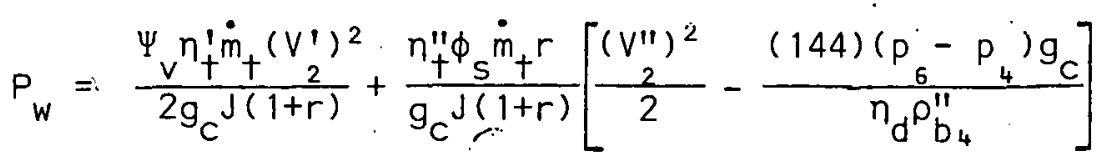

$$
\begin{aligned}
& -\frac{(144)\left(1-\phi_{S}\right) \dot{m}_{t} r\left(p_{g}-p_{8}\right)}{n_{p} p_{b_{8}}^{\prime \prime} J(1+r)}-\frac{(144) \dot{m}_{t}\left(p_{g}-p_{8}\right)}{\eta_{p} p_{a_{8}}^{\prime \prime} J(1+r)}
\end{aligned}
$$

In order to determine the mass ratio of component $B$ to component $A$ the flow in the nozzle must be considered. If $A$ and $B$ enter the nozzle in the liquid state and if $A$ is entirely vaporized until only $B$ remains in the liquid state then for an isentropic process:

$$
\dot{m}_{a} s_{a_{1}}^{\prime \prime}+\dot{m}_{b} s_{b}^{\prime \prime}=\phi_{x} \dot{m}_{a} s_{a x}^{\prime}+\left(1-\phi_{x}\right) \dot{m}_{a} s_{a x}^{\prime \prime}+\dot{m}_{b} s_{b x}^{\prime \prime}
$$

rearranging gives:

$$
\phi_{x} s_{a x}^{\prime}-\phi_{x} s_{a x}^{\prime \prime}=s_{a_{1}}^{\prime \prime}+r s_{b_{1}}^{\prime \prime}-s_{a x}^{\prime \prime}-r s_{b x}^{\prime \prime}
$$

or

$$
\phi_{x}=\frac{r\left(s_{b_{1}}^{\prime \prime}-s_{b x}^{\prime \prime}\right)}{\Delta s_{a x}}+\frac{s_{a_{1}}^{\prime \prime}-s_{a x}^{\prime \prime}}{\Delta s_{a x}}
$$

If $\phi=1$

$$
r=\frac{\Delta s_{a x}-\left(s_{a_{1}}^{\prime \prime}-s_{a x}^{\prime \prime}\right)}{s_{b_{1}}^{\prime \prime}-s_{b x}^{\prime \prime}}
$$

where $\phi_{x}=$ the mass fraction of $A$ vaporized by station $x$

$\dot{m}_{a}=$ mass flow rate of component $A$

$\dot{m}_{b}=$ mass flow rate of component $B$

$s_{a_{1}}^{\prime \prime}=\begin{aligned} & \text { entropy of I iquid } A \text { at the conditions of } \\ & \text { station } 1 \text { (inlet) }\end{aligned}$

$\Delta \mathrm{s}_{\text {ax }}=$ "entropy of vaporization of component $A$ at station $x$

The velocity at $x$ for an isentropic process is given by:

$$
\dot{m}_{a} h_{a_{1}}^{\prime \prime}+\dot{m}_{b} h_{b_{1}}^{\prime \prime}=\phi_{x} \dot{m}_{a} h_{a x}^{\prime}+\left(1-\ddot{\phi}_{x}\right) \dot{m}_{a} h_{a x}^{\prime \prime}+\dot{m}_{b} h_{b x}^{\prime \prime}+\left(\dot{m}_{a}+\dot{m}_{b}\right) v_{x i}^{2} / 2
$$


Solving for $v_{x i}{ }^{2}$ :

$$
\begin{aligned}
v_{x i}^{2} & =\frac{2}{1+r}\left[h_{a_{1}}^{\prime \prime}-\left(1-\phi_{x}\right) h_{a x}^{\prime \prime}-\phi_{x} h_{a x}^{\prime}+r h_{b_{1}}^{\prime \prime}-r h_{b x}^{\prime \prime}\right] \\
& =\frac{2}{1+r}\left[h_{a_{1}}^{\prime \prime}-h_{a x}^{\prime \prime}+\phi_{x} h_{a x}^{\prime \prime}-\phi_{x} h_{a x}^{\prime}+r\left(h_{b_{1}}^{\prime \prime}-h_{b x}^{\prime \prime}\right)\right] \\
& =\frac{2}{1+r}\left[\left(C_{p a}^{\prime \prime}+r C_{p b}^{\prime \prime}\right)\left(T_{1}-T_{x}\right)-\phi_{x} L_{v a}+\frac{p_{1}-p_{x}}{\rho_{a x}^{\prime \prime}}\left(1+r \frac{\rho_{a x}^{\prime \prime}}{\rho_{b x}^{\prime \prime}}\right)\right]
\end{aligned}
$$

And

$$
\begin{aligned}
& A_{x i}=\frac{\dot{m}_{a} \phi_{x}}{\rho_{a x}^{\prime} V_{x i}}+\frac{\dot{m}_{a}\left(1-\phi_{x}\right)}{\rho_{a x}^{\prime \prime} V_{x i}}+\frac{\dot{m}_{b}}{\rho_{b x}^{\prime \prime} V_{x i}} \\
& A_{x}=\frac{A_{x i}}{\sqrt{n}}
\end{aligned}
$$

$$
\begin{aligned}
\text { where } v_{x i} & =v_{x i}^{\prime}=v_{x i}^{\prime \prime}=\begin{array}{l}
\text { velocity of two-phase mixture after an } \\
\text { isentropic expansion from station } 1 \text { to } x
\end{array} \\
h_{a_{1}}^{\prime \prime} & =\text { enthalpy of component } A \text { liquid at station. } 1 \\
C_{p a}^{\prime \prime} & =\text { specific heat of component } A \text { liquid } \\
T & =\text { temperature } \\
L_{v a} & =\text { latent heat of vaporization of component } A \\
p & =\text { pressure } \\
\rho_{a x}^{\prime \prime} & =\text { density of component A liquid at station } x \\
A_{x i} & =\text { area at station } x \text { for an isentropic expansion from } 1 \text { to } x \\
A_{x} & =\text { area for a real expansion from } 1 \text { to } x \\
\eta_{n} & =v_{x}{ }^{2} / V_{x i}
\end{aligned}
$$


Two Components with Contact Heat Exchanger

Ihe contact heat exchanger variation of Figure 4 has the primary pump as an added component, but replacement of the primary tube and fin heat exchanger by a simple contact unit should result in a sugnificant savings in cost.

The heat transferred from the condenser is:

$$
Q_{C}=\frac{\dot{m}_{t}}{1+r}\left\{L_{v a}+\left(\frac{C_{1}}{1-C_{1}}\right) L_{v b}+C_{p a}^{\prime \prime} \Delta T_{s C^{+}}+\left|\left(\frac{C_{1}}{1-C_{1}}\right)+\left(1-\phi_{s}\right)(1+r)\right| C_{p b}^{\prime \prime} \Delta T_{s c}\right\}
$$

where the nomenclature was defined previously.

The turbine output power now becomes:

$$
\begin{aligned}
p_{n} & =\frac{\psi_{v} n_{t}^{\prime} \dot{m}_{t}\left(v_{2}^{\prime}\right)^{2}}{2 g_{c} J(1+r)}+\frac{n_{t}^{\prime \prime} \phi_{s} \dot{m}_{t} r}{g_{c} J(1+r)}\left[\frac{\left(V_{2}^{\prime \prime}\right)^{2}}{2}-\frac{(144)\left(\Delta p_{1}\right) g_{c}}{\dot{n}_{d} \rho_{b_{4}}^{\prime \prime}}\right] \\
& -\frac{(144)\left(1-\phi_{s}\right) \dot{m}_{t} r\left(p_{g}-p_{8}\right)}{n_{p_{1}} \rho_{b_{8}}^{\prime \prime} J(1+r)}-\frac{(144) \dot{m}_{t}\left(p_{g}-p_{8}\right)}{n_{p_{1}} \rho_{a_{8}}^{\prime \prime} J(1+r)} \\
& -\frac{(144)\left(\phi_{s}\right) \dot{m}_{t} r\left(p_{1}-p_{6}\right)}{n_{p_{2}} \rho_{b_{1}}^{\prime \prime} J(1+r)} .
\end{aligned}
$$

The same expression for mass ratio holds, but in general the temperature of the thermodynamic working fluid.at the nozzle inlet will be equal to the condenser temperature instead of the peak cycle temperature. single component single slage Calculaliuns

The engine chosen for consideration is the 38-TD8-1/8. The exhaust temperature and flow rate at full power are:

$$
\begin{aligned}
& \mathrm{T}_{\mathrm{i}}=719^{\circ} \mathrm{F} \\
& \dot{\mathrm{m}}_{\mathrm{e}} / \mathrm{P}_{\mathrm{d}} \doteq 15.17 \mathrm{lb} / \mathrm{bHP} \cdot \mathrm{h} \\
& P_{d}=1980 \mathrm{bHP} \text {. क्ष } \\
& \dot{\mathrm{m}}_{\mathrm{e}}=3.004 \times 10^{4} \mathrm{lb} / \mathrm{h}=8.344 \mathrm{lb} / \mathrm{s}
\end{aligned}
$$


If we chose a heat exchanger $\Delta T$ of $25^{\circ} \mathrm{F}$ (pgs. 3-26 of ref. 7), then the peak temperature of the bottoming cycle is:

$$
T=696^{\circ} \mathrm{F}
$$

In order to limit the pressure and provide a consistent calculational basis, let $T_{1}=680^{\circ} \mathrm{F}$. For saturated liquid, $P_{1}=2708.1$ psia.

The other conditions at state point 1 are:

$$
\begin{aligned}
v_{1}^{\prime \prime} & =.0305 \mathrm{ft}^{3} / \mathrm{lb} \\
v_{1}^{\prime} & =.1115 \mathrm{ft}^{3} / \mathrm{lb} \\
h_{1}^{\prime \prime} & =757.3 \mathrm{~B} / \mathrm{lb} \\
h_{1}^{\prime} & =1067.2 \mathrm{~B} / \mathrm{lb} \\
L_{v_{1}} & =309.9 \mathrm{~B} / \mathrm{lb} \\
s_{1}^{\prime \prime} & =.9351 \mathrm{~B} / 1 \mathrm{~b}^{\circ} \mathrm{F} \\
s_{1}^{\prime} & =1.2071 \mathrm{~B} / 1 \mathrm{~b}^{\circ} \mathrm{F} \\
\Delta_{v} & =.2719 \mathrm{~B} / 1 \mathrm{~b}^{\circ} \mathrm{F}
\end{aligned}
$$

The first case considered will be a condensing temperature of $212^{\circ} \mathrm{F}$. In this case:

$$
\begin{aligned}
& T_{2}=212^{\circ} \mathrm{F} \\
& P_{2}=14.7 \text { psia } \\
& v_{2}^{\prime \prime}=.01672 \\
& v_{2}^{\prime}=26.80 \\
& h_{2}^{\prime \prime}=180.07 \\
& h_{2}^{\prime}=1150.4 \\
& L_{v_{2}}=970.3 \\
& s_{2}^{\prime \prime}=.3120 \\
& s_{2}^{\prime}=1.7566 \\
& \Delta_{v_{2}}=1.4446
\end{aligned}
$$


Isentropic expansion would yield:

$$
\begin{aligned}
\Delta h_{i} & =h_{1}^{\prime \prime}-h_{2}^{\prime \prime}-T_{2}\left(s_{1}^{\prime \prime}-s_{2}^{\prime \prime}\right) \\
x_{2} & =\frac{T_{2}\left(s_{1}^{\prime \prime}-s_{2}^{\prime \prime}\right)}{L_{v_{2}}} \\
\Delta h & =(757.3-180.07)-672(.9351-.3120) \\
& =577.23-418.723=158.507 \mathrm{~B} / \mathrm{lb}=158.507 \mathrm{~B} / \mathrm{s} / \mathrm{lb} / \mathrm{s} \\
x_{2} & =(672)(.9351-.3120) /(970.3)=.432
\end{aligned}
$$

The heat rejected is:

$$
\begin{aligned}
Q_{C} & =(.432)(1)(970.3)+[(.99)(1)+(.432)(1)](1.0)(10) \\
& =419.7+14.22=433.39 \mathrm{~B} / \mathrm{s}
\end{aligned}
$$

For a nozzle efficiency of 0.85 , the exit velocity is:

$$
\begin{aligned}
& v_{2}{ }^{2} / 2 g_{c} J=n_{n} \Delta h_{i}=(158.507)(.85) \\
& v_{2}=\sqrt{(64.4)(778)(158.57)(.85)}=2598.68 \mathrm{ft} / \mathrm{s}
\end{aligned}
$$

For a turbine efficiency of .85 and a diffuser efficiency of .85 and $\Psi_{V}=1$ :

$$
\begin{aligned}
P_{n}= & \frac{(1)(.85)(.432)(1)(2598.68)}{(64.4)(778)}+\frac{(.85)(.99)(.568)(1)}{(32.2)(778)}\left[\frac{(2598.68)}{2}-\right. \\
& \left.\frac{(144)(2693.4+40)(32.2)}{(.85)(59.81)}\right]-\frac{(144)(.432+.01)(1)(2693.4+40)}{(.75)(59.81)(778)} \\
= & 49.49+59.667-4.883=104.27 \mathrm{~B} / \mathrm{s}
\end{aligned}
$$

The cycle efficiency is therefore:

$$
n_{c}=\frac{104.27}{104.27+433.39}=.1939
$$




\section{APPENDIX C \\ SUMMARY OF TURBINE DESIGN \\ METHODS AND,PARAMETERS}

\section{Mechanical Design Procedure}

1. Make use of standard and conventional parts and materials.

2. Estimate rotor component weights.

3. Calculate rotor shaft size by:

"A. Minimum static deflection with load (.001")

B. Bearing size for rotor speed and load

C. Material selection.

4. Calculate shaft stresses based on size, material, and drive horsepower.

5. Estimate first critical speed.

6. Adjust any of the above parameters as required.

7. Determine component balance required to minimize total load.

8. Calculate housing stresses and determine minimum thicknesses and bolt size.

9. Calculate inlet line size and outlet line size required for standard flow.

10. Design support members for maximum rigidity.

\section{Tultine Forametcrs*}

1. Two inlet nozzles - .939" exit diameter

2. Steam mass flowrate $=.659 \mathrm{lb} / \mathrm{s}$

3. DTA mass flowrate $=2.16 \mathrm{lb} / \mathrm{s}$

4. Separator $\mathrm{rpm}=16,322$

5. Turbine rpm $=8,161$

6. Separator speed $=1,600 \mathrm{ft} / \mathrm{s}$

* The final turbine parameters changed somewhat due to iterations, but not significantly enough to affect the mechanical deșign. 
7. Turbine power $=160 \mathrm{HP}$

8. Steam turbine power $=137.4 \mathrm{HP}$

9. Pump power $=38.7$ HP. @ 75\% efficiency

10. Nozzle exit velocity $=1,841 \mathrm{ft} / \mathrm{s}$ (@ 15\%)

11. Separator (nozzle exit) pressure $=14.7$ psia

12. Separator (nozzle exit) temperature $=212^{\circ} \mathrm{F}$

13. Turbine discharge pressure $=1.2$ psia $(.7$ psia minimum)

14. Separator drum inner diameter $=24 "$

15. Nozzle length $=12^{\prime \prime}$

Throat diameter $=.90^{\prime \prime}$

Exit diameter $=.939^{\prime \prime}$

16. Separator drum material - titanium

Numerical Calculations

1. Estimated rotor weights:

Steam turbine -20 lbs
Separator disc - 20 lbs
Liquid turbine -5 lbs
Shaft $\quad 8.5$ lbs

2. Rotor unbalance load:

$$
\begin{aligned}
& \text { Vapor turbine: } \quad 8,161 \mathrm{rpm} \\
& .04 \text { ounce inches maximum } \\
& \text { Force }=\frac{\text { Ounces } \times \text { inches }}{6172} \times(.1045 \times \mathrm{rpm})^{2} \\
& \text { Force }=\frac{.04}{6172}(728,702) \\
& \text { Force }=2.72 \mathrm{lbs} \\
& \text { Separator disc: } 16,322 \mathrm{rpm} \\
& \text {. } \quad .016 \text { ounce inches maximum } \\
& \text { Force }=\frac{.016}{6172}(2,914,809) \\
& \text { Force }=7.5 .1 \mathrm{bs}
\end{aligned}
$$$$
\text { I iquid turbine and shaft = Negligible }
$$$$
\text { Total Rotor Load }=65.72 \mathrm{Zbs}
$$$$
-104-
$$ 
3. Rotor shaft size:

$$
\begin{aligned}
\text { Deflection } & =\frac{W c^{2}}{3 E I} \times(c+l) \\
.001 & =\frac{(65.72)(4)^{2}}{3\left(30 \times 10^{6}\right) l}(4+7) \\
I & =.129=.049\left(d^{4}\right) \\
d & =1.344^{\prime \prime} \\
\text { where } W & =\text { Rotor weight }- \text { Ibs } \\
E & =30 \times 10^{6} \\
I & =.049\left(d^{4}\right) \\
c & =\text { Rotor overhang }- \text { inches } \\
\ell & =\text { Bearing spacing - inches } \\
d & =\text { Shaft diameter }- \text { inches }
\end{aligned}
$$

Bearing Size $=35 \mathrm{~mm}$. bore (1.3780" shaft size)

Bearing Type (test purposes only) - Extra Precision ABEC - 7

Typical Bearing Type = Fafnir Medium 2MM307 WI single and 2MM307 DB double

$$
\begin{aligned}
\text { Radial Load }=R_{e} & =X_{1} R+Y_{1} T \text { Equation } 1=65.72 \\
& =X_{2} R+Y_{2} T \text { Equation } 2=52.23
\end{aligned}
$$

where $X_{1}=1.0$

$$
\begin{aligned}
& y_{1}=0 \\
& x_{2}=.45 \\
& y_{2}=1.8 \\
& R=65.72
\end{aligned}
$$

Life Calculation: $L_{10}=1,500\left|\frac{C_{u}}{R_{e}}\right|^{3}$

$$
\text { where } \begin{aligned}
c_{u} & =i^{0.7}\left(C_{n}\right)=2,505.6 \\
\text { and } \quad c_{n} & =n_{f} \times c_{b} \\
c_{n} & =.16 \times 7,250
\end{aligned}
$$




$$
c_{n}=1,160
$$

Therefore, $L_{10}=82 \times 10^{6}$

Standard grease packed double seal bearings rated at $250^{\circ} \mathrm{F}$ are therefore suitable.

4. Rotor shaft size by stress:

ASME Power Code Equation: =

$$
d^{3}=\frac{16}{S_{s}} \sqrt{\left(K_{b} M_{b}\right)^{2}+\left(K_{t} M_{t}\right)^{2}}
$$

where $d=$ Shaft diameter - inches

$$
\begin{aligned}
\mathrm{S}_{S}= & \text { Maximum shear stress - torsion, bending } \\
& \text { and axial, Code for standard commercial } \\
& \text { with keyway }=6,000 \text { psi }
\end{aligned}
$$

$K_{b}=$ Combined shock and fatigue - bending

$M_{b}=$ Bending moment - in/lb

$\begin{aligned} K_{+}= & \text {Combined. shock and fatigue - torsional } \\ & \text { Code }-1.5 \text { for minor shock }\end{aligned}$

$M_{+}=$Torsional moment - in/lb

Neglecting bending stresses: @ $300 \mathrm{HP}$

$$
d^{3}=\frac{16}{\pi S_{S}} K_{+} M_{+}
$$

where $M_{+}=\frac{H P(33,000)(12)}{2 \pi r p m}$

$=2,318 \mathrm{in} / 1 \mathrm{~b}$

$$
d^{3}=\frac{16}{\pi 6,000} 1.5(2,318)
$$

$$
d^{3}=2.95^{\prime \prime}
$$

Therefore, $d=1.37^{\prime \prime}$

The $35 \mathrm{~mm}$. boaring size (1.3780) is correct. 
APPENDIX D

STEAM TURBINE ANALYSIS AND DLSION

The two-phase nozzle accelerates a steam/Dow-Therm A mixture. In the separator, the two fluids are separated and each is allowed to exchange momentum in a turbine wheel.

In the separator process, the liquid Dow-Therm A is centrifuged to the inside of the rotating separator rim. The steam, at essentially rim speed, exists below the liquid. If the pressure gradient is sufficient to initiate flow radially inward, the flow can be directed through properly shaped vanes and energy can be extracted. This would then be a radial inflow turbine configuration, and is selected here because it adapts so well to the rest of the geometry. Actually, a small performance penalty will be paid because the jet-speed ratio (U/C $C_{0}$ is somewhat low, even if two stages are used.

\section{Operating Conditions}

The conditions for which the turbine was designed are listed in Table D-1.

Analysis

In contradistinction to the ordinary radial inflow turbine where the working fluid. is accelerated in a regular nozzle located in the plane of the wheel and directed to provide a radial inflow component to the velocity, here the fluid is separated on the rotating drum and is directed with a slight axial component. Therefore, the analysis begins with the already accelerated steam jet. assuming a realistic value of velocity (tangential component $=1,800 \mathrm{ft} / \mathrm{sec}$, radial component $=250 \mathrm{ft} / \mathrm{sec}$ ). - The steam is also assumed to be saturated vapor at 14.7 psia. The 
TABLE D-1.

OPERATING CONDITIONS

$\begin{array}{lc}\text { Nozzle Exit Diameter, in. } & 0.939 \\ \text { Steam Mass Flowrate, Ib/sec } & 0.659 \\ \text { Dow-Therm Mass Flowrate, Ib/sec } & 2.16 \\ \text { Separator Speed, rpm } & 16,322 \\ \text { Turbine Speed, rpm } & 8,161 \\ \text { Nozzle Exit Velocity, ft/sec } & 1,841 \\ \text { Nozzle Angle, degrees } & 12 \\ \text { Separator Diameter, in. } & 24.0 \\ \text { Nozzle Exit Pressure, psia } & 14.7 \\ \text { Turbine Discharge Pressure, psia } & 1.2 \text { maximum } \\ & 0.7 \text { minimum }\end{array}$

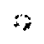


separator and nozzle diameters set the allowable inlet diameter to the turbine at 22.0 inches, making the tip speed $783 \mathrm{fl} / \mathrm{sec}$ at $8,161 \mathrm{rpm}$. This is the starting point of the analysis.

The variables which operate in the trade-off analysis include:

$$
\begin{aligned}
& \text { Diameter at inlet and outlet of each stage } \\
& \text { Intermediate stage pressures } \\
& \text { Blade angles } \\
& \text { Absolute velocities (mach numbers) } \\
& \text { Radial acceleration permissible }
\end{aligned}
$$

The objective, of course, is to minimize losses and maximize power output. In terms of the turbine analysis, the absolute leaving velocity should have the smallest possible tangential (whirl) component.

A preliminary trade-off was made to determine some of the variables. Diameters were selected and the radial acceleration was set at 20 percent. It would be best to have no acceleration but blade angles will be very shallow. Throughflow velocity was chosen to give reasonable blade height. A parametric analysis of intermediate stage pressures was performed.

Table D-2 lists the constraints imposed on the analysis. Figure D-1 shows the nomenclature used. Table D-3 is a summary of the calculations and Figures D-2 through D-5 show the results. From these data the selected configuration is as summarized in Table D-4. 
TABLE D-2

CONSTRAINTS AND EQUATIONS

$$
\begin{aligned}
& C_{u_{2}}=1,800 \mathrm{ft} / \mathrm{sec} \text {. } \\
& \text { Assumed, set by drum speed } \\
& c_{r_{2}}=250 \mathrm{ft} / \mathrm{sec} \\
& \text { Assumed, reasonable blade height } \\
& w_{3} i^{2}=w_{2}^{2}+2 g J\left(h_{2}-h_{3} i^{\prime}\right. \\
& \text { First Law } \\
& w_{3}=0.9 w_{3} \mathbf{i} \\
& \text { Assumed, Losses } \\
& \text { Stage Work }=\frac{\mathrm{C}_{\mathrm{U}_{2} \mathrm{U}_{2}}-\mathrm{C}_{\mathrm{U}_{3} \mathrm{U}_{3}}}{\mathrm{gJ}} \\
& c_{r_{3}}=1.2 c_{r_{2}}=300 \mathrm{ft} / \mathrm{sec} \\
& \text { Euler Equation } \\
& \text { Reasonable acceleration } \\
& C_{U_{4}}=C_{U_{3}}\left(D_{4} / D_{3}\right) \\
& \text { Vortex Law } \\
& c_{r_{5}}=1.2 C_{r_{4}}=360 \mathrm{ft} / \mathrm{sec} \\
& \text { Reasonable acceleration } \\
& C_{5} i^{2}=C_{4}^{2}+2 g J\left(h_{4}-h_{5 i}\right) \\
& \text { First Law } \\
& c_{5}=0.9 c_{5} i \\
& h_{6}=h_{4}-C_{0}^{2} / 2 g J \\
& c_{r_{7}}=1.2 c_{r_{6}}=432 \mathrm{ft} / \mathrm{sec} \\
& \text { Stage Work }=\frac{\mathrm{C}_{\mathrm{U}_{6} \mathrm{U}_{6}}-\mathrm{C}_{\mathrm{U}_{7}} \mathrm{U}_{7}}{\mathrm{gJ}} \quad \text { Euler Equation } \\
& \text { Assumed, Losses } \\
& \text { First Law } \\
& \text { Reasonable acceleration } \\
& \text { Total Work = Sums of Stage Work } \\
& \text { Power = Total Work } \times \text { Flowrate }
\end{aligned}
$$

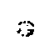


Fig. D-1 - Typical Diagrams
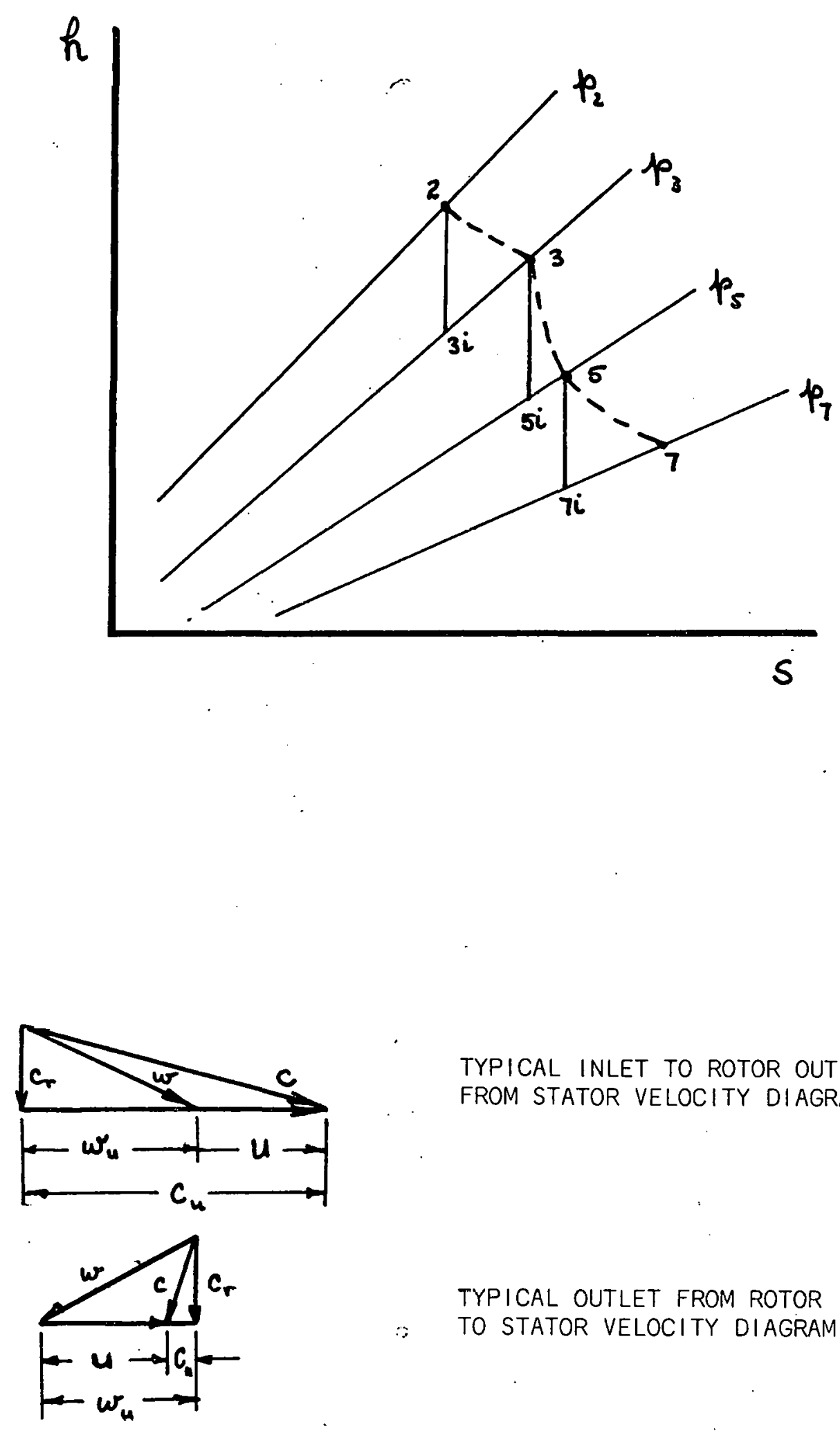

TYPICAL INLET TO ROTOR OUTLET

FROM STATOR VELOCITY DIAGRAM

TYPICAL OUTLET FROM ROTOR INLET

$\therefore$ TO STATOR VELOCITY DIAGRAM 
TABLE D-3

TYPICAL CÁLCULATIONS

Point 2

$$
\begin{aligned}
& p_{2}=14.7 \text { psia } \\
& h_{2}=1,150.5 \mathrm{~B} / \mathrm{lb} \\
& c_{2}=1,817.3 \mathrm{ft} / \mathrm{sec} \\
& u_{2}=783.4 \mathrm{ft} / \mathrm{sec} \\
& \omega_{2}=1,046.9 \mathrm{ft} / \mathrm{sec} \\
& c_{u_{2}}=1,800 \mathrm{ft} / \mathrm{sec} \\
& c_{r_{2}}=250 \mathrm{ft} / \mathrm{sec}
\end{aligned}
$$

\begin{tabular}{|c|c|c|c|c|c|c|c|c|}
\hline$P_{3}$ & $=$ & 14.7 & psia & 12.0 & 8.0 & 6.0 & 4.0 & 1.2 \\
\hline$h_{3} \mathbf{i}$. & $=$ & $1,150.5$ & $B / I b$ & 1,136 & 1,108 & 1,089 & 1,063 & 992 \\
\hline$\omega_{3}$ & $=-$ & 942 & $f t / \sec$ & $-1,215$ & $-1,616$ & $-1,845$ & $-2,112$ & $-2,706$ \\
\hline $\mathrm{U}_{3}$ & $=$ & 712 & $\mathrm{ft} / \mathrm{sec}$ & 712 & 712 & 712 & 712 & 712 \\
\hline $\mathrm{C}_{\mathrm{r}_{3}}$ & $=$ & 300 & $f t / \sec$ & 300 & 300 & 300 & 300 & 300 \\
\hline $\mathrm{C}_{\mathrm{u}_{3}}=$ & $=-$ & 181 & $\mathrm{ft} / \mathrm{sec}$ & -465 & - 876 & $-1,108$ & $-1,379$ & $-1,977$ \\
\hline Stage & ge $W$ & lork $=6$ & $1.4 \mathrm{~B} / \mathrm{Ib}$ & 69.5 & $\Rightarrow 81.2$ & 87.8 & 95.5 & \\
\hline
\end{tabular}

\begin{tabular}{|c|c|c|c|c|c|c|c|}
\hline$c_{u_{4}}=-$ & 181 & $\mathrm{ft} / \mathrm{sec}$ & $\begin{array}{c}-470 \\
.\end{array}$ & -885 & $-1,119$ & $-1,393$ & $-1,997$ \\
\hline$C_{r_{4}}=$ & 300 & $f+/ \sec$ & 300 & 300 & 300 & 300 & 300 \\
\hline
\end{tabular}

Point 3

Point 4 


\section{Point 5}

$P_{5}=10$ psia

$h_{5 i}=1,132 \mathrm{~B} / \mathrm{lb}$

$C_{5}=883 \mathrm{ft} / \mathrm{sec}$

$c_{r_{5}}=360 \mathrm{ft} / \mathrm{sec}$

$C_{u_{5}}=806 \mathrm{ft} / \mathrm{sec}$

$C_{u_{6}}=815 \mathrm{ft} / \mathrm{sec}$

$u_{6}=627 \mathrm{ft} / \mathrm{sec}$

$\omega_{U_{6}}=188 \mathrm{ft} / \mathrm{sec}$

$c_{r_{6}}=360 \mathrm{ft} / \mathrm{sec}$

$\omega_{6}=406 \mathrm{ft} / \mathrm{sec}$

$c_{6}=891 \mathrm{ft} / \mathrm{sec}$

$h_{6}=1,135 \quad B / 1 b$

$p_{7}=1.2$ psia

$h_{7 i}=1,003 \quad B / 1 b$

$\omega_{7}=-2,338 \mathrm{ft} / \mathrm{sec}$

$U_{7}=556 \mathrm{ft} / \mathrm{sec}$

$c_{r_{7}}=432 \mathrm{ft} / \mathrm{sec}$

$C_{u_{7}}=-1,742 \quad f t / \sec$

Stage Work $=59.0 \mathrm{~B} / \mathrm{Ib}$

Power

$$
=120 \mathrm{HP}
$$

$$
\underline{P_{3}=12.0}
$$

6

1.2

1,097

1,490

360

1,446

1,462

627

835

360

360

$909^{\circ}$

1,895

1,506

2,513

1,027

1.2

1.2

1,006

1,027

$-2,121$

$-2,171$

$-1,706$

556

556

432

432

$-1,572$

$-1,094$

$-1,520$

71.4

86.5

132

146
1,017

66.4

$\frac{p_{3}=8.0}{4}$

1,088

1,015

1,750

2,557

360

360

1,293

1,712

2,531

1,732

2,560

627

627

681

1,105

1,933

360

360

770

1,162

1,966

1,356

1,770

2,585

1,116

1,090

1,021

1.2

1.2

1.2

1,021

1,018

$-2,012$

$-1,769$

556

556

432

432

432

$-1,409$

$-1,160$

89.3

.2

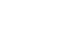


Fig. D-2

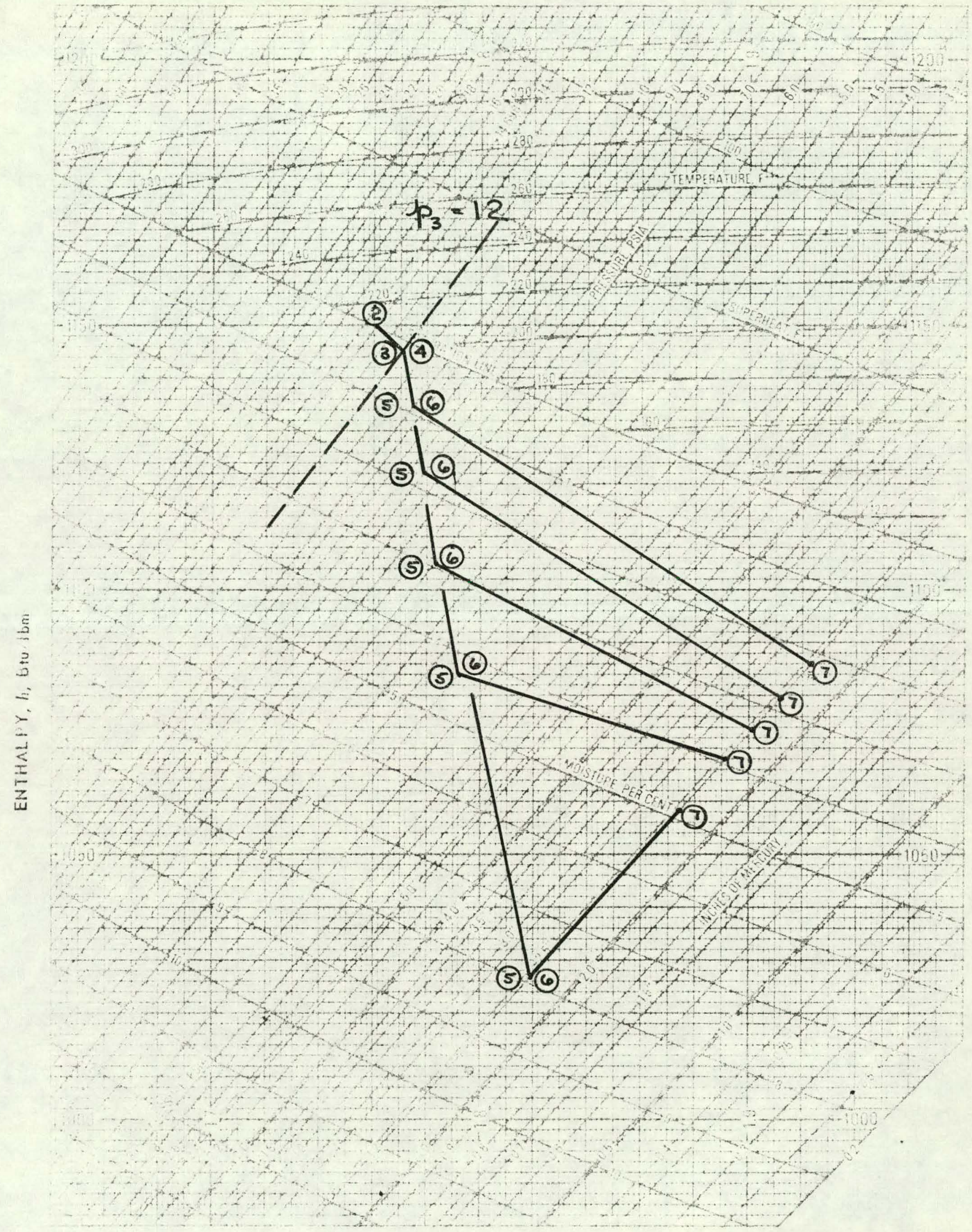

ENTROPY S, Btu $16 \mathrm{bm}$. F 
Fig. D-3

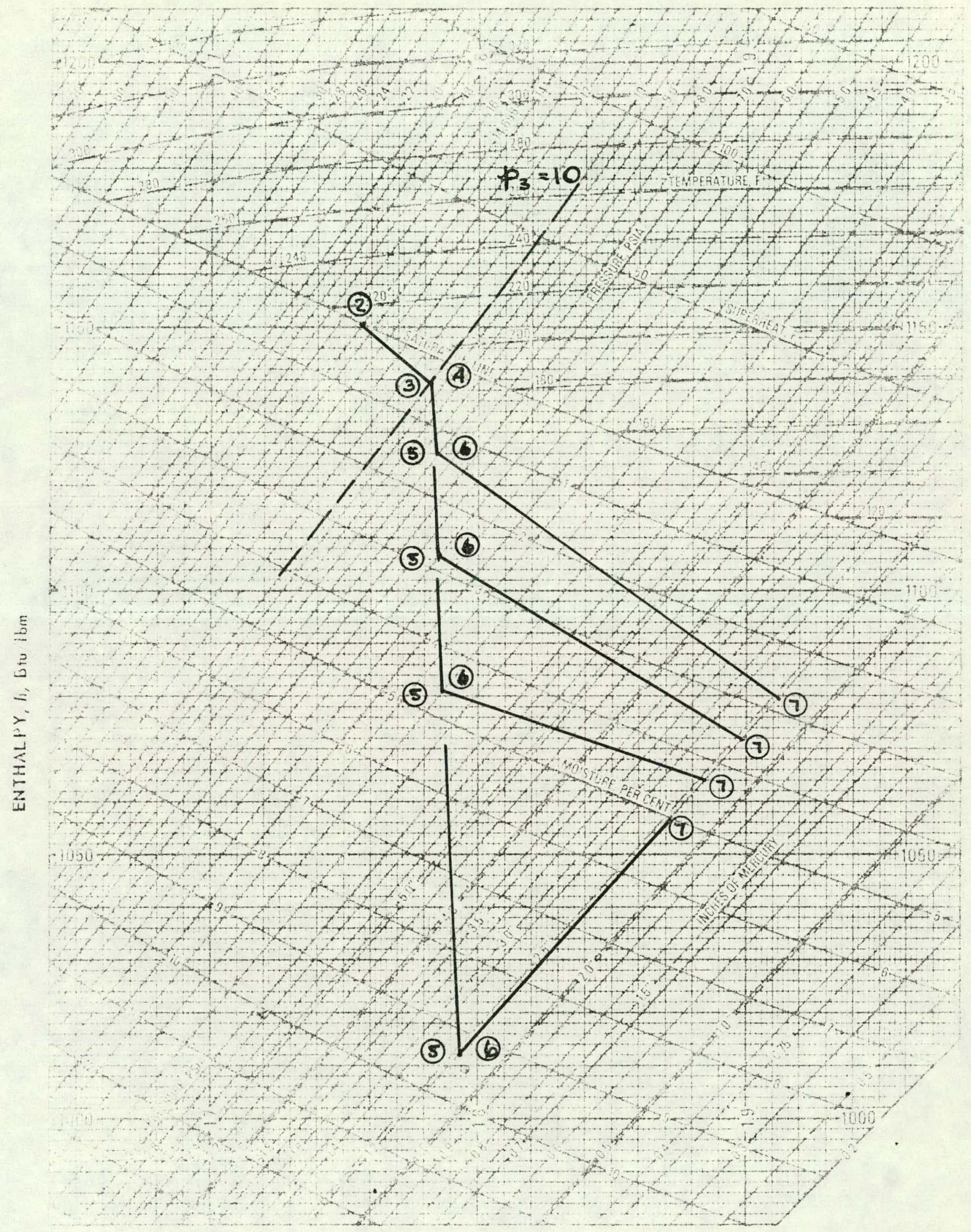

ENTROPY, S, Btu/bm F F 
Fig. D-4

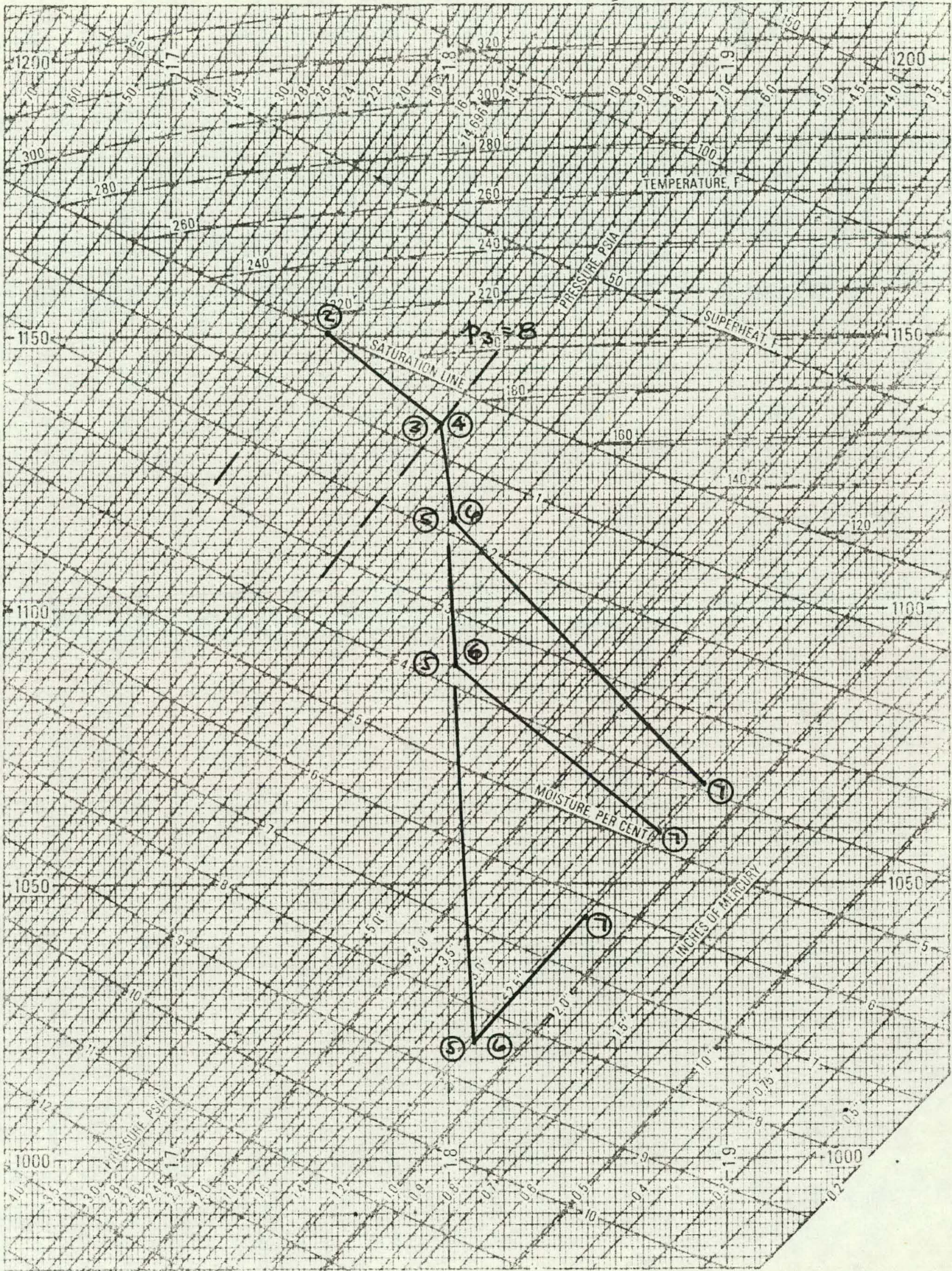

ENTROPY, S, BTU/ $/ \mathrm{bm} \cdot F$ 


\section{TABLE D-4}

CONFIGURATION DATA

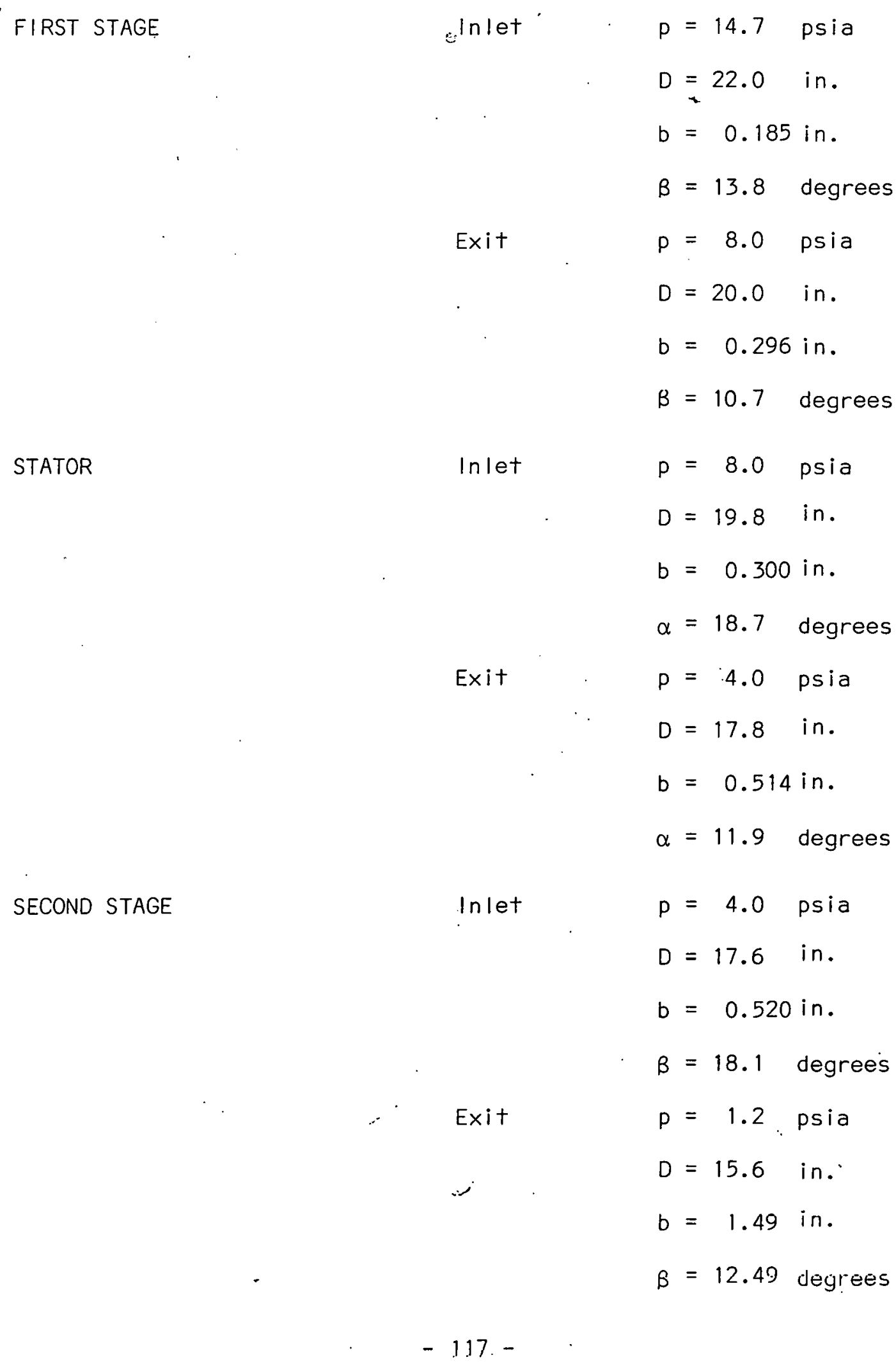




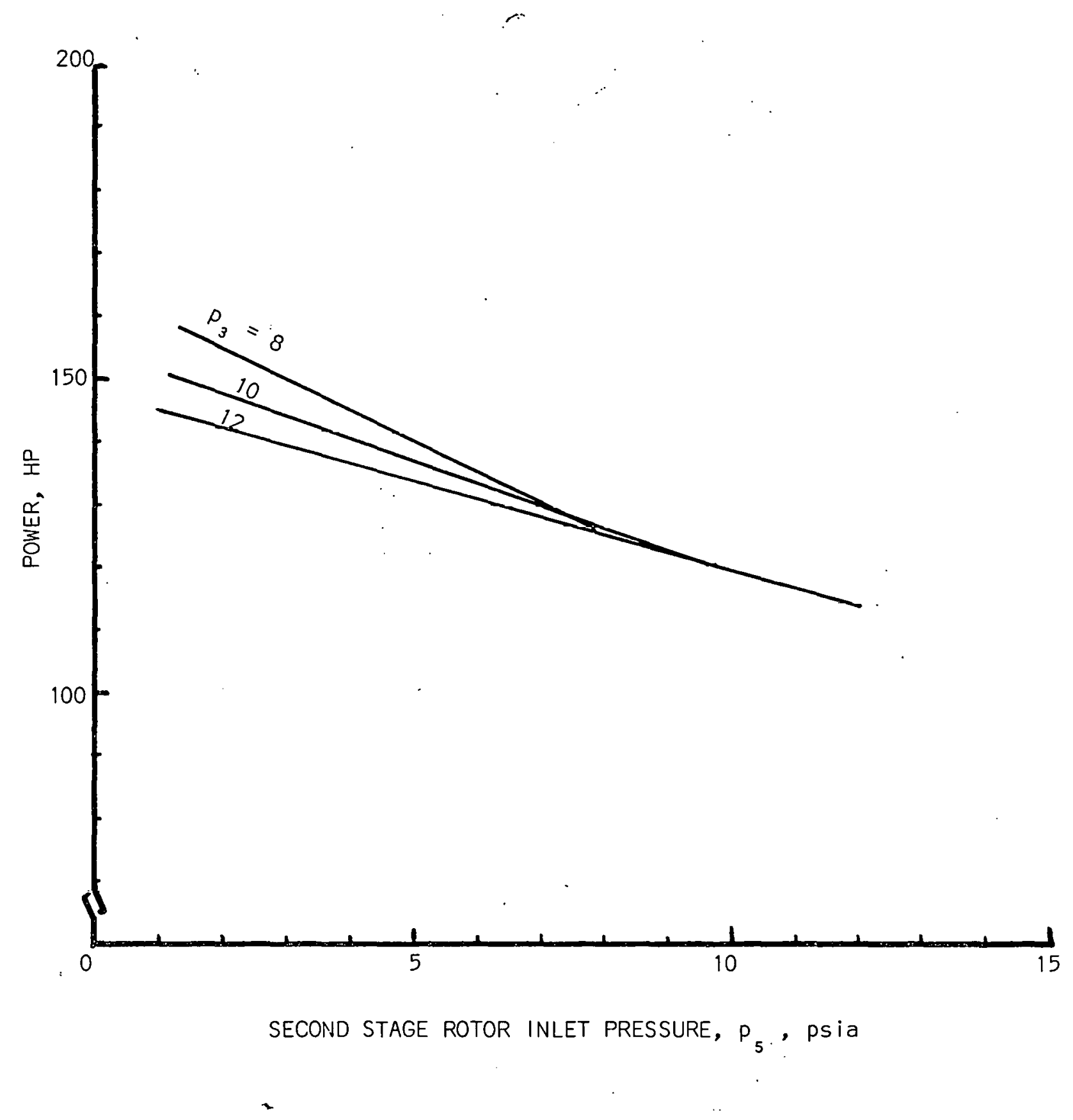

Fig. D-5 - Results of Trade-off Study 